\title{
DISAGREEMENT AND CHANGE OF VIEW
}

By KIRK LOUGHEED, B.A. (HONS), M.A., M.A.

\begin{abstract}
A Thesis Submitted to the School of Graduate Studies in Partial Fulfillment of the Requirements for the Degree Doctorate in Philosophy
\end{abstract}

McMaster Univeristy (C Copyright by Kirk Lougheed 


\section{Acknowledgements}

There are many people who contributed to the success of this dissertation. I first started thinking about disagreement when I wrote a major research paper on religious disagreement under Klaas Kraay at Ryerson University. Klaas continues to be an excellent interlocutor on these issues. I begun work on this dissertation at Monash University under the direction of Graham Oppy and Robert Mark Simpson. While the project evolved a lot since my time at Monash, their early input was invaluable. My supervisor at McMaster University, Nicholas Griffin, provided detailed and timely feedback on multiple drafts. The finished project benefited greatly from his careful reading. The other members of my departmental committee in Sandra Lapointe and Mark Johnstone also provided helpful comments along the way. Their comments at the defense were particularly helpful. Christopher Tindale (Windsor) served as an external and offered written feedback prior to the defense. During the defense he helped me to think about how this project hangs together as a whole and so I'm very grateful for his challenging questions.

Three professors from earlier in my philosophical education have remained supportive of my philosophical endeavors. They are Rich Davis, Paul Franks, and Myron A. Penner. I have also had the privilege of discussing the epistemology of disagreement with two emerging stars in the field, Nathan Ballantyne and Jonathan Matheson. They have been extremely generous with their time. Many chapters and subsections of this dissertation have been presented at conferences. There are too many individuals to name, but I'm grateful to the audiences of those presentations. Finally, I'm grateful to feedback from anonymous referees who offered comments on sections of this dissertation that are published. Ideas from this dissertation appear in the following places:

(forthcoming). "Catherine Elgin on Peerhood and the Epistemic Benefits of Disagreement." Synthese.

(2018). “The Epistemic Value of Deep Disagreements.” Informal Logic 38 (2): 263-292.

(2017). "The Role of Idealized Cases in the Epistemology of Disagreement." Southwest Philosophy Review 33 (2): 251-270.

I have many friends outside of academia who have offered encouragement throughout my time in graduate school. However, I would most like to thank my parents, Stephenson and Diane Lougheed. They have supported me emotionally and financially throughout my studies in ways that surely go beyond the normal obligations that parents have to their adult children. It's unlikely I would have finished this without their support. I dedicate this dissertation to them. 
Acknowledgements.....i

Table of Contents.....ii

Introduction.....1

I. Introduction to Disagreement and Change of View.....1

II. Chapter Summary.....2

Part I. The Epistemology of Disagreement: The Current Debate

Chapter One: Introduction to the Epistemology of Disagreement
I. Introduction to the Epistemology of Disagreement.....5
II. Conciliationism.....8
III. Objections to Conciliationism.....11
IV. Non-Conciliationism.....15
V. Conclusion.....18

Chapter Two: The Special Insight View
I. Introduction.....20
II. Four Explanations of the Special Insight View....21
III. Three Additional Considerations.....33
IV. Conclusion.....37

Chapter Three: An Analysis of Toy Cases of Disagreement
I. Introduction...39
II. The Different Disagreements Argument.....39
III. Classic Cases Supporting Conciliationism.....42
IV. Unclear Cases.....46
V. Cases Supporting Non-Conciliationism.....51
VI. Objections.....57
VII. Conclusion.....60

Chapter Four: An Analysis of Epistemic Peerhood
I. Introduction.....62
II. The Strict Notion of Epistemic Peerhood.....62
III. Problems with the Strict Notion of Peerhood.....63
IV. Two Reformulations of Peerhood and of the Problem of Disagreement.....72 
V. The Significance of Disagreement Reformulated.....78

VI. Objections to Sceptical Epistemic Peerhood.....87

VII. Conclusion.....89

Part II. A Limited Version of Non-Conciliationism: The Benefits to Inquiry Argument

Chapter Five: The Benefits to Inquiry Argument

I. Introduction.....92

II. The Benefits to Inquiry Argument.....92

III. Empirical Support.....104

IV. Connections to Mill's Political Philosophy.....117

V. The Benefits to Inquiry Argument and Toy Cases.....119

VI. Conclusion.....120

Chapter Six: Objections to the Benefits to Inquiry Argument

I. Introduction.....121

II. Initial Objections to the Benefits to Inquiry Argument.....121

III. Epistemic Rationality versus Practical Rationality.....138

IV. All-Things-Considered Epistemic Rationality.....152

V. Conclusion......158

Chapter Seven: The Benefits to Non-Inquiry Argument

I. Introduction.....159

II. The Benefits to Non-Inquiry Argument.....159

III. Objection: Including Non-Inquiry Beliefs Makes the Argument Too Permissive.....162

IV. Non-Inquiry Beliefs, Different Cases of Disagreement, and Worldview.....163

V. Conclusion.....166

Chapter Eight: Worldview Disagreement

I. Introduction......168

II. The Due Diligence Argument.....168

III. Motivating the Due Diligence Argument.....171

IV. The Criteria for Worldview Evaluation.....172

V. Objections to Worldview Evaluation.....175

VI. Worldview Disagreement and Deep Disagreement.....182

VII. Conclusion.....189

Chapter Nine: Disagreement and Change of View

I. Introduction.....189

II. Intellectual Humility as an Objection.....189 
III. Competing Epistemic Values.....194

IV. Two Dynamic Views on Disagreement.....198

V. The Difficulty of Changing Worldviews.....211

VI. Conclusion.....214

Bibliography....215 


\section{Introduction}

\section{Introduction to Disagreement and Change of View}

In his 2006 paper, "Epistemological Puzzles about Disagreement” Richard Feldman argued for the highly sceptical conclusion that an agent ought to suspend judgment about any belief over which she encounters peer disagreement. ${ }^{1}$ David Christensen's 2007 paper "The Epistemology of Disagreement: The Good News" suggests that at very least peer disagreement entails that an agent ought to lower the confidence she had in a belief that is disputed by an epistemic peer. While I feel the intuitive force of Feldman and Christensen's position, if they are correct then many of people's most cherished political, ethical, and religious beliefs turn out to be unjustified, or at least less justified than originally thought. But many also have the intuition that such widespread scepticism is not plausible. This project is intended to explore competing intuitions about the epistemic significance of peer disagreement.

In many ways this project is a direct response to Feldman (2006), Christensen (2009). In this project I offer a relatively unexplored argument that they and other conciliationists (those defending the view one should conciliate in the face of disagreement) are incorrect in their initial articles. I argue that in the face of peer disagreement there are at least some cases where an agent need not necessarily lower confidence or suspend judgment regarding the belief in question. This project consists of two main parts. 'Part I. The Epistemology of Disagreement: The Current Debate' is primarily methodological and sets the stage for the second part. To begin, I argue that much of the current literature on the epistemology of disagreement is misguided in its focus. This is for a variety of reasons including the fact that authors often shift inappropriately between simple

${ }^{1}$ Feldman 2009 appears to take a weaker stance. He suggests that peer disagreement is always additional evidence that needs to be weighed with the total evidence. But he thinks it is impossible to offer general principles about how to weigh the evidence of peer disagreement (other than the simple fact that it ought to be weighed). 
and complex cases of disagreement, implicit definitions of epistemic peerhood are overly strict, and completely shared evidence is impossible in real-life scenarios. In sum, there has been too much focus on highly idealized cases of peer disagreement - where parties are (near) cognitive and evidential equals - which cannot offer insight into everyday real-life cases of disagreement. For the sake of argument, in 'Part II. A Limited Version of Non-Conciliationism: The Benefits to Inquiry Argument' I assume that Feldman, Christensen, and other conciliationists are correct. I explore and defend an underdeveloped and underappreciated argument that appeals to future potential epistemic benefits of remaining steadfast in a disputed belief as the proximate epistemic justification for that belief. If successful, my argument constitutes a new response to Feldman and Christensen.

\section{Chapter Summary}

The first four chapters of the dissertation make up Part I. In the introductory chapter I introduce the epistemology of disagreement in more detail. I conclude with an outline of some of the main arguments in the literature. In Chapter Two I focus on why the special insight view is not a plausible response to peer disagreement. This is the view that an agent can be rational to remain steadfast in her own beliefs because she enjoys a special insight her opponents lack. Chapter Three is an analysis of the toy cases of disagreement often used in the literature. I argue that there are important differences between simple and complex cases of disagreement that are often

overlooked in the literature. These differences show that lessons from simple cases of disagreement do not apply to complex cases of disagreement. In Chapter Four I survey the concept of epistemic peer. I suggest that definitions are often vague but when they are precise they are usually so strict as to never obtain in cases of real-world disagreement. I offer a broader definition 
of epistemic peerhood that can accommodate cases of real-life worldview disagreement. Chapters One through Four are intended to set the stage for my main argument.

In Chapter Five I offer the Benefits to Inquiry Argument. The basic idea is that future epistemic benefits can serve as the proximate justification for an agent remaining steadfast about inquiry beliefs in research contexts. I offer a number of examples in support of this argument, particularly from the history of science. In Chapter Six I explore the most significant worry for the Benefits to Inquiry Argument, which is that it only makes a belief practically rational, but not epistemically rational. That is, future epistemic benefits are not relevant to how an agent ought to assess the current evidence she possesses. In other words, the current evidence is the only thing relevant to epistemic rationality. In Chapter Seven I explore whether the Benefits to Inquiry Argument can also be applied to beliefs outside of research contexts. I suggest that we need a lot more empirical information to successfully expand the argument to non-inquiry beliefs. I conclude by exploring some potential implications of such an expansion should that empirical information be made available.

In Chapter Eight I suggest that the Benefits to Inquiry argument would be easier to frame with respect to worldviews rather than isolated propositions. I formulate the Benefits of Worldview Disagreement Argument and then demonstrate that it avoids some of the problems associated with the Benefits to Inquiry Argument. I discuss worldview evaluation in order to help explain when an agent is rational to maintain her worldview in the face of disagreement, or when she ought to adjust or altogether switch worldviews. In the concluding Chapter Nine, I claim that at the very least worldview disagreement should cause an agent to re-evaluate the first order reasons she possesses for her worldview beliefs. Given the difficulty of worldview evaluation, along with the 
fact that modifying or changing worldviews altogether is a very significant process, this is far from a trivial conclusion.

Part I. The Epistemology of Disagreement: The Current Debate 


\section{Chapter One: Introduction to the Epistemology of Disagreement}

\section{Introduction to the Epistemology of Disagreement}

Part of the recent explosion in the literature on the epistemology of disagreement was sparked by the Feldman and Christensen articles I mentioned in the introduction. The literature has generally confined itself to the following problem: Suppose that after an agent comes to believe proposition $P$ she finds out that there is an epistemic peer - someone of equal intelligence and ability - who has evaluated the same body of evidence and come to believe not-P. What should her reaction be upon discovering peer disagreement? Does the existence of peer disagreement constitute a (partial) defeater to her original belief that $P$ ? Or is she rationally permitted to maintain her belief that $P$ even in the face of peer disagreement?

There are two main schools of thought when it comes to answering these questions about peer disagreement. First, conciliationism holds that when an agent encounters such disagreement, a certain amount of weight must be given to both views and hence the agent should revise her belief in $P$. Weak conciliationism requires that an agent lower her confidence that $P$ but not necessarily below the threshold for rational belief. Strong versions of conciliationism require that the agent lower her confidence in $P$ below the rational threshold for belief or altogether withhold belief in $P .^{2}$ Feldman and Christensen are paradigmatic strong conciliationists. Second, nonconciliationism claims that there are cases in which awareness of her peer's belief that not-P does not require changing her belief that $P .{ }^{3}$ Thus, the conciliationist denies that there can be rational disagreement between epistemic peers, whereas the non-conciliationist claims that epistemic peers can rationally disagree. ${ }^{4}$

\footnotetext{
2 This view is also known as revisionism or equal weight.

3 This view is also known as non-conciliationism or steadfast.

4 Kelly 2010, Lackey 2010a, 2010b offer hybrid views that sometimes recommend conciliating and sometimes do not. However, these are minority views in the literature and I will defer discussing them until Chapter
} 
As noted above, conciliationism poses a serious epistemic threat to important beliefs such as ethical, political, and religious beliefs. If a strong version of conciliationism is true, then it entails widespread scepticism about many important and cherished beliefs. Closely held ethical, political, and religious beliefs are essential to a person's overall worldview. Thus, conciliationism places many worldviews in less than epistemically favourable circumstances. In the following section I survey some of the main themes found in the epistemology of disagreement literature. Note that I am not attempting an exhaustive survey here. Time and space constraints make such a survey impossible. Rather, I hope to highlight what I think are some of the most important and influential ideas in the literature. ${ }^{5}$

Before offering the survey, it is worth noting that some have suggested that much apparent disagreement in philosophy is merely verbal disagreement (Chalmers 2011). Philosophers often unknowingly have different meanings of the same term in mind when they engage in disputes that involve the term in question. Or, philosophers are offering different answers to different questions, while mistakenly thinking they are answering the same question. Once this is discovered, the disagreement evaporates and hence is not a genuine disagreement. ${ }^{6}$ It is an open question how much disagreement in philosophy is merely verbal as opposed to genuine. It is also an open question how much verbal versus genuine disagreement exists in topics other than philosophy. While these questions are important and deserve careful attention, I will not address them in this project. Even if many cases of disagreement in philosophy are verbal, there need only be one case

Nine. Besong 2017 responds to Lackey's hybrid account. Everett 2015 offers a hybrid view by distinguishing between two different types of rational belief.

${ }^{5}$ For an excellent survey of some of the major themes in the literature see Matheson 2015b. See Palmira $2013 \mathrm{~b}$ for problems with suspending judgment.

${ }^{6}$ Interestingly Ballantyne argues that sceptics about the amount of genuine disagreement in philosophy are also committed to scepticism about cases of apparent agreement in philosophy, He writes, "[i]f we think philosophers cannot tell the difference between genuine and verbal disagreements, we should not expect them to tell the difference between genuine and verbal agreements, either" (Ballantyne 2016, 759). Thus, scepticism about the amount of disagreement is traded for another type of scepticism. 
of genuine disagreement in order for the debate between conciliationism and non-conciliationism to gain traction in philosophical disputes. The same is true of disagreement in other subject areas. I will assume there are cases of genuine disagreement in philosophy and other subjects throughout the rest of this project. ${ }^{7}$

The literature in the epistemology of disagreement focuses on the sceptical threat or defeaters posed by cases of genuine epistemic peer disagreement. But Brian Riberio (2011) points out that one possible consequence of disagreement is relativism, rather than the scepticism advocated by many proponents of conciliationism. With respect to, say, moral disagreements, Riberio writes that perhaps the opponents in a dispute each have "an idiosyncratic set of standards, and therefore the apparently conflicting claims are not really in conflict. Nothing is good, bad, or indifferent simpliciter, but only in relation to some frame of reference and there is no universal frame of reference." (Riberio 2011, 10). ${ }^{8}$ Throughout this project I will assume that such relativistic responses to disagreement are implausible. I will assume that critical realism is true, and hence that relativism cannot explain every case of disagreement. Thus, I claim that there are important cases of genuine (non-verbal) disagreements that cannot be explained away by appeals to relativism. ${ }^{9}$

It is worth observing that the literature generally proceeds by examining cases in which there are only two epistemic peers who disagree with one another about the truth-value of a proposition. ${ }^{10}$ For the most part, my project will continue the discussion in the same way. I

${ }^{7}$ The introduction of Ballantyne 2016 provides an excellent survey of these issues. See also Chalmers 2011; Chalmers et al. 2009; Graham 2014; Jackson 2014; Jenkins 2014; Rott 2015. Rowbottom 2016 discusses the conditions needing to be met for agreement from a formal perspective.

${ }^{8}$ Riberio also explains that this relativistic response can be found in Wittgenstein's On Certainty (1969) where disagreement is attributed to the fact that people use different sets of rules, but there is no objective set of rules. See Riberio 2011, 8-9.

${ }^{9}$ See also Hazlett 2014a.

${ }^{10}$ For exceptions see Boyce and Hazlett 2014; Carter 2014; Tebben 2013. 
recognize that in real-world disagreements there are likely to be multi-peer disagreements, and disagreements between multiple peers, inferiors, and superiors. I will assume that what I say can be translated to fit with disagreements involving more than two opponents. I limit the number of people involved in my cases for the sake of simplicity.

Finally, much of the literature does not make explicit connections to many other areas of epistemology, particularly to debates around epistemic justification. ${ }^{11}$ This is because it is typically (implicitly) assumed that the epistemic puzzles about disagreement can emerge on any conception of justification. For instance, peer disagreement may call into question one's foundation, the coherence of one's beliefs, or the reliability of one's belief forming process. Likewise, it may challenge whether knowledge is safe. It doesn't appear to matter whether one has an internalist or externalist view of justification in mind. I will continue to assume that the sceptical threat based on disagreement can be generated on any conception of justification or knowledge.

\section{Conciliationism}

The following arguments support conciliationist responses to peer disagreement.

\section{The Independence Thesis}

A major line of reasoning in support of conciliationism is that without a relevant asymmetry between the two disagreeing parties, there is no independent reason to favour one position over the other. Typically, conciliationists assume that evidence exists independently of agents and that there is only one correct doxastic stance an agent can take toward it. Thus, when an agent encounters peer disagreement, she cannot conclude that both parties are rational. Only if she knows that her peer has made a particular mistake in reasoning, or is tired, inebriated, or otherwise impaired in judging the evidence correctly can she discount her opponent's judgment. An agent

\footnotetext{
${ }^{11}$ de Ridder 2014 is an exception.
} 
has no reason to give special credence to her own beliefs simply because they are her own. Without an independent reason to think her own beliefs are correct, she must give equal weight to her peers (Feldman 2006, 231). ${ }^{12}$ Throughout this project I will refer to this line of thought as the Independence Thesis. Here is Christensen's explicit formulation: "In evaluating the epistemic credentials of another's expressed belief about $\mathrm{P}$, in order to determine how (or whether) to modify my own belief about P, I should do so in a way that doesn't rely on the reasoning behind my initial belief that P" (Christensen 2011, 1-2). Indeed, some have speculated that the main disagreement between conciliationists and non-conciliationists is over the truth-value of the Independence Thesis (Christensen 2011, 1; Kelly 2013, 37). ${ }^{13}$

Exactly how much should an agent revise her belief when she encounters disagreement with a peer? Some philosophers shy away from stating precise guidelines, but Adam Elga offers a helpful (although still somewhat vague) answer: it depends. ${ }^{14}$ How much an agent revises a belief should be thought of as on a graded scale. ${ }^{15}$ She should give much more credence to an epistemic superior (Elga 2007, 483). For instance, she should always defer to a person who is ideally rational and hence always correct. But she should take an epistemic inferior less seriously than herself. Just how epistemically inferior her opponent is will dictate how much she should adjust her belief. ${ }^{16}$

\section{Arguments from Analogy}

\footnotetext{
${ }^{12}$ This conciliationist response assumes that the Uniqueness Thesis is true. This is the view, roughly, that there is only one unique rational response to any given body of evidence. I discuss uniqueness in Chapter Four.

${ }^{13}$ See also Matheson 2015a. Moon 2018 defends a modified version of Independence. Lord 2014 rejects Independence and related principles. Lord points out that Independence has gained significance in other philosophical debates: Copp 2007 relies on it in defending moral independence. Independence is also appealed to in evolutionary debunking arguments found in Street 2011 and Vavova 2014a. I will not discuss these connections any further in this project.

${ }^{14}$ This response appears similar to Feldman 2009.

${ }^{15}$ See Jehle and Fitelson 2009 for the difficulties involved in formulating the equal weight view in a Bayesian framework. Elkin and Wheeler 2018 also argue a Bayesian framework cannot accommodate the type of updating mandated by conciliationism. Heesen and Kolk 2016 take a game-theoretical approach to conciliationism. Martini 2013 argues that belief updating does not solve questions about how to respond to epistemic peer disagreement.

${ }^{16}$ See also Brossel and Eder 2014; Grundmann 2013; Lam 2013; Wiland 2016.
} 
Support for conciliationism has also been garnered by various arguments from analogy to measuring devices, including thermometers and watches. Thermometers, like agents, process information and reach a verdict. Consider the following case:

\section{Theo's Thermometer:}

Theo has a reliable thermometer. So does Ted. In fact, each of their thermometers is equally reliable. Further, both Theo and Ted are aware of this fact. One day, Theo and Ted are playing with their thermometers in the same room. Ted's thermometer reads '76', and he believes that the room is 76 degrees Fahrenheit on this basis. Theo's thermometer reads ' 74 ', and he believes that the room is 74 degrees on this basis. At $\mathrm{t} 1$, Theo and Ted share their readings and are both surprised to discover the conflicting verdicts (Matheson 2015, 71).

Once Theo and Ted become aware of the disagreement, they each possess a defeater for the temperature given by their respective thermometers. They each have gained a reason to think at least one thermometer has malfunctioned (with no way to tell which one). This is due to the fact that "[o]n Ted's evidence, the explanation that his thermometer has malfunctioned is no better (or worse) than the explanation that Theo's thermometer has malfunctioned" (Matheson 2015, 71). If this case is relevantly similar to cases of peer disagreement, then a strong argument from analogy is on offer in favour of conciliationism. That is, "[s]ince conciliation is called for in the thermometer case, analogous reasoning dictates that it is called for also in cases involving epistemic agents" (Matheson 2015, 71) ${ }^{17}$

\section{Non-Conciliationism Can't Avoid Kripke's Dogmatism Paradox}

Catherine Elgin observes that if someone always remains steadfast in the face of peer disagreement she is liable to fall victim to Kripke's Dogmatism Paradox $(2018,14)$. Consider:

If $\mathrm{S}$ knows that $\mathrm{p}$, then $\mathrm{p}$ is true.

If $\mathrm{p}$ is true, then any evidence against $\mathrm{p}$ is misleading.

If $\mathrm{S}$ wants to retain her knowledge, she should disregard misleading information.

${ }^{17}$ Matheson offers this argument within the context of 'idealized' disagreements where two peers are close cognitive and evidential equals. In Chapters Three I explore whether lessons from idealized disagreements apply seamlessly to real-world disputes. 
So $\mathrm{S}$ should be dogmatic and disregard any evidence that seems to tell against $\mathrm{p}$ (Elgin 2018, 14)

Elgin notes that this paradox applies equally well to first-order evidence and higher-order evidence including the evidence presented by the existence of peer disagreement. If one ignores the higherorder evidence of disagreement in order to maintain knowledge she appears to be acting against the requirements of rationality. Such requirements surely include open-mindedness which implies that one not ignore conflicting evidence. ${ }^{18}$

\section{Objections to Conciliationism}

\section{Conciliationism leads to mistakes}

One might object that conciliationism leads to the bizarre result that it is sometimes epistemically rational for an agent to revise her beliefs even when doing so moves her further away from the truth. An agent's original position might have been correct and conciliationism forces her to adjust her beliefs towards her peers, which sometimes turn out to be wrong (Christensen 2007, 210). This, however, is not a reason to reject the conciliationist position. An agent is never an infallible intellect who can always be completely certain about her judgments. If this were the case then peer disagreement would not pose a problem. Thus, "other people's opinions serve, alongside our own introspection and hard thinking, as evidence about whether we've made a mistake, rationality requires taking account of this evidence" (Christensen 2007, 210).

\section{Scepticism}

Another prominent objection to conciliationism is that in cases of all-or-nothing belief, disagreement will often lead to suspension of belief. This means an agent will be forced into wideranging scepticism about many topics. Conciliationists may not see this as a negative consequence if agents are aiming for the truth. There are considerable bodies of belief in, say, science and math

\footnotetext{
${ }^{18}$ See also Kripke 2011.
} 
concerning which there is widespread agreement. Perhaps in subjects like philosophy, politics, and religion the epistemic conditions are quite poor, and this accounts for widespread disagreement. ${ }^{19}$ As Christensen claims:

It seems clear that disagreement flourishes when evidence is meager or poorly distributed, or when, due to our emotional or intellectual limitations, we are just not very good at reacting correctly to the evidence. In other words, disagreement flourishes when epistemic conditions are bad... I think that we all should acknowledge that epistemic conditions are not so great in philosophy (Christensen 2007, 214).

While Christensen does not see this scepticism as a negative result, some philosophers will reject any view that entails scepticism about philosophy, politics, or ethics. ${ }^{20}$

\section{Self-referential incoherence}

Finally, it could be objected that conciliationism is self-referentially incoherent. Thus, "in many situations involving disagreement about disagreement, [conciliationist] views call for their own rejection. But it is incoherent for a view on disagreement to call for its own rejection. So [conciliationist] views on disagreement are incoherent" (Elga 2010, 179). Elga admits that conciliationism is self-referentially incoherent but argues that no inductive method for determining what to believe can coherently recommend an alternative. This is because "it is in the nature of giving consistent advice that one's advice be dogmatic with respect to its own correctness. And views on disagreement give advice on how to respond to evidence. So, in order to be consistent, views on disagreement must be dogmatic with respect to their own correctness" (Elga 2010, 185). If this is right, it might not be inappropriately arbitrary to ignore disagreement about disagreement.

19 Interestingly, Matheson 2016 argues that the scepticism entailed by disagreement on a variety of controversial moral actions implies that we should exercise moral caution and refrain from those actions. This is a rare application of the disagreement literature to applied ethics. See also Vavova 2014b.

20 Sosa 2010 does reject conciliationism, in part, because it leads to scepticism. See also Rotondo 2015; Machuca 2013 and 2015. 
John Pittard argues that Elga's argument is not an appropriate response to the arbitrary objection. This is because Elga's argument only establishes that there is a special circumstance where the rule of revising in the face of peer disagreement should not apply in order for conciliationism to maintain coherence (Pittard 2015, 446). According to Pittard, Elga is correct that one way to maintain coherence is to claim that conciliationism does not apply to itself. But another response is that given disagreement about conciliationism the agent should lower her credence in conciliationism while still applying it to other cases of disagreement. Yet another possible response is to reject conciliationism altogether. Thus, "[w]hile Elga is right that a selfexempting conciliatory policy is one way for the conciliationist to preserve coherence, he has not given us a good reason for thinking that this is the only way" (Pittard 2015, 447).

Pittard maintains a better way to show that conciliationism does not arbitrarily apply to itself is based on the idea of epistemic deference. He explains that this sort of deference represents "a commitment to showing epistemic deference that is proportionate to the epistemic qualifications of different thinkers, so that the views of an epistemic peer are given equal weight to one's own views, while the views of an epistemic superior are accorded more weight" (Pittard 2015, 449). Suppose an agent believes conciliationism with close to a credence of 1 and her non-conciliationist opponent believes it with a credence close to 0 . If the conciliationist adjusts her belief credence to .5 she does so using reasoning that her non-conciliationist opponent claims is illegitimate (Pittard 2015, 449-450). Thus, “[i]n relying on such reasoning, I seem to simply ignore any worries raised by the disagreement. So at one level (the credence level) I show equal deference, but at another level (the reasoning level) I show my peer no deference at all” (Pittard 2015, 450).

On the other hand, if the conciliationist remains steadfast in conciliationism in the face of disagreement, then she is showing no deference at the level of credence for conciliationism, while 
being completely deferential to her opponent at the reasoning level by remaining steadfast. Pittard

concludes that:

To the extent that I attempt to defer to my disputant by moving towards a mid-point credence as typically required by conciliationism, I will be non-deferential in my reasoning that grounds the new credence; and to the extent that I attempt to defer to my disputant by minimizing my reliance on any conciliatory rationale, my credence will be non-deferential. (Pittard 2015, 450)

Pittard says there is no reason to privilege deference at the credence level over the reasoning level, or vice versa. ${ }^{21}$ Thus, conciliationism allows its proponents to choose whether or not to respond at the credence or reasoning level (Pittard 2015, 450-451). ${ }^{22}$

Finally, Brian Ribeiro argues that raising the self-referential objection changes the topic in a way that fails to address the seriousness of the sceptical threat posed by conciliationism. He points to a Richard Popkin quote which asks the reader to suppose that:

[A]n anonymous letter received by a dogmatic philosopher... hold[s] a position. The letter raises fundamental problems for the [dogmatic] recipient by questioning whether he had adequate grounds for his assertions and assumptions or whether his system is free from contradictions or absurdities. The recipient may try to fend off the attack by challenging whether any philosopher could write the letter without opening himself to similar attacks. By impugning an author, the dogmatist may show the problem involved in consistently stating skepticism, but he does not thereby reply to the arguments in the letter (Popkin quoted in Ribeiro 2011, 23). ${ }^{23}$

21 Pittard's view is more complex than the way I have explained it here. He argues for a moderate conciliationist position in which less controversial conciliationist principles are not subject to self-referential worries, but more controversial conciliationist principles may have to be given up (or less confidently believed) in the face of disagreement. See Pittard 2015 for more details. For more on the self-referential worry see also Weintraub 2013. Weintraub explores whether it is rational for both conciliationists and non-conciliationists to remain steadfast in their positions on disagreement, even in the face of peer disagreement about their respective views. Sampson (forthcoming) responds to Pittard and argues that the self-referential objection cannot be solved.

${ }^{22}$ See Reining 2016a, 308-312 for an excellent survey of the self-referential incoherence objection. Reining himself argues that in cases of disagreement "one is rationally ... required to treat the disagreement as a pro tanto reason to significantly lower one's confidence in one's initial opinion" (Reining 2016a, 322). Understanding disagreement as a pro tanto reason avoids the self-referential problems other views suffer from. Christensen 2013 argues that in cases where the self-reference worry arises one epistemic norm of rationality will necessarily be violated, but I will take it for granted that a reply which recommends irrationality (in some sense) is highly implausible.

${ }^{23}$ See Popkin 1967, 459. For more solutions to the self-reference problem see Bogardus 2009 and Graves 2013. Decker 2014 argues that the self-reference problem is unresolvable. See also Machuca 2017 ; Mulligan 2015. Psaroudaki 2016; and Stewart 2016. 


\section{Bootstrapping}

In certain situations conciliationism makes it too easy for an agent to bootstrap her way to rationality. If two peers evaluate a body of evidence and both come to believe proposition $P$, then conciliationism says that their belief in $P$ is rational (on the assumption they are both only aware of each other's position on $P$ ). But conciliationism can make belief in $P$ rational even if both agents wrongly evaluate the original body of evidence (Kelly 2010, 126). Kelly explains that a "view for which there is in fact little good evidence or reason to think true beliefs can bootstrap their way into being rationally held simply because two rationally overconfident peers encounter one another and confirm each other's previously baseless opinions" (Kelly 2010, 128). Perhaps even easier bootstrapping occurs in cases with just one individual agent. If an agent evaluates a body of evidence and comes to believe $P$, then the agent should take the psychological fact that she believes $P$ as evidence for $P$. Since there are no peers (or superiors or inferiors) who disagree with her in this case, the fact she believes $P$ turns out to be strong evidence for $P$ (Kelly 2010, 129-130). While bootstrapping to rationality in this way is clearly problematic, with certain restrictions in place the conciliationist may be able to avoid it.

\section{Non-Conciliationism}

The following is a brief summary of what I take to be some of the most important arguments in defence of non-conciliationism. Again, note that I am not attempting completeness in this section.

\section{a. Moral Intuitions}

Michael Bergmann argues that there can be rational disagreement between two peers even after full disclosure of the relevant evidence. He argues that this is true on both an external and internal view of rationality. External rationality requires that beliefs be based on appropriate evidence and not the result of cognitive malfunction. A belief can be internally rational, even if it is the result of 
cognitive malfunction (Bergmann 2009, 337). In regards to external rationality, Bergmann affirms that "[i]n a case where two people of roughly equal intellectual virtue... continue knowingly to disagree even after full disclosure, it is possible that both parties are externally rational in continuing to disagree and in thinking that the other may well be externally rational in continuing to disagree" (Bergmann 2009, 341).

Interestingly, Bergmann admits he has no argument for his intuitions on the possibility of rational peer disagreement. ${ }^{24}$ Rather, he offers two examples to help explain his intuitions. First, consider scepticism about the external world. Bergmann contends that he cannot prove that there is an external world and yet it remains rational to believe in an external world (Bergmann 2009, 345). He says that "[1]ikewise, the fact that we think someone is mistaken... despite her being confident in ways similar to the ways in which we are confident doesn't automatically mean that we should seriously question or doubt the reliability of our beliefs in which we're so confident" (Bergmann 2009, 345). Second, Bergmann imagines a disagreement between himself and two other epistemic peers about killing and torturing small children for no good reason. He strongly believes that such killing is morally wrong. But one peer, a moral nihilist, denies that there are any moral facts about killing children. The other peer, an ethical egoist, holds that it could be right for a particular individual to kill and torture children. If true, the conciliationist position implies that Bergmann ought to lower his confidence in his belief that killing and torturing children is wrong. But Bergmann claims this is a bizarre result that should be rejected. ${ }^{25}$ These examples show the strong intuitive appeal behind the claim that epistemic peers can reasonably disagree. ${ }^{26}$

\footnotetext{
${ }^{24}$ In a more recent article Bergmann does in fact offer an argument from intuitions against conciliating in the face of disagreement, specifically with respect to religious beliefs. He applies solutions to external world scepticism to support non-conciliationism about non-inferred religious beliefs. See Bergmann 2017 for more.

${ }^{25}$ See also Fritz 2018. Three.

${ }^{26}$ I discuss additional cases in support of both conciliationism and non-conciliationism extensively in Chapter
} 


\section{b. Peer Disagreement is Higher-Order Evidence and only First-Order Evidence Matters}

Thomas Kelly argues that peer disagreement constitutes higher-order evidence about a particular body of evidence..$^{27}$ That is, the disagreement constitutes information about the character of the evidence itself (Kelly 2005, 186). He suggests that "[a]t the very least, evidence about one's evidence will make a difference to what it is reasonable for one to believe about one's evidence" (Kelly 2005, 186). However, that does not mean it should count in favour of the truth or falsity of propositions which are not about the evidence. Consider "(1) E is good evidence that $\mathrm{H}$ is true" (Kelly 2005, 187). Imagine that Bob, an epistemic peer, affirms (1). Kelly claims that this fact counts as evidence for (1) but not for $\mathrm{H}$. If an agent is undecided about the truth of $\mathrm{H}$, she should not count Bob's affirmation of (1) as evidence in favour of $\mathrm{H}$. She needs to evaluate the first-order evidence for herself when deciding whether or not to believe $\mathrm{H}$ is true. If she adds Bob's affirmation as additional evidence to her evaluation of $\mathrm{H}$, then she engages in a kind of irrational double-counting (Kelly 2005, 188). ${ }^{28}$ Kelly concludes that "[a]t the very least then, there seems to be a certain awkwardness in my giving additional weight to your belief that $\mathrm{H}$ is true when I have already taken into account all of those considerations on which your belief is based, considerations which you take to exhaust the case for H" (Kelly 2005, 188-189). Therefore, when an agent does not include higher order evidence as evidence about a proposition she is undecided on, there can be reasonable disagreement. ${ }^{29}$

\section{c. Remaining steadfast yields more true beliefs}

${ }^{27}$ Christensen 2016b discusses types of higher-order evidence other than disagreement. Another way of construing higher-order evidence, at least with respect to peer disagreement, is 'evidence of evidence is evidence'. See also Roche 2014. Tal and Comesana 2017 responds and Roche (2018) offers a rejoinder.

${ }^{28}$ See also Konigsberg 2013.

${ }^{29}$ See also Titelbaum 2015. Kelly 2010 is a distinct move away from this position. Rasmussen, SteglichPetersen, and Bjerring 2017 formalize a higher-order approach to disagreement. See also Silwa and Horowitz 2015. 
Suppose that there are two judges whose verdicts are right $95 \%$ of the time and wrong $5 \%$ of the time. If an agent decides to follow both judges on cases in which they agree, she will get things right $90 \%$ of the time. But if she suspends judgment concerning cases in which they disagree, she actually ends up with a lower success rate than if she simply chose to follow one judge. If she followed one judge she would get things right $95 \%$ of the time instead of $90 \%$ of the time (while suspending judgment $10 \%$ of the time). Graham Oppy argues that "[u]nless you think that any increase in avoidance of falsehood trumps any decrease in acquisition of truth, you're bound to think that there can be cases in which you do better to follow a single judge of the kind under consideration than to follow the combined strategy that requires suspension of judgment when the judges disagree" (Oppy 2010, 193). ${ }^{30}$ Also, note that if there were 20 judges with a 95\% success rate, the conciliationist position would require suspending judgment $100 \%$ of the time, at least in cases where the judges disagree. Surely this is worse than choosing to follow one judge in order to arrive at the truth $95 \%$ of the time at least if, on every claim, one of them disagree. If an agent is usually correct, then she should stick to her beliefs, even in the face of disagreement (Oppy $2010,193-195) .^{31}$

\section{Conclusion}

This chapter serves as an introduction to my project on the epistemology of disagreement. After a brief chapter summary, I highlighted some of the main ideas in the epistemology of disagreement literature. Conciliationists like Feldman and Christensen hold that unless an agent can identify a relevant asymmetry between herself and her peer that would give her a reason to downgrade her opponent's status as a peer, she must revise her belief in the face of peer disagreement. Objections

\footnotetext{
${ }^{30}$ This is related to issues about epistemic values that I discuss in Chapter Nine. This example also assumes that their wrong judgments do not overlap.

${ }^{31}$ Zach Barnett (2019b) argues that if experts are expected to reach the same conclusion, much epistemic weight ought to be given to it.
} 
to conciliationism include that it can cause an agent to acquire false beliefs, it entails an implausible form of scepticism, and that it is self-referentially incoherent. Non-conciliationists claim that an agent is rational to remain steadfast in her beliefs in the face of peer disagreement. Arguments in favour of non-conciliationism include an appeal to cases of moral disagreement where it seems intuitively plausible to remain steadfast, the idea that higher-order evidence ought not to count in the rational assessment of beliefs, and the idea that at least in certain scenarios remaining steadfast will yield more true beliefs than suspending judgment. 


\section{Chapter Two: The Special Insight View}

\section{Introduction}

In this chapter I critically evaluate a particularly popular way of defending non-conciliationism. Some philosophers have attempted to defend non-conciliationism by appealing to a special insight view. These arguments suggest that an agent is rational to maintain her beliefs in the face of disagreement because she enjoys an insight that her opponent lacks. In this chapter I explore four distinct explanations of what might constitute the special insight which could count as a relevant asymmetry between two opponents who are otherwise epistemic peers. They are (i) self-trust, (ii) immediacy, (iii) diagnosing bias in an opponent, and (iv) introspection. I argue that none of these explanations is satisfactory given that appealing to any of these features is equally available to both parties in any given dispute. While in this project I will ultimately defend a version of nonconciliationism, arguments located in the special insight view do not justify non-conciliationism.

Peter van Inwagen's provocative essay, titled after W.K. Clifford's “It is Wrong, Everywhere, Always, and for Anyone, to Believe Anything upon Insufficient Evidence," is one of the earliest non-conciliationist responses to peer disagreement (1996). van Inwagen insists that in the face of disagreement he is reasonable to maintain his beliefs. The most plausible asymmetry that van Inwagen can identify between himself and any of his opponents is simply that he must enjoy a special kind of insight that his opponents necessarily lack. Regarding his disagreement about the incompatibility of free will and determinism with David Lewis, van Inwagen explains that:

$[\mathrm{M}] \mathrm{y}$ best guess is that I enjoy some sort of philosophical insight... that, for all his merits, is somehow denied to Lewis. And this would have to be an insight that is incommunicable - at least $I$ don't know how to communicate it - for I have done all I can to communicate it to Lewis, and he has understood perfectly everything I have said, and he has not come to share my conclusions... not only do my beliefs about these questions seem to me to be undeniably true, but (quite independent of any 
consideration of which theses it is that seem to me to be true), I don't want to be forced into a position in which I can't see my way clear to accepting any philosophical thesis of any consequence (van Inwagen 1996, 139). ${ }^{32}$

Interestingly, in discussing peer disagreement with philosophers not researching in the epistemology of disagreement this type of special insight and emphasis on autonomy is the most common response I have encountered. Admittedly, my evidence for this is highly anecdotal, but rarely have I encountered a philosopher who seems very much troubled by peer disagreement. The explanation for this, I think, is that at least implicitly many philosophers believe they hold special insights that those who are otherwise their epistemic peers lack. This is not only the case for philosophers and philosophical beliefs, but the same also holds for those with strong political, ethical, and religious beliefs. For instance, Bryan Frances notes that many religious believers fail to give any epistemic significance to the fact of widespread religious disagreement, even though they are aware of such disagreement. Frances claims that "in an enormous number of cases people think, at least implicitly, that their group is in a better position to judge [the truth about religious claims]. I will think my group knows something the critics have missed" (Frances 2014, 165). This is another way of claiming that groups can have special insights that each member of the group enjoys. But what is needed to motivate the special insight view is more information as to what precisely constitutes the special insight in order to understand the (alleged) relevant epistemic asymmetry that it purports to provide. ${ }^{33}$

\section{Four Explanations of the Special Insight View}

\section{Self-Trust}

\footnotetext{
${ }^{32}$ Related to the special insight view is the idea that in cases of disagreement, if an agent suspends judgment or lowers confidence it would violate her epistemic autonomy. Conciliationism forces the agent to arbitrarily submit to another person's authority, rather than trusting her own insight (Elga 2007, 485). Perhaps each person is rational to maintain her own beliefs when faced with disagreement because of enjoying special insight and prima facie epistemic autonomy.

${ }^{33}$ For a recent discussion of van Inwagen see Bogner et al. 2018.
} 
Self-trust is a potential candidate to explain what constitutes the special insight. From a thirdperson perspective to a peer disagreement perhaps there is no reason to prefer one peer's view to the other peer's view. But considerations about self-trust may justify an agent in the dispute herself in remaining steadfast in the face of peer disagreement. Gurpreet Rattan appeals to Richard Foley's account of self-trust to bring this point to light. For Foley, self-trust is reliable inasmuch as the agent is unable to offer a successful critique of the belief she holds which is under dispute (Rattan 2014, 39). She must also be unable to offer a critique of the reliability of the process which produced the disputed belief. Rattan explains that on this view that "[o]ne does not privilege one's own opinion merely because it is one's own; indeed, in general, one does not privilege one's own opinion. But one can privilege one's own opinion when one has self-trust in it” (Rattan 2014, 39). Reply:

Rattan notes that Foley's account of self-trust is supposed to undermine more general worries about scepticism, for example, regarding the veracity of perception. But Foley's account can apply to perception and other sceptical worries without necessarily applying to scepticism formulated on the basis of disagreement (Rattan 2014, 40). This is because disagreement involves the existence of another mind. The existence of disagreement must be understood as distinct from the firstperson perspective, otherwise it is not a disagreement at all. Importantly, the disagreement is not only based on another mind, but on the judgments formed by another mind. Rattan concludes that this self-trust response "fails to recognize that the challenge issues from another mind, and indeed a peer; and even if it does recognize that the challenge issues from another mind, it takes the other mind to be a demoted one, and thus becomes a form of [a] demotion strategy [which lacks independent grounds for the demotion]" (Rattan 2014, 41). ${ }^{34}$

\footnotetext{
${ }^{34}$ See also Foley 2001.
} 
Additionally, this strategy would be equally available to both opponents in a disagreement. Either peer could demote her opponent on the basis of self-trust. Ultimately self-trust is only able to add another point of symmetry in a peer disagreement. The discussion of bias and introspection below will provide further reason to doubt the legitimacy of appeals to self-trust. ${ }^{35}$

\section{Immediacy}

Another way of explaining what constitutes the special insight is that an agent's first-person beliefs are immediate while her beliefs about others are mediated. Ralph Wedgewood argues for nonconciliationism based on an egocentric bias which justifies an agent preferring her own intuitions. Without a special reason to do otherwise, an agent ought to hold that her intuitions are prima facie justified. Rattan explains that Wedgwood calls this type of justification primitive trust (Rattan 2014, 41-42). According to Rattan, Wedgwood argues that there is a "'general requirement of rationality' that one minimize the sources in which one has primitive trust and for this reason, primitive trust is reserved for one's own, and not extended to other's intuitions. This is [a justified] egocentric epistemic bias" (Rattan 2014, 42). Wedgwood claims that:

It does not seem possible for me currently to form a moral belief directly on the basis of your moral intuitions. At best, I can only directly base my current formation of a moral belief on my beliefs about your moral intuitions... [T] here is no such immediate tendency for your moral intuitions to incline me to accept the corresponding moral beliefs; even my own beliefs about your moral intuitions do not seem immediately to incline me to accept the corresponding moral beliefs... [I]t is simply out of the question that other people's intuitions should play the same role in rationally guiding my reasoning as my own intuitions. But my intuitions seem to be such different mental states from my beliefs about other people's intuitions that it is implausible to claim that they should play exactly the same role in guiding my reasoning (Wedgewood quoted in Rattan 2014, 42). ${ }^{36}$

\footnotetext{
${ }^{35}$ For more on disagreement and self-trust see Pasnau 2015 and Schafer 2015.

36 This quote is originally in Wedgwood 2010, 7.
} 
The immediacy of such intuitions can therefore serve as the basis for a relevant asymmetry between two parties who are otherwise epistemic peers. ${ }^{37}$

Reply:

Disagreement, however, is supposed to be a relevant reason which causes an agent to lose confidence in her intuitions, even if those intuitions enjoy prima facie justification. Rattan explains that the conciliationist:

[D]oes not require that other's intuitions be objects of primitive trust, but only that beliefs about them, in particular beliefs that one's peer's intuitions differ from one's own intuitions, be such as to be able to defeat, perhaps together with other considerations, the primitive trust that one has in one's own intuition. Wedgwood does not explain why this primitive trust is not defeated by the awareness of the disagreement (Rattan 2014, 43)

Additionally, Wedgewood's response doesn't have any special feature which precludes it from being equally available to both parities in a dispute (just like responses to conciliationism). The following sections on bias and introspection will also show that it is unreasonable to hold that intuitions ought to enjoy prima facie justification because they are immediate.

\section{Diagnosing Bias in an Opponent}

Another way to reformulate the special insight response is not so much that the agent in question enjoys a special insight that her peers lack but rather that her peers must be somehow cognitively deficient. Otherwise she would have arrived at the same conclusion as the agent in question. Diagnosing bias in an opponent provides an agent with an explanation of cognitive deficiency. Nathan Ballantyne argues that "[a]lthough debunking reasoning [based on bias] promises to preserve rational belief in the face of disagreement, debunking often won't be reasonable for us, once we realize what it demands, and once we know how people tend to make judgments about biases" (Ballantyne 2015a, 143).

\footnotetext{
${ }^{37}$ See also Wedgwood 2010.
} 


\section{A. Different Debunking Strategies}

Ballantyne believes the thought behind debunking reasoning based on bias looks like this:

Bias Premise: Some thinker is biased regarding proposition $\mathrm{p}$.

Debunking Conclusion: We have reason to reduce confidence in that thinker's report about p (Ballantyne 2015a, 144).

Ballatyne explains that there is probably no general argument for moving from the premise to the conclusion. There could be deductive, inductive, or abductive arguments that would justify moving from the premise to the conclusion. Assuming this is correct, Ballantyne explores when an agent might have reason to accept the bias premise. He clarifies that the bias premise is:

[A] claim about some thinker's disposition, in some situation, to form inaccurate or unreasonable attitudes regarding a proposition $\mathrm{p}$. Biases may prevent someone from accurately forming attitudes about $\mathrm{p}$ or from being reasonable in responding to evidence regarding p. Being biased doesn't imply actual inaccuracy or unreasonableness, but it carries a non-trivial risk of error, due to a tendency to form attitudes or evaluate evidence in an unreliable way. Being biased means being unreliable to some degree or other, though the converse doesn't hold (Ballantyne 2015a, 145).

There are a number of strategies an agent might employ to know when to accept the bias premise. The strategy of assuming that because she is correct her opponent must be exhibiting bias, risks begging the question. It also licenses a dogmatic response to any and all opponents and is thus not an effective debunking strategy. Likewise, the strategy of claiming that the other party has failed to respond appropriately to compelling evidence and is therefore biased is unlikely to be effective in many cases. Most real-life disagreements are not on topics about which there is compelling evidence (Ballantyne 2015a, 145-147). Two possibly more effective approaches to figuring out when to accept the bias premise are the following:

Biasing-Factor-Attribution Strategy. We have reasons to accept (1) that a factor F tends to bias judgments about proposition $p$, (2) that factor $\mathrm{F}$ holds for a disagreeing thinker's judgment about $p$, and (3) that we know of no 'enlightening' factor that holds for the thinker's judgment about $p$ (i.e., a factor that tends to counteract or neutralize 
F's influence). On the basis of (1)-(3), we infer that the Bias Premise is (probably) true (Ballantyne 2015a, 148).

Self-Exculpating Strategy. We have reasons to accept (1) that we are not biased and (2) that one side of the disagreement has made a mistake due to bias (rather than differences in evidence or intellectual abilities or other factors including a performance error). On the basis of (1) and (2), we can infer that the Bias Premise is (probably) true (Ballantyne 2015a, 149).

The problem, though, is that while these two strategies are more plausible than the initial strategies, Ballantyne argues that they will still not provide agents with a reason to accept the bias premise in a great number of cases of disagreement. This is because of the existence of what psychologists call the bias blindspot (Ballantyne 2015a, 149).

\section{B. The Bias Blindspot}

Ballantyne offers an interesting survey of the psychological research regarding the bias blindspot. This research suggests that there is "a broad and pervasive tendency for people to see the existence and operation of bias much more in others than in themselves" (Pronin 2007, 37). This type of bias is referred to as the bias blindspot and is a very widespread phenomena (Ballantyne 2015a, 150). ${ }^{38}$ Ballantyne explains that "[s] everal cognitive mechanisms have been found to generate the bias blindspot: ( $i$ ) an important evidential asymmetry between judgments of self and others, (ii) the tendency to assume what has been called 'naïve realism', and (iii) the motive of self-enhancement" (Ballantyne 2015a, 149-150).

Regarding (i) Ballantyne says that the judgements an agent makes about herself are based on introspective evidence. But the judgments she makes about others are based on extrospective evidence. This is an important difference because it turns out that introspective evidence is highly unreliable (Ballantyne 2015a, 150). ${ }^{39}$ If an agent uses introspection to detect her bias she might

\footnotetext{
${ }^{38}$ Ballantyne cites Pronin, Lin, and Ross 2002.

${ }^{39}$ Ballantyne cites Nisbett and Wilson 1977; Wilson and Brekke 1994; Kahenman 2003.
} 
become confident that her judgments no longer suffer from bias. This reasoning, however, is inaccurate. ${ }^{40}$ Ballantyne explains that:

It's not just that people actually rely asymmetrically on introspective and behavioral evidence. They also think they should place less weight on behavioral evidence in their own case and more weight on their own introspective evidence. In fact, researchers have noted that subjects sometimes show surprising disregard for the subjects' own actions, even when those actions become salient. Subjects insist their behavior isn't relevant to decide whether they are biased (Ballantyne 2015a, 150).

Even when the evidential symmetry is broken by reporting the introspections of others, the agent inspecting for bias still fails to remove her own bias blindspot. Even with the introspective reports the agent is still more likely to attribute bias to others than to herself (Ballantyne 2015a, 150).

Concerning (ii) Ballantyne explains that naïve realism is "the idea that our experience of the world, others, and ourselves is veridical. We normally assume that our experience gives us a more or less 'unmediated' picture of how things really are" (Ballantyne 2015a, 151). Thus, an agent is likely to think that those who agree with her are objective thinkers. Since an agent typically assumes that she is tracking reality, she is likely to think that there must be something wrong with those who disagree with her. The diagnosis of the problem is often bias (Ballantyne 2015a, 151).

Finally, with respect to (iii) Ballantyne states that people tend to view themselves in an unrealistically optimistic light. That is, "[f]or valuable or desirable traits, we tend to overrate ourselves, even when the evidence suggests otherwise. In a classic study that should be close to every college teacher's heart, 94\% of college teachers rate themselves as doing above-average work" (Ballantyne 2015a, 151). Also interesting is that the idea that "self-enhancement bias is regarded as a key element of health. People with major depression tend to have more accurate selfassessments and fewer illusions about themselves, but at the cost of healthy functioning" (Ballantyne 2015a, 151-152).

${ }^{40}$ Ballantyne cites Ehrlinger, Gilovich, Ross 2005, 686. 


\section{The Bias Blindspot and Debunking Strategies}

Ballantyne suggests that awareness of the psychological picture regarding bias makes it difficult to use the Biasing-Factor-Attribution or the Self-Exculpating strategies as reasons to affirm the bias premise. Regarding the Self-Exculpating strategy Ballantyne says that:

Learning of the psychological evidence, then, tends to undermine belief in (1) [i.e. that we are not biased]. If we ourselves wish to accept (1), in full awareness of the psychological picture, we need reason to think we are not subject to the blindspot. Insofar as we lack reason to think we're not subject to it, we have reason to doubt (1) is true and so the Self-Exculpating Strategy will fail to deliver the Bias Premise (Ballantyne 2015a, 154).

There might be a reason to accept (1) if an agent could avoid bias or somehow debias herself. But this cannot be accomplished through introspection. There would have to be a method for reliably concluding that an agent had not been impacted by the bias blindspot in the case in question. Again, this cannot be accomplished by simply thinking very hard about it. Debiasing would require an agent to have extensive knowledge of herself and biases. This is knowledge that most people almost always lack (Ballantyne 2015a, 155).

Ballantyne suggests that to successfully employ the Biasing-Factor Attribution Strategy an agent needs to lack a reason for thinking that the bias factor F does not also apply to her, rather than both her and her opponent. Otherwise, "it will debunk our dissenters and ourselves, and fail to preserve our rational belief" (Ballantyne 2015a, 156). Setting this aside, however, there is still reason to think that in regards to (1) agents are sometimes guilty of over attributing bias to others (Ballantyne 2015a, 156-157). ${ }^{41}$ (2) (that one side of the disagreement has made a mistake due to bias) might be infeasible because an agent's method for requiring behavioral evidence might not be reliable. Consider, for example, that an agent is more likely to attribute character as the main

\footnotetext{
${ }^{41}$ See Kruger and Gilovich 1999.
} 
explanation for a person's behavior rather than the particular situation that person is in when assessing someone else's action but not her own (Ballantyne 2015a, 156). Thus:

[I]f we are unsure whether we can competently gather factor F-relevant evidence concerning a disagreeing thinker, we should be unsure whether $\mathrm{F}$ holds for that thinker's judgment. The idea here is that reason to accept (2) amounts to reason to think our techniques for gathering behavioral evidence are reliable. But if we take the psychological research seriously, many of us often lack reason to think this (Ballantyne 2015, 157).

Ballantyne is careful not to imply that the Self-Exculpating Strategy and the Biasing-FactorAttribution Strategy can never be used to successfully debunk the testimonial evidence of opponents. Rather, it is just that "in light of the psychological picture, we often have reason to doubt that these strategies do help" (Ballantyne 2015a, 158).

Ballantyne concludes that "in light of the psychological picture [described above], we often have powerful reasons to doubt that debunking delivers us from epistemic trouble" (Ballantyne 2015a, 159). While Ballantyne concludes that reflection on bias lends support to conciliationist responses to disagreement, it also has direct implications for the special insight view. First, it is often implausible to attribute bias as a cognitive deficiency in an opponent. Second, someone like van Inwagen is just as likely to be exhibiting bias as his opponents. Reflections on bias provide reasons to reject the claim that van Inwagen, or anyone in a similar situation, possesses special insights that can serve as a relevant tie-breaking asymmetry in cases of peer disagreement.

\section{Introspection}

Finally, perhaps introspection might provide a positive reason for an agent to reasonably believe that she enjoys an epistemic advantage over her opponents. For she cannot introspect another agent's phenomenological experience. An agent's own phenomenology can ground the claim that she enjoys a special insight which her peers lack. Or at least it might ground the claim that she is reasonable to prefer her own beliefs in the face of disagreement. Since she is only able to introspect 
her own phenomenological experiences, she has a reason - all else being equal - to favour her own beliefs. Perhaps introspection can help make reasonable the intuition that an agent can reasonably prefer her own beliefs simply because they are her own. In this section, however, I argue that it is far from clear that introspection is reliable.

Brie Gertler explains:

The term 'introspection' - literally, 'looking within' - captures a traditional way of conceiving how we grasp our own mental states. This term expresses, in spatial language, a divide between an 'inner' world and an 'outer' or 'external' world. For most philosophers, the spatial connotations of this language are purely metaphorical: to say that a state or entity is internal to the mind is not to say that it falls within a given spatial boundary. The term 'introspection' is standardly used to denote a method of knowing unique to self-knowledge, one that differs from the method we use to grasp the 'outer' world, namely, perception (Gertler 2011).

Eric Schwitzgebel provocatively argues that while "current conscious experience is... possible, important, necessary for a full life, and central to the development of a full scientific understanding of the mind... [it is also] highly untrustworthy" (Schwitzgebel 2008, 246). He claims that:

Most people are poor introspectors of their own ongoing conscious experience. We fail not just in assessing the causes of our mental states or the processes underwriting them; and not just in our judgments about nonphenomenal mental states like traits, motives, and skills; and not only when we are distracted, or passionate, or inattentive, or self-deceived, or pathologically deluded, or when we're reflecting about minor matters, or about the past, or only for a moment, or where fine discrimination is required. We are both ignorant and prone to error. There are major lacunae in our selfknowledge that are not easily filled in, and we make gross, enduring mistakes about even the most basic features of our currently ongoing conscious experience (or 'phenomenology'), even in favorable circumstances of careful reflection, with distressing regularity. We either err or stand perplexed, depending - rather superficially, I suspect - on our mood and caution." (Schwitzgebel 2008, 247)

Many are tempted to construe doubts about introspection in terms of an agent's ability to identify nonconscious mental states such as motivations, hidden beliefs and desires, the basis for decisions, etc. Thus, many assume that thoughtful and careful introspection is generally reliable in other cases 
(Schwitzgebel 2008, 247-248). Schwitzgebel argues that even this slightly weaker version of fallibilism about introspection is not nearly weak enough.

Consider that emotions - whatever they may be - can at least sometimes involve or be accompanied by conscious experience. Think of an emotion such as joy or anger. Is it a short or long experience? Is it a feeling throughout the body, or is it located in the brain? Does being angry involve literally seeing red? Or "is joy sometimes in the head, sometimes more visceral, sometimes a thrill, sometimes an expansiveness - or, instead, does joy have a single, consistent core, a distinctive, identifiable, unique experiential character" (Schwitzgebel 2008, 249)? The inconsistency in descriptions does not amount to a deficiency in the language available to describe phenomenological experience. Schwitzgebel suggests that it is the very phenomenology itself that is very difficult to accurately describe. That is, "[r]eflection doesn't remove our ignorance, or it delivers haphazard results" (Schwitzgebel 2008, 250).

Maybe general descriptions of phenomenology are difficult, but agents are more accurate when they attend only to particular instances of ongoing emotional experiences. Again, Schwitzgebel asserts that this view is mistaken. He asks the reader to consider her current emotional state at this very moment. How clear is it? Is it as clear as perception? Schwitzgebel asks "[c]an you trace its spatiality (or nonspatiality), its viscerality, or cognitiveness, its involvement with conscious imagery, thought, proprioception, or whatever, as sharply and infallibly as you can discern the shape, texture, and color of your desk" (Schwitzgebel 2008, 251).

The problem with introspection as described thus far might only be that understanding emotions is particularly difficult. Consider the visual experience of red. Could an agent really be wrong in introspecting an inward experience of 'redness'? The answer might seem obviously 'no' but upon further reflection this is less obvious. Vision is much less accurate than most people tend 
to believe. Sight is very inaccurate outside of a very few degrees directly in front of a person's vision. Schwitzgebel says:

If I'm right about this, then most naïve introspectors are badly mistaken about their visual phenomenology when they first reflect on it, when they aren't warned and coached against a certain sort of error, even though they may be patiently considering that experience as it occurs. And the error they make is not a subtle one; the two conceptions of visual experience differ vastly. If naïve introspectors are as wrong as many later confess to be about the clarity and stability of visual experience, they're wrong about an absolutely fundamental and pervasive aspect of their sensory consciousness (Schwitzgebel 2008, 256).

Noteworthy here is that if this account by Schwitzgebel is correct it implies that careful introspection even about vision is unreliable. Maybe introspection about imaginings has some general agreed upon phenomenological characteristics. But imaginings vary greatly from agent to agent. They vary much more than reports of the external world. Widespread disagreement about phenomenology implies that many agents are deeply mistaken. Thus, "the introspection of current conscious experience, far from being secure, nearly infallible, is faulty, untrustworthy, and misleading - not just possibly mistaken, but massively and pervasively" (Schwitzgebel 2008, 259). While there is a lot of human variability, there is not so much with respect to introspection. For example, "human livers are all different but none are made of rubber" (Schwitzgebel 2008, 264). Schwitzgebel asks:

Should phenomenology prove the exception by varying radically from person to person - some of us experiencing one hundred degrees of visual clarity, some only two degrees, some possessed of a distinctive phenomenology of thought, some lacking it, and so forth - with as little commonality as these diverse self-attributions seem to suggest? Of course, if ocular physiology differed in ways corresponding to the differences in report, or if we found vastly different performances on tests of visual acuity or visual memory, or if some of us possessed higher cognition or sympathetic emotional arousal while others did not, that would be a different matter. But as things are, two people walk into a room, their behavioral differences are subtle, their physiologies are essentially the same, and yet phenomenologically they're so alien as to be like different species? Something might be unreliable because it often goes wrong or yields the wrong result, or it might be unreliable because it fails to do anything or yield any result at all... Introspection is unreliable in both ways. Reflection on basic 
features of ongoing experience leads sometimes to error and sometimes to perplexity or indecision (Schwitzgebel 2008, 264-265).

Assessing Schwitzgebel's scepticism towards introspection is not my focus here. His critique of introspection is without a doubt controversial and there is a body of literature on it that I will refrain from exploring here. ${ }^{42}$ Rather, the lesson is that in order to appeal to introspection as an explanation of the special insight view a lot more work needs to be done. At the very least the nonconciliationist who wishes to appeal to special insight would have to demonstrate (i) how introspection is connected to the special insight view, and (ii) that introspection is reliable (or more precisely, that it is reliable when it is appealed to as an asymmetry in a disagreement). Schwitzgebel's account provides reasons to doubt that satisfying these conditions is probable in many cases of disagreement. ${ }^{43}$

\section{Three Additional Considerations}

In this section I address three additional considerations with respect to the Special Insight View that are important to consider.

\section{Special Insight and a G.E. Moore Shift}

\footnotetext{
${ }^{42}$ For an excellent introductory resource on introspection see Eric Schwitzgebel, "Introspection", The Stanford Encyclopedia of Philosophy (Summer 2014 Edition), Edward N. Zalta (ed.), URL = $<$ http://plato.stanford.edu/archives/sum2014/entries/introspection/>.

${ }^{43}$ A further discussion of self-knowledge might be somewhat relevant here. While self-knowledge can sometimes refer to the conditions for personhood, it typically refers to knowledge an agent has of her mental states that is distinct from knowledge of the external world. Since at least Descartes there has been a philosophical tradition which holds self-knowledge is uniquely privileged. It might be privileged because it enjoys a unique epistemic security or because an agent uses a unique method to determine her own mental states. Non-epistemic reasons for privileging self-knowledge include that an agent is uniquely positioned to regulate her own mental states. Another is that an agent's own pronouncements about her mental states come with a special authority. The non-inferential nature of selfknowledge might make it more reliable than reports of a peer's mental states. But this does not seem to help the nonconciliationist in the face of peer disagreement. This is simply a claim about how it is easier for an agent to have accurate knowledge of her own mental states rather than a peers. I will not press this point further as I think if there is any relevance between self-knowledge and the special insight view it will be found in introspection. For a very informative introduction to self-knowledge see Brie Gertler, "Self-Knowledge", The Stanford Encyclopedia of $\begin{array}{llll}\text { Philosophy (Spring } & 2011 \quad \text { Edition), Edward }\end{array}$ <http://plato.stanford.edu/archives/spr2011/entries/self-knowledge/>.
} 
Perhaps there is a more charitable way of understanding the special insight view. Michael Thune suggests that van Inwagen's response is best understood as motivated by the following argument:

(1) Philosophical scepticism [as entailed by strong versions of conciliationism] is intuitively false.

(2) If the fact of disagreement alone always or nearly always required both sides in a dispute to suspend judgment, then (since there is so much disagreement about much that is of interest) we as philosophers would all have to adopt philosophical scepticism.

Therefore,

(3) It is not the case that the fact of disagreement alone always or nearly always requires both sides in dispute to suspend judgment (i.e. it usually must not be the case that there is or that one need believe that there is epistemic parity) (Thune 2010a, 715).

Thune argues that van Inwagen implicitly endorses a distinction between internal and external parity with respect to peers. Internal parity is about the evidence, arguments, judgments, and perhaps even the felt attractiveness that two peers cite as relevant to forming the competing beliefs under dispute. External parity concerns facts that they might not be aware of such as the subject's overall epistemic situation (e.g. whether the belief was formed by a reliable process) (Thune 2010a 715). Thune claims that "[d]isagreements that involve internal parity but not external parity obviously do not admit of parity all things considered and thus, van Inwagen seems to say, need not result in a defeater" (Thune 2010a, 715).

The external asymmetry is probably best explained by the fact that one agent enjoys a special insight that her opponent lacks. But I have already shown that appealing to a special insight to establish a relevant asymmetry between the parties is implausible. But what of the argument above? This appears to be a G.E. Moore shift style argument. van Inwagen is more sure that the widespread scepticism about many controversial beliefs implied by certain conciliationist 
responses to disagreement are false than he is about the epistemic significance of disagreement. Therefore, he is reasonable to reject conciliationist views of disagreement and embrace nonconciliationism.

This G.E. Moore shift response brings the debate to an end. The arguments in favour of conciliationism make it less than obvious that non-conciliationism is true. Or at least they ought to make it less than obvious. This response seeks to end the discussion. The very fact that van Inwagen felt compelled to write a response about disagreement suggests that the appropriate conclusions are far from obvious. However, for those who accept (1) then inasmuch as conciliationism entails scepticism perhaps this line of argument is convincing. Still, for most philosophers, the arguments in favour of conciliationism make understanding van Inwagen's argument as a G.E. Moore shift unconvincing.

\section{Special Insight and Widespread Disagreement}

In beginning his discussion on disagreement van Inwagen writes that is quite rare to "find universal or near-universal agreement about very many important theses or arguments in philosophy. Indeed, it would be hard to find an important philosophical thesis that, say 95 percent of, say, American analytical philosophers born between 1930 and 1950 agreed about in, say, 1987” (van Inwagen 1997, 138). It is the special insight response that van Inwagen offers to explain why he can remain steadfast in the face of such disagreement, but there is another more pressing issue here. While Hilary Kornblith does not think conciliationism is correct, he notes that widespread disagreement in philosophy implies that in many cases at most only one person has a true belief on the issue under dispute (Kornblith, 2010). If past and future disagreements are included, then the problem is further compounded. In philosophy, then, it seems that hardly any philosophers 
hold any true philosophical beliefs. The same argument will hold for other areas where widespread disagreement exists such as politics, ethics, and religion.

The lesson here is that the existence of widespread disagreement is another reason to reject the special insight view. The existence of widespread disagreement implies that most of an agent's controversial beliefs are false, and thus there is little reason for that agent to suppose that she, or anyone else, possesses a special insight. If there existed a lot of agreement regarding a particular thesis, then perhaps the existence of a small amount of disagreement would fail to motivate this claim. But this is not the situation regarding most beliefs about controversial subjects. Thus, the existence of widespread disagreement entails that it is highly unlikely that any philosopher enjoys a special insight.

\section{Special Insight and Religious Diversity}

The special insight view is closely connected to the literature on religious diversity. The existence of religious diversity is thought to pose a challenge to the rationality of religious belief because:

$[I] t$ is generally assumed that one's awareness of the fact that there are sincere, morally and epistemically virtuous, intelligent, and thoughtful people who hold religious beliefs incompatible with one's own threatens to undermine or defeat any justification that one's particular religious beliefs may otherwise hold. This threat stems from the intuition that one rationally ought to treat like cases alike. That is, the existence of apparent epistemic symmetry between the religious beliefs of practitioners from a variety of different traditions is thought to result in a situation where it would be epistemically arbitrary to affirm any one 'exclusive' belief (or set of beliefs) over another (Thune 2010a, 712).

The epistemology of disagreement literature takes a different approach to precisely the same epistemic problem. The connection is interesting because van Inwagen has the rationality of religious belief in view throughout his essay. Religious exclusivists are those who claim that their particular religion is the only way to achieve salvation. Thune notes that Alvin Plantinga justifies 
his exclusivism about Christianity along the same lines as the special insight view. Plantinga acknowledges that an agent "may agree that she and those who dissent are equally convinced of the truth of their belief, and even that they are internally on a par, that the internally available markers are similar, or relevantly similar" (Plantinga quoted in Thune 2010a, 716). Plantinga claims that:

An important ['external'] epistemic difference: she thinks that somehow the other person has made a mistake, or has a blind spot, or hasn't been wholly attentive, or hasn't received some grace she has, or is blinded by ambition or pride or mother love or something else (Plantinga quoted in Thune 2010a, 716).

But consider how untenable Plantinga's claim here is if any of the arguments from Ballantyne and Schwitzgebel I outline above provide justification for scepticism about identifying bias in others, or about the reliability of introspection.

\section{Conclusion}

A prominent defense of non-conciliationism is the idea that in the face of disagreement an agent is reasonable to remain steadfast in her beliefs because she enjoys a special insight that her opponent lacks. I examined whether appeals to self-trust, immediacy, diagnosing bias in an opponent, and introspection could be used to explain what constitutes the special insight. Self-trust does not take seriously enough the fact that the disagreements are the result of judgments issued from another mind. Appeals to immediacy fail to explain why disagreement does not count as a defeater for the prima facie justification of intuitions. The fact that an agent is just as likely to be as biased as her opponent's provides another reason to reject the special insight view. Finally, introspection and considerations about self-knowledge offer little hope of identifying the specific features of special insight. All of these explanations suffer from the fact that both agents in a dispute are equally justified in appealing to them. It is thus difficult to see how a relevant epistemic asymmetry, which is needed to justify reasonable disagreement, can be generated between the two 
parties. Thus, the special insight view cannot be successfully employed to defend nonconciliationist responses to disagreement. While in this project I will argue that a certain limited form of non-conciliationism is true, it is for reasons other than any related to the special insight view. 


\section{Chapter Three: An Analysis of Toy Cases of Disagreement}

\section{Introduction}

In the epistemology of disagreement literature, many authors use certain cases of disagreement in order to lend support to either conciliationism or non-conciliationism. Richard Feldman and David Christensen, among others, are advocates of the view that lessons from simple idealized cases of disagreement shed light on complex cases of disagreement. In this chapter I analyze some of these simple cases in order to demonstrate that while they do lend support for conciliationism, the lessons do not necessarily carry over to more complex cases of disagreement. ${ }^{44}$ This is because there are a number of epistemically relevant differences between simple and more complex cases of disagreement. The most important difference involves appealing (loosely) to Quine's idea of a web of belief. Cases of disagreement vary depending on how difficult it is to maintain a coherent web of beliefs in the face of disagreement. The difficulty in maintaining coherence is based in part on the number of propositions under dispute, and the location of the proposition in an agent's web of belief. Another important difference between cases I will discuss is whether confirmation is possible on the subject in question. In this chapter I explicate the Different Disagreement Argument in defense of my thesis. ${ }^{45}$

\section{The Different Disagreements Argument}

In this chapter I aim to defend the following argument:

\section{The Different Disagreements Argument:}

1. If there are epistemically relevant differences between cases of disagreement, then lessons from one type of disagreement do not apply to all cases of disagreement.

44 At least one prominent advocate of conciliationism, Adam Elga, acknowledges that simple cases and complex cases should be treated differently based on the fact that epistemic peerhood is more likely to obtain in the former than the latter. See Elga 2007.

45 Thanks to John Roman for extensive comments on this chapter, and in particular for his suggestion about the connection between location of belief on the web and the complexity of the case. 
2. There are epistemically relevant differences between cases of disagreement. [The simple cases lend intuitive support to conciliationism. The complex cases lend intuitive support to non-conciliationism (or at least they don't clearly support conciliationism).]

3. Epistemically relevant differences are based on the complexity of the case of disagreement in question. Complexity is determined (at least in part) by the difficulty of maintaining a coherent set of beliefs if one revises in the face of disagreement, and also whether it is possible to confirm which disputant is correct.

4. The difficulty in determining coherence is based in part on the number of propositions under dispute and the location of the proposition in one's web of belief. [In simple cases it is either very easy or very difficult to revise. Confirmation about the disagreement is in principle possible. In complex cases it is very difficult to revise and confirmation about the disagreement is not available in any straightforward sense.]

5. The possibility of confirmation depends on whether there is an agreed upon method by which to check which opponent is correct.

Therefore,

6. Lessons (e.g. conciliationism) from one type of disagreement (e.g. simple cases) do not apply to all cases of disagreement (e.g. complex cases).

(1) is the conditional, the consequent of which I am attempting to prove in this chapter. (2) is the antecedent of (1). (3), (4), and (5) support (2). (5) follows logically from the truth of (1) and (2). Of course, the key to defending the argument is to demonstrate that (2) is true. Thus, the focus of this chapter will be to explain and defend (3), (4), and (5) since if they are true then (2) is true too. Before offering my defense of the Different Disagreements Argument, which consists primarily of exploring the specific details of the different cases in question, it is important to get clear on a few important concepts.

\section{Coherence}

A coherent set of beliefs implies that minimally no beliefs in that set contradict one another. Maximally, it entails that no beliefs are in tension with one another. Part of what it means for a set 
of beliefs to be rational is the degree to which those beliefs cohere with one another. ${ }^{46}$ Coherence is partly a function of rationality. While it is not sufficient for rationality, it is necessary for rationality. Throughout the rest of this chapter I will assume that coherence is a degreed property and also that it is a philosophically defensible concept. It is not within the scope of my project to defend the concept of coherence. ${ }^{47}$

\section{Web of Beliefs}

By web of beliefs I refer loosely to Quine's notion (Quine and Ullian 1970). It consists of all of the beliefs that an agent holds, it makes up her worldview. The closer a belief is to the centre of an agent's web, the more difficult it will be to change while maintaining a coherent web of beliefs. The beliefs in the centre are in some sense foundational to other beliefs.

Example of Web of Beliefs:

Centre

- mathematics

- scientific laws

- religion

- morality
Middle

- similarity judgments

- abduction

- inference
Edge

- isolated perceptual observations (based merely on perception)

\section{Confirmation}

There are different accounts of confirmation, but I do not need a very precise definition for my purposes. For certain subjects such as mathematics and empirical sciences, truth-tracking criteria can be used to confirm success or truth. Other disciplines such as politics, religion, and ethics lack obvious or agreed upon truth-tracking criteria. There is no agreed upon method for checking who is right regarding these subjects.

\section{Expertise}

46 Note that this is distinct from the coherence theory of truth. Throughout this project I assume a correspondence theory of truth. Thus, my claim that coherence is a partly a function of rationality is compatible with a set of beliefs being coherent but false. See Young 2015.

${ }^{47}$ For more on coherence see: Olsson 2014; Rescher 1973. 
In this chapter I distinguish between expertise that any properly functioning ordinary adult should have and special expertise that is the result of specialized training. I further differentiate between alethic experts and non-alethic experts where it is inappropriate to evaluate expertise based using a truth-tracking record.

\section{Classic Cases Supporting Conciliationism}

Surveying all of the cases in the epistemology of disagreement literature would be an enormous task. Thus, in what follows I will focus on the seminal cases that are widely cited and employed throughout the literature. As I present cases I will show how they support (3), (4), and (5), and hence (2) of the Different Disagreements Argument. The first three cases that I examine are typically offered in support of various forms of conciliationism. After that I will shift focus to more controversial cases of disagreement where the appropriate response to them is either not clear, or seems to support conciliationism. This supports my theory of the relevant epistemic differences between simple and more complex cases. Consider Richard Feldman's oft-cited quad case:

\section{The Quad}

Suppose you and I are standing by the window looking out on the quad. We think we have comparable vision and we know each other to be honest. I seem to see what looks to me like the dean standing out in the middle of the quad. (Assume that this is not something odd. He's out there a fair amount.) I believe that the dean is standing on the quad. Meanwhile, you seem to see nothing of the kind there. You think that no one, and thus not the dean, is standing in the middle of the quad. We disagree. Prior to our saying anything each of us believes reasonably. Then I say something about the dean's being on the quad, and we find out about our situation. In my view, once that happens, each of us should suspend judgment. We each know that something weird is going on, but we have no idea which of us has the problem. Either I am "seeing things," or you are missing something. I would not be reasonable in thinking that the problem is in your head, nor would you be reasonable in thinking that the problem is mine (Feldman 2007, 207-208). ${ }^{48}$

\footnotetext{
${ }^{48}$ It may need to be that for this case to really be simple it needs to be stipulated that both parties have an equally good track-record when it comes to basic sense perception (i.e. like cases) and are aware of each others'
} 
Like Feldman's example, Adam Elga's horse race example also involves disagreement about immediate perception:

\section{Horse Race}

You and a friend are to judge the same contest, a race between Horse A and Horse B. Initially, you think that your friend is as good as you at judging such races. In other words, you think that in case of disagreement about the race, the two of you are equally likely to be mistaken. The race is run and the two of you form independent judgments. As it happens you become confident that Horse A won, and your friend becomes equally confident that Horse B won... Here is the bottom line. When you find out that you and your friend have come to opposite conclusions about a race, you should think that the two of you are equally likely to be correct (Elga 2007, 166-167).

These two cases are both about disagreements over simple perceptual claims. For Quine perception occupies a position near the outer edge of an agent's web of beliefs. These beliefs, then, can be easily changed or revised without greatly impacting the overall coherence of one's entire web of beliefs. There is only one proposition under dispute and it is not connected to the agent's other beliefs such that other beliefs are obviously dependent on it (hence why it is near the outside of the web). Also, it is in principle possible to confirm who is correct in these cases. ${ }^{49}$ That is, it is relatively easy to discover decisive evidence that would settle the dispute in question. Likewise, the notion of expertise is relevant inasmuch as any ordinary adult should have the skills to collect and assess the relevant evidence in question. All of this explains why at the initial point of awareness of the disagreement the two agents ought to suspend judgment or lower their belief credences. It takes little time and effort for an agent to re-check in these cases.

Now consider David Christensen's oft cited restaurant bill disagreement:

\section{Restaurant Bill}

record. However, I will not delve into such details further since the literature almost universally treats this as a simple idealized case of disagreement.

${ }^{49}$ Verification is one point of difference between simple and certain complex cases that Christensen recognizes in his later work on disagreement (2014b). 
Suppose that five of us go out to dinner. It's time to pay the check, so the question we're interested in is how much we each owe. We can all see the bill total clearly, we all agree to give a 20 percent tip, and we further agree to split the whole cost evenly, not worrying over who asked for imported water, or skipped desert, or drank more of the wine. I do the math in my head and become highly confident that our shares are $\$ 43$ each. Meanwhile, my friend [epistemic peer] does the math in her head and becomes highly confident that our shares are $\$ 45$ each. How should I react, upon learning of her belief (Christensen 2007, 193)?

Christensen explains that the two friends have often had dinner together and that they have equally good track records at successfully calculating the bill. There is no reason to think there is any relevant epistemic asymmetry between the two friends that could justify one of them remaining steadfast about the amount owed on the bill. Neither friend, for example, is especially tired, inebriated, or otherwise epistemically disadvantaged (Christensen 2007, 193). Christensen believes that the answer to how one should reasonably respond to disagreement over the bill is obvious: both friends should lower their confidence in the initial amounts they arrived at. In this instance, equal weight should be given to both calculations.

Again, notice that at first glance just one proposition is under dispute. But for Quine, mathematical beliefs are near the centre of an agent's web of belief because they are foundational for inquiry and knowledge. Thus, changing foundational mathematical belief will be devastating to the coherence of one's web of beliefs. The entire web will have to change to be coherent, if it is even possible to maintain coherence in such a case. One might wonder whether this is not a strong consideration in favour of remaining steadfast in the face of disagreement. As I will show later in my discussion of more complex cases, remaining steadfast might be rational if this were the only consideration at play. But consider that one has a defeater for a basic mathematical belief and that confirmation is possible in this case. It is relatively easy to re-check one's math with a calculator. Suspending judgment until one has does this is more reasonable than completely shattering the coherence of your web of beliefs. The existence of disagreement in this case has given you a 
defeater to a simple arithmetic belief and an agent risks the coherence of her web of beliefs if she does not revise. The easiest way to maintain coherence in this case is to revise (or re-check).

Notice that simple cases often involve a relatively encapsulated task. It is easy to establish that the disputing parties are epistemic peers - cognitive and evidential equals - at least with respect to the dispute in question (Oppy 2010, 185). Any properly functioning adult has the ability to find and assess the evidence relevant to the proposition under dispute in these simple cases. For example, any ordinary adult has the competence to use a calculator to check a bill, or ask a third party to look for the dean in the quad (or to go out to the quad for a closer look), or examine pictures from a photo finish. Thus, only a common expertise is required to settle disputes over the simple cases of disagreements, though the expertise in question is still alethic.

In all of these cases there is only one proposition under dispute and hence only one way to revise to achieve coherence. An incorrect assessment as to whether or not the dean is in the quad can not be incorporated into a web of beliefs in a way that will straightforwardly achieve coherence with all of one's other beliefs (though incorrect perceptual beliefs may not be that important to one's web of beliefs). Importantly, the individual proposition under dispute in these cases is not connected to other beliefs in a way that has multiple paths to coherence. The ability to confirm the initial proposition means it cannot be incorporated into a web of beliefs when disagreement occurs with the possibility of easily maintaining coherence. So I agree with the authors of these cases when they suggest they lend intuitive support to conciliationism.

Perhaps the best way to understand these cases is that Christensen, among others, implicitly relies on supervenience with respect to how agents should respond to disagreement. He implicitly assumes what I will refer to as the Supervenience Conciliationist Principle: If there are certain factors f1-fn which make it rationally obligatory for an agent to revise in situation S, then any other 
situation $\mathrm{S}^{*}$ with the same factors will be a situation where the agent should also revise, unless there is some relevant difference. ${ }^{50}$ What is tacit in the accounts of Christensen and Feldman is the claim that there are no relevant differences between the simple and more complex cases of disagreement. ${ }^{51}$ Christensen asserts that:

The restaurant case is designed to be simple in two ways: in the evidential situation and in the evaluation of the general capacities my friend and I exercise in reacting to that sort of evidential situation. This makes our intuitions about the case particularly clear. But the same lessons emerge, I think, from cases involving a bit more complexity. Let us consider a case that more closely resembles more interesting cases of disagreement (Christensen 2007, 193; emphasis mine). ${ }^{52}$

Thus, while the Supervenience Conciliationist Principle is sound, the Different Disagreement Argument shows that there are relevant differences between simple and more complex cases of disagreement. This is why Christensen and others are not entitled to conclude that agents ought to revise in more complex cases of disagreement, including the meteorologist case that comes next.

\section{Unclear Cases}

In what follows I explore some cases that, contra Christensen, I think neither obviously support conciliationism nor non-conciliationism. Consider, for comparison, the more complicated case that comes next in Christensen's analysis:

\section{Meteorologist}

Suppose I'm a meteorologist who has access to current weather data provided by National Oceanic and Atmospheric Administration, the National Weather Service, and

${ }^{50}$ Thanks to Paul Silva for helping me to clarify this point.

${ }^{51}$ Elsewhere, in a later article Christensen acknowledges that there are a lot of differences between simple and complex cases, but according to him such differences further support conciliationism in complex cases. This is because one will not be able to use personal information in complex cases (e.g. your opponent is biased) to demote them as a peer $(2014 \mathrm{~b}, 147)$. But this makes it all the more puzzling why Christensen is still insistent that there are important lessons to be learned about disagreement from examining the simple cases.

52 Elsewhere Christensen writes that "[t]he hope is that by understanding the rational response to disagreement in the simple cases, we'll get some insight into what the rational response is in the more complex ones involving the public controversies among groups that give the issue much of its urgency" (Christensen 2014, 143). He goes on to argue that in public controversies where a group of people disagree that conciliatory principles are even more forceful because one will not be able to use personal information (e.g. your opponent is biased) as easily when it comes to a group of people. 
so forth, and that I have learned to apply various models to use this data in making predictions. To make this less like the restaurant case and more like many cases of real-life disagreement, let us suppose that applying the models is not just a matter of clear-cut calculation - say it involves similarity judgments. After thoroughly studying the data and applying the various models I know, I come to have a 55 percent level of credence in rain tomorrow. But then I learn that my classmate from meteorology school - who has thoroughly studied the same data, knows the same models, and so on - has arrived at only a 45 percent level of credence. We may even suppose that we have accumulated extensive track records of past predictions, and she and I have done equally well... Should I take her opinion into account and reduce my confidence in rain? It seems obvious to me that, absent some special reason for thinking that I had some advantage over her in making this forecast, I should revise my belief (Christensen 2007, 195-197).

As with the restaurant bill case, Christensen claims that the rational response in these circumstances is for the meteorologist to revise her beliefs. He is hardly alone in his assessment.

Consider what Jonathan Matheson says about the restaurant case:

Disagreements like that involving the restaurant check can occur in a wide variety of cases. Such disagreements seems to occur frequently concerning matters of politics, religion, ethics, and philosophy in general. What I have said about the restaurant check [i.e. that both agents should revise] seems to apply equally well to these other cases of disagreement. (Matheson 2009, 271)

Indeed, Matheson (2015a) builds on this claim in his book The Epistemic Significance of

Disagreement. He spends the first five chapters of the book defending the equal weight view with respect to idealized cases of disagreement, because he believes they are informative about realworld disagreements. But the idealized cases included in Matheson's defense of the equal weight are more complex than the first three seminal cases mentioned above. Consider the following example of philosophical disagreement from Matheson:

\section{Epistemologists and Evil Demons}

Suppose that two equally qualified epistemologists, Rich and Alvin, strike up a conversation on what things would be like, epistemically speaking, in a world where an evil demon subjected the other inhabitants of the world to massive deceptions. Rich concludes that the victims of that world would nonetheless be justified in their beliefs. Alvin concludes that although the victims would not be blameworthy, they would not 
be justified in their beliefs. They share their arguments with each other, but the disagreement nevertheless persists (Matheson 2015a, 69).

In sum Matheson concludes that:

In a case of idealized disagreement the disagreement is explained equally well by locating the error with either party - both parties are in an equally good epistemic position on the disputed matter. So, to give more weight to either of the parties would be a mistake - it would be to exhibit some sort of epistemic bias (either in favor of yourself or in favor of your peer). However, the fact that you are one of the disagreeing parties does not add (or take away) any epistemic weight to your opinion on the matter. Since your evidence supports that your epistemic position regarding the disputed proposition is exactly as good as that of your peer's, both your opinions on the matter are to be given equal weight. So, it is plausible that in an idealized disagreement, each party's opinion should be given equal weight - the higher-order evidence about you is equally good as the higher-order evidence about your peer (Matheson 2015a, 72).

Later, when attempting to explore real-world cases of disagreements that are not as idealized, Matheson writes that he "will examine the epistemic effects of stripping off our idealizations. In doing so, we can take the lessons from idealized disagreements into real-world scenarios" (Matheson 2015a, 113). This is one of the main claims the Different Disagreements Argument challenges. Christensen, Matheson, and others want to operate as if the simple cases of disagreement are relevantly similar to the complex cases of disagreement with respect to how one ought to respond to such disagreements. Finally consider a similar case offered by Jennifer Lackey and added to by Graham Oppy.

\section{Medical Diagnosis}

Dr. Haggard and Dr. Wolf are both impeccably educated and highly respected physicians with fifteen years of practising medicine under their belts. Ruby, who has been thoroughly examined by both doctors, has been suffering for months from extreme fatigue, swollen joints, muscle pain, memory loss, sensitivity to light, and persistent fevers. After running the same tests and receiving identical results, Dr. Haggard is quite confident that Ruby has chronic fatigue syndrome, and Dr. Wolf is just as confident that she suffers from lupus (Lackey 2010a, 290-291). ${ }^{53}$

${ }^{53}$ Lackey does not use this example to defend non-conciliationism. She defends a dynamic 'Justificationist View' which states that sometimes disagreement requires revision and sometimes it does not require revision. See Lackey 2010a for more details. I also discuss her view in more detail in Chapter Nine. 
If we suppose that each physician is aware of the judgment of the other-and if we suppose that each regards the other as a doxastic peer-should we also suppose that each ought to move towards the confidence level of the other (Oppy 2010, 191-192)?

In Meteorologist, Epistemologists and Evil Demons, and Medical Diagnoses while there is one proposition under dispute it is immediately clear that it is connected to a number of other propositions. For instance, applying models and using similarity judgments involves interconnected beliefs that fall somewhere in the middle of an agent's web of beliefs. The proposition under dispute is not as firmly held as a mathematical belief, but not as unreliable as a perceptual claim (at least if Quine is followed here). Abduction and induction are involved in these cases which make the propositions less than self-evident to their proponents. Maintaining coherence is not as difficult as in cases where the belief is in the centre of one's web, and yet it is not as easy to maintain coherence when one makes changes to beliefs on the edge of her web.

Likewise, confirmation is not in principle impossible when it comes to Meteorologist and Medical Diagnosis. ${ }^{54}$ For example, at first glance a disagreement between meteorologists involves simply waiting to find out which forecast is correct. But recall the specific details of the meteorologist case. One has a 55\% credence that it will rain tomorrow while the other has a $45 \%$ credence. Whether or not it rains the next day will not settle the dispute in this case. Both meteorologists could maintain that their initial credence was correct. ${ }^{55}$ But suppose the details of the meteorologist case are slightly different:

\section{Meteorologist*:}

Suppose I'm a meteorologist who has access to current weather data provided by National Oceanic and Atmospheric Administration, the National Weather Service, and so forth, and that I have learned to apply various models to use this data in making predictions. To make this less like the restaurant case and more like many cases of real-life disagreement, let us suppose that applying the models is not just a matter of

\footnotetext{
54 There, of course, medical cases where confirmation is possible (e.g. how a patient responds to different treatments).

55 Thanks to Lloyd Humberstone for bring this point to my attention.
} 
clear-cut calculation - say it involves similarity judgments. After thoroughly studying the data and applying the various models I know, I come to have a 55 percent level of credence that there will be $2 \mathrm{~mm}$ to $5 \mathrm{~mm}$ of rain tomorrow. But then I learn that my classmate from meteorology school - who has thoroughly studied the same data, knows the same models, and so on - has arrived at only a 45 percent level of credence that there will be $3 \mathrm{~mm}$ to $6 \mathrm{~mm}$ of rain. We may even suppose that we have accumulated extensive track records of past predictions, and she and I have done equally well. ${ }^{56}$

When a specific estimate is provided with a standard deviation it is possible to track the success rate of each meteorologist over time. Thus, confirmation is possible in this slightly modified case. Unlike in the simple cases, the notion of special alethic expertise is relevant in the intermediate cases of disagreement. For instance, medical doctors and meteorologists require extensive specialist training. Likewise, truth-tracking criteria can be used to assess the success rate of each expert in question. ${ }^{57}$ Ordinary non-specialists are unable to collect and assess the evidence needed to resolve the dispute in intermediate cases of disagreement. There is widespread agreement on what would constitute decisive evidence that would settle the dispute in question, though it may or may not be possible to confirm any specific example of disagreement. Alethic expertise is required to gather and assess the relevant evidence in Meteorologist and Medical Diagnoses. Finally, in Epistemologist and Evil Demons there is no obvious route to check which epistemologist is correct, though of course it does not follow from this fact that expertise does not exist in a discipline like philosophy. ${ }^{58}$

Contra Christensen and Matheson, I doubt there will be consensus amongst philosophers about whether these three cases support conciliationism or non-conciliationism. The differences I describe above demonstrate why this is so, and why the intuitions may differ about these cases, but not the simple cases. Intuitions are mixed because the beliefs are in the middle of the web. The

\footnotetext{
56 This example is modified from Christensen 2007, 195-197.

57 This could also probably be explicated using safety conditions for knowledge.

${ }^{58}$ I will say more about this later in the chapter.
} 
lack of a simple and clear-cut way to confirm in these cases also make intuitions less clear. Finally,

maintaining coherence is not as difficult as in cases where the belief is in the centre of one's web and yet it is not as easy to maintain coherence as when one makes changes to beliefs on the outer edge of her web. This analysis serves to support premise (3), (4), and (5).

\section{Cases Supporting Non-Conciliationism}

There are also cases of disagreement that intuitively support non-conciliationism, rather than conciliationism. The following two cases that feature disagreement on even more complex subject matters again helps to demonstrate that there are problems with attempting to move seamlessly between simple and more complex cases.

\section{Moral Disagreement}

Consider... a case of moral disagreement about how to evaluate the following very disturbing behavior of Jack. Jack takes great pleasure in slowly killing young children by torturing them while forcing their parents and siblings to watch. He has devised a way to do this often, without fear of getting caught. I assume that you think this behavior of Jack's is morally wrong-extremely so... But you have two friends-both of whom seem to you to be about as intellectually virtuous as you-who disagree. One is an ethical egoist who thinks this behavior of Jack's is morally right since it maximizes Jack's self-interest; the other is a moral nihilist who thinks it's not the case that Jack's behavior is morally wrong since there are no moral facts and nothing is either morally wrong or morally right. All three of you feel disgusted by Jack's behavior and very strongly wish that Jack wouldn't engage in it. But only you think it is morally wrong. Now, each of you lays before the others all of the relevant considerations you can think of for your respective views on Jack's behavior, including arguments for and against moral nihilism and ethical egoism... Now, consider this question: should you, in light of all this, have significant doubts about the reliability of your own apparent insight that Jack's behavior is morally wrong (Bergmann 2009, 345-346)? ${ }^{59}$

Finally, consider the following case that plausibly occurs with some frequency:

\section{Religious Disagreement}

${ }^{59}$ Bergmann claims that even if an agent is aware of all of the evidence, while her peer's opposing view might be internally rational, the intuitive force behind the example lends support to the claim that she remains justified to trust her own insight or intuition despite the disagreement. 
Jack is raised in a Christian home, in a culturally Christian homogenous small town. Jack believes that what he is told about Christianity is true ${ }^{60}$ He sees the universe through a Christian lens. When Jack attends university away from home in a large and diverse big city, he encounters many people who oppose his Christian worldview. He studies philosophy and makes friends with many people who are not Christians. $\mathrm{He}$ comes to think it may have been a matter of chance that he is a Christian. After all, his beliefs are mostly the product of his upbringing and environment. Yet despite openly and honestly discussing competing views amongst his friends he still thinks Christianity is true. Is Jack reasonable to remain steadfast?

The intuitive appeal behind these two cases tends to favour non-conciliationism, especially in light of the factors I have been discussing thus far. At the very least, they don't seem to intuitively support conciliationism.

While Michael Bergmann explicitly claims to have no argument for non-conciliationism, perhaps he would defend something like the following Supervenience Non-Conciliationism Principle: If there are certain factors f1-fn which make it rationally obligatory for an agent to remain steadfast in situation $S$, then any other situation $S^{*}$ with the same factors will be a situation where the agent should also remain steadfast, unless there is some relevant difference. Again, this argument is also sound. What I take issue with is the claim that no relevant differences exist between the different cases of disagreement discussed in this chapter. Neither Christensen nor Bergmann identify the specific factors, but both seem to assume that there are no relevant differences between simple and complex cases of disagreement. The Different Disagreements Argument, however, shows that there are significant differences between simple and complex cases of disagreement. ${ }^{61}$

${ }^{60}$ It's perhaps a bit odd to speak of Christianity as true or false since it represents numerous claims. For the purposes of argument take Christianity here to refer to the truth of the Apostle's and Nicene Creeds.

${ }^{61}$ To be fair, Bergmann is not explicit about how far reaching his argument is (i.e. whether it is intended to apply to the simple cases given by Christensen and Feldman). Still, Bergmann is likely to think there are other cases like his moral example, where remaining steadfast is rational. What I want to know is what the epistemically relevant similarities are between those cases. 
In these more complex cases there is very little agreement on how to find out which party in a dispute is correct. There is no agreed upon set of criteria for what would constitute decisive evidence for or against the proposition in question. Thus, many disagreements over controversial moral or religious matters should be categorized as complex. While there can be experts in these areas, they are only what I call 'non-alethic experts' because it is inappropriate to use a truthtracking criteria to evaluate their success. Perhaps they know all of the first-order reasons on the topic in question, but there is no clear way to tell whether their assessment of those reasons is accurate. Both Moral Disagreement and Religious Disagreement are clearly different from the simple cases which involve no alethic expertise and are easy to re-check or confirm which peer is correct. I am not claiming that epistemic justification for moral or religious beliefs is illusory. ${ }^{62}$ But I am suggesting it is impossible to initiate a course of action to verify or confirm those beliefs in the same way that one could for beliefs regarding the other cases of disagreement mentioned. This is partly due to the fact that it is far from clear what would constitute decisive evidence regarding some of these more complex subject matters. Opponents in a dispute are not going to agree on what would constitute decisive evidence that would resolve a disagreement over a controversial subject (and it is far from clear that they ought to agree on this point). If they agreed on what would constitute decisive evidence, they might not disagree at all in the first place. But such agreement will be difficult to reach when it comes to beliefs about complicated subjects.

For instance, in discussing Feldman's view David M. Holley notes:

Feldman begins with an intuition that gains its plausibility from a great many ordinary cases [i.e. the Dean in the quad case] in which proper belief formation calls for adequate evidence. But when he makes evidential support into a general rule of justification, he has to stretch the concept of evidence. He stretches things to the breaking point when he interprets reasons for fundamental starting points in terms of a paradigm applicable to ordinary cases of evidence assessment (Holley 2013, 42).

${ }^{62}$ I assume that there are political facts too, though I recognize that some philosophers deny that this is the case. 
The reason Holley claims that Feldman 'stretches things' is because he holds that "[ $\mathrm{t}]$ he closer we get to describing a significant difference with regard to starting points of the kind characteristic of religious disputes, the more implausible it becomes to postulate a common body of evidence whose evidential significance is accepted by all parties to the dispute" (Holley 2013, 42). Holley does not seem to think there will be a way to adjudicate between different fundamental starting points, whereas Feldman holds those can be rationally evaluated (Holley 2013, 43). To Holley's mind, this can justify reasonable disagreement over something as complex as religious belief. But notice that one need not agree with Holley on that point to still affirm the more general claim that, with respect to disagreements over complex matters, there will be little agreement over what constitutes evidence and how such evidence should be evaluated. By contrast, in the simple disagreements agents ought to agree on what would constitute decisive evidence and the appropriate evaluation of such evidence. There is a distinct sense in which, when it comes to disagreement over a complex subject, it is impossible to 'go and check', even given an unlimited amount of time and resources. ${ }^{63}$ Another important difference between simple and complex cases of disagreement is that disagreements about complex cases initially occur when two agents disagree over one proposition, but the proposition in question turns out to be connected to many of the agent's beliefs. Thus, the initial disagreement is really a disagreement over numerous propositions. This is so when one considers that moral and religious beliefs are near the centre of one's web of beliefs. They often appear self-evident to the agent who holds them. ${ }^{64}$ They cannot be easily changed since doing so

${ }^{63}$ Robert J. Fogelin (1985) argues for a position even stronger than Holley's. He believes that for the very conditions of argument to be possible there must be a lot of shared background assumptions between the two opponents in question. When two opponents disagree with one another but lack many shared background assumptions the framework for argument doesn't even exist. Fogelin calls these types of disagreement 'deep'.

${ }^{64}$ Including religious belief in the centre is (probably) a move away from Quine, since it is not clear he thought religious beliefs were meaningful. But that is not important to my purposes. I am using Quine's concept of a web of beliefs, but I do not claim to explicate it exactly as he would. 
would require numerous changes to the rest of the agent's beliefs in order for her web of beliefs to maintain coherence. The coherence of one's entire web of beliefs, then, comes under scrutiny in these sorts of complex disagreements. If one thinks of an entire web of beliefs as a worldview, then, such disagreements amount to (partial) disagreements about the agents' broader worldviews. While changing the belief under dispute may involve an overhaul of one's entire web of beliefs, in some cases there will be numerous ways for the agent to maintain the coherence of her beliefs. Admittedly, this is not true when it comes to mathematics, but for other self-evident beliefs at the centre of the web this may be the case.

Rob Lovering explains that:

[I]n any given philosophical exchange, if the worldviews to which each interlocutor adheres were to be evident and recognized as playing an important role in the interchange, the potential for confusion and lack of communication would be, all things considered, greatly reduced. Indeed, it is claimed that in most cases, disagreement (philosophical or otherwise) is rooted in disagreement regarding worldviews (Lovering 2001, 23).

Ronald Nash concurs in that "[i]t is important for us to understand that competing worldviews are the fundamental cause of our disagreement" (Nash quoted in Lovering 2001, 23). Philip Pettit also notes the distinction between different cases of disagreement:

The difference between the [simple] case and the [complex case] is that the belief under pressure in [the simple] case is not deeply embedded in your Quinean web of belief, whereas the beliefs in the other [more complex] cases are. You can come to think that the car went through on the green without revising any of your other beliefs, except perhaps the belief, if you did indeed hold that belief, that there was nothing unusual about the way your eyesight was working on the occasion of the accident. This lack of embedding is a typical if not inevitable feature of perceptual beliefs. But you cannot come to think that intelligent design is false, or that abortion is not grievously wrong, without a range of adjustments in other matters of belief; not, at least, if you are like the normal run of epistemic beings (Pettit 2006b, 181) ${ }^{65}$

${ }^{65}$ Pettit's discussion is in the context of determining when to defer to a group majority. But the conclusion also applies to how an agent should respond to certain types of disagreement. For more on group disagreement see Skipper and Steglich-Petersen (forthcoming). 
And finally, Jay Rosenberg claims that:

As the discussion develops, it emerges that the actual clash operates not simply over the isolated thesis... but between two whole systematic structures of beliefs, which [the thesis] or its denial is embedded... The disagreement is transferred from conclusion to premises and from premises to presuppositions, ultimately pulling in whole complex families of beliefs and commitments... Ultimately, the challenge is not to this or that individual thesis but to the consistency and coherence of a whole family of beliefs in which the thesis is embedded. It is not particular states or these, then, which are genuinely at issue in a philosophical dispute, but rather rich, more or less systematic worldviews (Rosenberg quoted in Lovering 2001, 23-24).

This is a significant difference between simple and more complex cases of disagreement. Difference in worldview is also a major reason why it is so difficult to agree on what constitutes decisive evidence regarding complex cases of disagreement. An agent's worldview determines what she thinks constitutes decisive evidence for a belief in the first place. The application of simple idealized cases in the epistemology of disagreement literature has failed to appreciate this fact.

Note that I am not endorsing the claim that if a belief is deeply connected to a worldview (i.e. in the centre of one's web) then it is necessarily protected from any sceptical threat based on the existence of disagreement. For if an agent can downgrade the credibility of the view of her opponent based on her worldview as a starting point, then her opponent is equally entitled to do the same. Robert Mark Simpson explains that:

[I]t seems more or less inevitable that they [i.e. two epistemic peers] will both perceive an epistemic inferiority on the other person's behalf, and hence that they will both confidently stick to their guns. This cannot be right... if I find myself in disagreement with someone who has a similar belief-system to mine, the disagreements in those cases should impact upon my beliefs (Simpson 2013, 573).

While Simpson claims that this is a problem in cases between peers with similar belief-systems, it is also a problem between peers with quite different belief-systems, at least in certain cases. 
Different worldviews do not provide an obvious reason to downgrade an opponent's view. This is because it is possible to evaluate the rationality of a worldview. ${ }^{66}$

Moral Disagreement is a case of complex disagreement. There is a sense in which it is impossible to check or confirm which party in a moral dispute is correct. While there could be non-alethic expertise regarding morality (e.g. a moral philosopher) there is very little agreement among such experts, thus it is hardly appropriate for a lay person to defer to such an expert based on track record. The moral nihilist can coherently maintain that torturing children for fun is neither wrong nor right since this claim coheres with a broader nihilistic moral framework. Furthermore, the belief in moral nihilism itself can cohere with a broader nihilistic philosophical picture of the world. The realist and egoist can similarly maintain the coherence of their moral beliefs. Thus, the agents in a complex disagreement about morals often have multiple ways of achieving coherence. Of course, it would be difficult to see how one could make false beliefs about simple arithmetic fit into a broader mathematical framework, let alone an even broader worldview that included such false beliefs. But in all of these complex cases, the beliefs cannot be changed without a major overhaul of one's worldview. Again, this is not to say that when a disagreement about one proposition reduces to worldview disagreement that revision is never required. Remember that I am merely arguing against appealing to simple cases of disagreement in order to justify conciliationism about all cases of disagreement. The analysis of the different cases of disagreement offered here shows that premises (3), (4), and (5) of the Different Disagreements Argument are true and hence that (2) is also true. In the next section I respond to a number of objections to this argument.

\section{Objections}

${ }^{66}$ This is something I will simply assume throughout this project. Defending this claim in any detail is well beyond the scope of what I'm attempting to accomplish. 
I conclude this chapter by examining a number of objections to my defense of the Different Disagreement Argument.

\section{Confirmation in the Simple Cases}

Recall the disagreement over the horse race. Suppose the details of the case are such that there is no way to go back and check which horse won this particular race. There are no electronic implants in the horses and there are no video recordings of the race, etc. This makes particular horse races where confirmation is impossible more like what was described with respect to complex cases of disagreement.

Reply:

To be clear, my claim is that it is possible not actual confirmation that is the relevant difference between cases. For any particular horse race there might not be a way to confirm which horse won but there is remains an in principle difference based on ease and possibility of confirmation if the relevant means of confirming the disagreement in question were available. The point is that there is never any similar method by which to check which party is correct over controversial disputes in politics, religion, and ethics.

\section{Expertise cancels in the complex cases}

The non-alethic expertise in complex cases cuts both ways. They cancel out in complex cases because truth-tracking criteria cannot be used to assess any and all of the non-alethic experts in question. Thus, it is not a relevant difference between simple and more complex cases of disagreement.

Reply:

Non-alethic expertise may be irrelevant in complex cases with respect to determining how one should respond to disagreement in a complex case. It is possible, however, with respect to both 
ordinary expertise in the simple cases and alethic expertise in Meteorologist and Medical Diagnosis to use a truth-tracking criterion to assess the opponents in question. For instance, one friend may be slightly better than their friend at simple mental math. Or a doctor might have a slightly better track record than her colleague with respect to accurate diagnosis. Thus, the existence of truth-tracking criteria is a relevant difference between cases, even if it offers no help in showing one how to respond to disagreement.

\section{Worldview and Simple Cases of Disagreement}

A worldview could depend on a simple case of disagreement. Suppose that two agents disagree over the colour of a dress. Further suppose that the set-up of their cognitive equipment is such that their entire worldview will be created based on what they believe about the colour of the dress. Charlie believes the dress is blue. This belief triggers Charlie to adopt a Muslim worldview. Sarah believes the dress is green. This causes her to adopt a Christian worldview. Sarah and Charlie have fundamental disagreements about important religious claims. But this worldview disagreement should be treated as a simple case of disagreement, given that the disagreement is ultimately the result of a simple perceptual disagreement similar to which horse won the race or whether the dean is in the quad. ${ }^{67}$

Reply:

The way people form their entire worldview, in reality, seems incredibly complex. I have tried to focus on the nature of real-life worldview disagreement. Still, the above story is logically possible. On my account the above example would have to be treated as a simple case of disagreement, which means treating worldview disagreement as simple, at least in this case described above. This objection shows that one implication of my account is that worldview beliefs have to be formed in

${ }^{67}$ Thanks to John Pittard for bringing this type of objection to my attention. 
an epistemically responsible way in order for disagreements between them to be treated as genuinely complex. It would be an enormous task to explain what this means, but minimally worldviews based solely on a simple unrelated perceptual belief have not been formed in an epistemically responsible way. ${ }^{68}$

A related and simpler reply is that because the beliefs here are only causally connected, the issue is not epistemic. Coherence can be easily maintained if the agent simply changes her belief about the colour of the dress. The belief in question isn't formed in either an epistemically responsible or irresponsible way because it isn't formed in an epistemic way at all. There's a sense in which it might be epistemically regrettable that an agent's beliefs are causally connected in this way, but the agent in question isn't epistemically responsible for it (she beliefs through no epistemic fault of her own). ${ }^{69}$

\section{Conclusion}

To reiterate, in this chapter I have not argued that conciliationism is false. Rather, I presented and defended the Different Disagreements Argument, the conclusion of which is that lessons from one type of disagreement do not apply to all cases of disagreement. Epistemologists ought not to treat all cases of disagreement alike. Lessons about one type of disagreement do not apply seamlessly across the different cases of disagreement because of the epistemically relevant differences I have discussed throughout this chapter. Cases can be distinguished from one another based on the number of propositions under dispute, and the location of the belief in the agent's web of beliefs. Thus, they can be distinguished based on the number of possible ways of maintaining coherence. Likewise, the notion of confirmation and expertise also help to distinguish between cases. The following chart summarises the difference between the cases:

\footnotetext{
${ }^{68}$ Of course, what constitutes unrelated here will not be uncontroversial.

69 Thanks to Nick Griffin for bringing this response to my attention.
} 


\begin{tabular}{|l|l|l|l|}
\hline & Simple Cases & Unclear Cases & Complex Cases \\
\hline Confirmation & Easy (in principle) & Sometimes & Impossible \\
\hline Experts & Ordinary & Alethic & Non-Alethic \\
\hline Location on Web & Centre or Edge & Various & Centre \\
\hline $\begin{array}{l}\text { Maintaining } \\
\text { Coherence }\end{array}$ & $\begin{array}{l}\text { Very easy or very } \\
\text { difficult }\end{array}$ & Somewhat difficult & Very difficult \\
\hline
\end{tabular}

One of the lessons from this chapter is that philosophers ought to focus on the nature of disagreements between entire webs of belief or worldviews, rather than disagreements over isolated propositions, at least when it comes to disagreements about controversial matters. I discuss the nature of worldview disagreement in Chapter Seven. In the next chapter, however, I analyze the concept of 'epistemic peer' and offer a new formulation that is more likely to obtain in cases of real-world complex disagreements than current definitions. 


\section{Chapter Four: An Analysis of Epistemic Peerhood}

\section{Introduction}

In the previous chapter I argued that there are significant differences between simple and complex cases of disagreement. In this chapter I analyze the strict notion of epistemic peerhood used throughout the epistemology of disagreement literature. Such notions typically involve the idea that agents are strict evidential and cognitive equals. I show that this notion rarely, if ever, obtains in cases of real-world disagreement. I conclude with a new account of epistemic peerhood that is broad enough to apply to many cases of real-world disagreement, and yet not so permissive as to lose the epistemic significance of disagreement.

\section{The Strict Notion of Epistemic Peerhood}

Many contributors to the epistemology of disagreement make little attempt to spend significant time offering a detailed definition of epistemic peerhood. Consider these different definitions of peerhood in the literature, which can be categorized into two broad categories:

Same Evidence and Background Belief Peers:

Let us say that two individuals are epistemic peers with respect to some question if and only if they satisfy the following two conditions: (i) they are equals with respect to their familiarity with the evidence and arguments which bear on the question, and (ii) they are equals with respect to general epistemic virtues such as intelligence, thoughtfulness, and freedom from bias (Kelly 2005, 174-175). ${ }^{70}$

\section{Outcome Peers:}

$\mathrm{A}$ and $\mathrm{B}$ are epistemic peers relative to the question whether $p$ when, conditional on disagreeing about this question, A and B are equally likely to be mistaken (Elga 2007, 487). ${ }^{71}$

\footnotetext{
${ }^{70}$ See also Bergmann 2009, 336; Christensen 2009, 756; Elgin 2010, 53; Goldberg 2013, 169; Lackey 2013, 243; Matheson 2009, 270

${ }^{71}$ See also Feldman 2006, 217; Kornblith 2010, 30; Kraft 2007, 417; Moffett 2007, 356-357; Weatherson 2013, 54. Thune 2010, 359 seems to have both definitions in view.
} 
As shown here, authors usually offer short descriptions of peerhood and fail to pay sufficient attention to questions surrounding how to define peerhood. Some contributors fail to offer explicit definitions of peerhood before proceeding to offer their analysis of peer disagreement. Since epistemic peerhood is a requirement to generate the epistemic significance of disagreement, it is surprising that so little attention has been given to the concept. It is required because, unless two opponents are epistemic peers, there could be relevant epistemic asymmetries between opponents which could justify reasonable disagreement. ${ }^{72}$

\section{Problems with the Strict Notion of Peerhood}

Two main features are found throughout the common criteria implicit in most uses of epistemic peerhood. For two parties to be considered epistemic peers, they must be cognitive and evidential equals (Lackey 2014; Oppy 2010). Most of the features of peerhood are cognitive. This includes things such as intelligence, education, intellectual virtue, and competence. Ultimately, two agents are cognitive peers if they are both equally reliable at assessing the same body of evidence. Evidential peerhood obtains when two peers share the same body of evidence with respect to the disputed proposition. Therefore it is possible to be cognitive peers but not evidential peers, and evidential peers but not cognitive peers. Thus, two parties to a dispute are epistemic peers if they are both cognitive and evidential equals, at least according to the popular strict notion of peerhood.

There are a number of problems with the understanding of strict peerhood discussed above. Nathan King explains that the literature typically focuses on cases where the following conditions are satisfied:

(a) The disagreement condition: $\mathrm{S}$ believes $\mathrm{P}$, while $\mathrm{T}$ believes $\sim \mathrm{P}$.

(b) The same evidence condition: $\mathrm{S}$ and $\mathrm{T}$ have the same P-relevant evidence, $\mathrm{E}$.

\footnotetext{
72 Jaakko 2017 uses the notion of safety to offer a modal conception of peerhood. I will not discuss this since it is non-standard, but it deserves further exploration. McGrath 2008, 2011 and Benjamin 2014 discuss peerhood specifically with respect to moral questions.
} 
(c) The dispositional condition. $\mathrm{S}$ and $\mathrm{T}$ are equally disposed to respond to $\mathrm{E}$ in an epistemically appropriate way.

(d) The acknowledgement condition: $\mathrm{S}$ and $\mathrm{T}$ have good reason to think conditions (a)-

(c) are satisfied. (King 2012, 253)

King argues that conditions (b) to (d) are very difficult to satisfy. He says that "the same evidence, dispositional, and acknowledgement conditions are fairly difficult for subjects to satisfy. Taken jointly, the conditions are quite difficult to satisfy - so difficult that it is probably rare for two subjects to satisfy them in cases of at least moderate complexity" (King 2012, 263). And this is so even when the specific standards for the same evidence and dispositional condition are not overly strict. Even if the evidence condition holds that external evidence that can be shared by both parties is the only type of legitimate evidence, the same evidential condition is still rarely satisfied. Even if the dispositional condition allows opponents to respond differently to the evidence, provided that they are equally reliable, it rarely obtains (King, 2012, 265) ${ }^{73}$ In what follows I examine a number of further problems with the common understanding of epistemic peerhood. I demonstrate that a broader understanding of epistemic peerhood is needed in order to understand the epistemic significance of real-world disagreements.

\section{The Same Evidence Condition is Too Strict}

Consider external or public evidence. This is evidence that is in principle accessible to anyone. Private evidence, on the other hand, is only accessible to certain individuals in certain cases. It might initially seem plausible that even if private evidence can never be shared, that public evidence can be shared. But in real-world disagreements, two parties are never exposed to exactly the same body of public evidence. If public evidence is a culmination of everything one has been exposed to since birth, then shared public evidence is impossible. Such evidence is public in the

73 See also De Langhe 2013; Matheson 2014; Lo Guercio 2012 and; Vahid 2014. Palmira 2013a argues against Lo Guercio and defends the need for evidential equality between epistemic peers. My final account addresses Palmira, if only indirectly. Lo Guercio 2013 responds directly to Palmira 2013a. 
sense that it is not in principle unique to the individual (i.e. others could have had access to it at the same time the agent was exposed to it), and yet in practice no one else has exactly the same evidence. Thus, two philosophers who disagree about the truth value of a proposition never share exactly the same public evidence.

Relatedly, public evidence is often too subtle or too complex to be completely accurately assessed (Sosa 2010, 15-16). More importantly, agents almost never hold the reasons for a belief all at once. Beliefs are often formed very gradually, "through the subtle influence of diverse sources. Some are testimonial, others perceptual, others inferential, and so on...We are social beings and do well, socially and intellectually, to rely on such influence by our social and intellectual communities" (Sosa 2010, 16). Ernest Sosa challenges the idea that the full disclosure of public evidence between two peers is possible. He argues that:

The idea that we can always or even often spot our operative 'evidence' for examination is a myth. If we can't even spot our operative evidence- so much of which lies in the past and it is no longer operative except indirectly through retained beliefs- then we cannot disclose it, so as to share it. And this will apply to our opinions on complex and controversial topics... We have reasons... that, acting in concert, across time, have motivated our present beliefs, but we are in no position to detail these reasons fully (Sosa 2010, 16).

Now consider the notion of private evidence. Earl Conee, for example, argues that intuitions inaccessible to an outsider should count as evidence (Conee 2010, 73). At the subconscious level an agent might be unaware or unable to share precisely the method by which she evaluates public evidence. This is the case in G.E. Moore's disagreement with the sceptic about the existence of his hand. Moore simply insists on downgrading his opponent, even though he cannot provide the specific reasons for the downgrade. He believes that he has conclusive evidence that he is not dreaming and has hands, even though he cannot expound the evidence to his peer, nor perhaps 
even himself (Sosa 2010, 13). Thus, the claim that two people ever share exactly the same evidence is even less plausible if private evidence is included as part of one's total evidence.

\section{The Dispositional Condition is Too Strict}

In complex real-world disagreements, it is never the case that two parties share the same experience, education, and qualifications as each other. If qualifications mean degrees or certification, then this criteria can easily be met. But this is not so when it comes to experience and education. Even two students who attend the same university and exactly the same lectures (which would be quite rare indeed) hardly have identical experiences. They will study differently and research differently. They will absorb and understand lectures in different ways. As soon as one objects that it can simply be stipulated that they are identical in these ways and proceed to evaluate their disagreement, the debate moves very far away indeed from cases of real-world disagreement. Consider a typical real-world disagreement between two professional philosophers. Even if they have the same credentials, the same number of publications, have been exposed to the same literature on the subject in question (which is all very unlikely), it is still not the case that they are exact cognitive peers.

\section{The Uniqueness Thesis Does not Apply}

Some have thought that the Uniqueness Thesis has much significance for the epistemology of disagreement. The Uniqueness Thesis is the claim that: "Given one's total evidence, there is a unique rational doxastic attitude that one can take to any proposition" (White 2005, 445). Certain philosophers argue that considerations of uniqueness directly support conciliationism (Feldman 2007; Christensen 2007), while others suggest that the very existence of peer disagreement demonstrates that anything like the Uniqueness Thesis must be false (Douven 2009; Kelly 2010; Ballantyne and Coffman 2012; Schoenfield 2014). There are also formulations of conciliationism 
that do not rely on uniqueness principles (Elga 2007; Kornblith 2010; Frances 2010), and others outright reject the idea that uniqueness has any significant connection to conciliationism (Elga 2010; Lee 2012a, 2012b). ${ }^{74}$ For the sake of discussion, I will assume that uniqueness is connected to conciliationism. I argue that it can only be employed to successfully motivate conciliationism in highly idealized cases that are quite removed from complex real-world disagreements. However, I also show that uniqueness is not necessary in order to generate significant support for conciliationism. $^{75}$

If true, the Uniqueness Thesis helps to undermine the non-conciliationist claim that there can be rational disagreement between two epistemic peers. This is because, for any body of evidence, there can only be one unique rational response to that evidence. The Uniqueness Thesis is not necessarily undermined in cases where the evidence appears to equally support two or more different responses. According to the Uniqueness Thesis, in such cases, an agent ought to suspend judgment about the proposition in question. Even if the Uniqueness Thesis is true, however, it would only apply to simple cases of disagreements, not to complex real-world disagreements. This is because two parties never have access to exactly the same body of evidence in cases of complex real-world disagreement.

Note that a weaker version of the Uniqueness Thesis is that for any possible piece of evidence an agent receives, there is only one way in which the agent ought to revise her beliefs in light of that evidence. This Bayesian approach to uniqueness implies that when an agent receives new evidence, she conditionalizes on her prior probabilities. Subjective Bayesians reject the Uniqueness Thesis as formulated above because they allow for freedom regarding the distribution of prior probabilities. Thus, new evidence does not necessarily entail only one correct doxastic

\footnotetext{
${ }^{74}$ Much of this summary is borrowed from Christensen 2016a.

75 See Anantharaman 2015; Matheson 2011; and White 2005 for defenses of Uniqueness.
} 
attitude. ${ }^{76}$ While this weaker formulation of the Uniqueness thesis might seem obviously compatible with reasonable peer disagreement, this may not necessarily be the case.

Christensen argues that even on a more permissive account of rationality, one that allows for different rational credences, conciliationism is not necessarily defeated (Christensen 2016a). He distinguishes between rationality-peers and accuracy-peers. Denying uniqueness implies that two parties can have competing rational beliefs (i.e. there can be rational disagreement). Still, if an agent's peer has an equally good track record of holding true beliefs, the existence of peer disagreement could motivate conciliationism based on accuracy, not rationality. Unless an agent has a reason to think her beliefs are more likely to be accurate than those of her peers, she has a piece of evidence against her current position (Christensen 2016a). Thus, it is still possible to generate a meaningful problem of peer disagreement, even if the Uniqueness Thesis is false.

\section{Awareness Requirement is Underdeveloped and Possibly Too Strict}

Many authors in the epistemology of disagreement literature stipulate that an awareness of actual peer disagreement is necessary to motivate conciliationism in the face of peer disagreement. In other words, unless an agent is aware of actual peer disagreement, the fact of such disagreement in and of itself does not provide a defeater for the belief in question. It is only when an agent becomes aware of a peer who disagrees with her that the epistemic status of the belief in question is affected. There are a number of interesting issues surrounding this requirement.

It could be that awareness is a requirement, but more details are needed. What sort of obligation is an agent under with respect to seeking out, or avoiding becoming aware of, disagreement? That is, an agent could go out of her way to avoid finding out about the existence of peer disagreement, but that seems epistemically inappropriate. Suppose an agent reads one

\footnotetext{
${ }^{76}$ Graham Oppy brought this weaker version of the Uniqueness Thesis to my attention.
} 
article defending libertarian free will. She finds libertarian free will intuitively plausible and the article offers some reasons in support of her intuitions. Suppose further that the agent knows that disagreement about free will exists, so she actively avoids reading more articles on free will, or discussing the topic with her philosophical peers. She actively avoids discovering peer disagreement. It appears that in this instance the agent is doing something epistemically blameworthy by avoiding becoming directly aware of peer disagreement about free will.

On the other hand, perhaps agents are not under any epistemic obligation to constantly seek out peer disagreement. If an agent decided to read everything ever written on free will, or to constantly discuss the subject with her peers, maybe this would be epistemically supererogatory, rather than obligatory. Plus, an agent cannot realistically do this for every philosophical thesis she holds, let alone every proposition she believes. ${ }^{77}$ Perhaps the awareness requirement only entails that an agent should not actively avoid discovering peer disagreement. And while the agent ought always to remain open to discovering peer disagreement, she need not constantly seek it out. Still, all of this remains vague, and more discussion of the epistemic obligations an agent has regarding becoming aware of peer disagreement is needed in the literature.

\section{Actual and Presently Existing Requirement is too Strict}

Consider the requirement that for a disagreement to have epistemic significance an epistemic peer needs to actually exist. Again, as with the awareness requirement, much of the literature does not discuss this requirement in any detail. There are, I believe, a number of reasons to think that restricting the scope of peer disagreement to actually existing peers is arbitrary. ${ }^{78}$ Suppose that Peter van Inwagen and David Lewis are the only two experts on evidence for compatibility of free will and determinism. They alone are epistemic peers with each other, at least with respect to the

\footnotetext{
${ }^{77}$ If ought implies can then such a strict requirement is necessarily false.

${ }^{78}$ Discussions with Klaas J. Kraay brought this to my attention.
} 
question of whether free will and determinism are compatible. Imagine that they are both flying together to a conference where they will give competing presentations on whether compatibilism is true. But the plane malfunctions and crashes into the ocean. Lewis is the only survivor, and manages to swim to a small island. Now that van Inwagen has perished Lewis has no actual peer with respect to compatibilism. Note that the awareness condition obtains in this example. Lewis was aware that only van Inwagen was his peer and that they disagreed about compatibilism. Surely Lewis cannot reasonably dismiss the significance of peer disagreement simply by pointing out van Inwagen does not exist anymore. Therefore, the epistemic significance of peer disagreement, whatever it may be, does not require that an actual peer presently exist.

It is difficult to know how far to broaden the presently exists requirement. Nathan Ballantyne offers reasons to think that at least in a controversial subject such as philosophy, counterfactual peer disagreement is just as epistemically significant as actual peer disagreement. Ballantyne argues that there are many counterfactual philosophers and "we know that we regrettably do not have all of the arguments, distinctions, and objections that the counterfactual philosophers would have devised" (Ballantyne 2014, 368). In philosophy, it is very likely that in some nearby possible world there is a philosopher with an undermining or rebutting defeater for just about any philosophical thesis. Ballantyne claims that "believing that kind of counterfactual [about philosophers in other worlds] can be a rebutting or an undermining defeater for our actual belief [in a philosophical thesis in our world]" (Ballantyne 2014, 370). This is because in some nearby possible world it is extremely likely that such counterfactuals obtain. In a discipline such as philosophy, there is an incredibly vast amount of actual peer disagreement. Thus, it is not a leap to claim that had things turned out slightly differently, there would have been different arguments 
and evidence in philosophy. ${ }^{79}$ Ballantyne's argument is specific to philosophy, but it also applies to other controversial subjects rife with disagreement, including religion, politics, and ethics. ${ }^{80}$

I remain unsure how much the presently existing requirement should be loosened from current accounts of peerhood. ${ }^{81}$ But there is good reason to think that, if an actual peer dies, or it is likely that a counterfactual peer exists, the epistemic significance of such non-present peer disagreement is just as epistemically great as in actual peer disagreement. At minimum, there needs to be a principled reason explaining why one should give deference to actually present peer disagreement, as opposed to disagreement with an agent's past self, past peers, future self, future peers, etc. Otherwise, the actually presently existing requirement is arbitrary. ${ }^{82}$

\section{Conclusion on Strict Peerhood}

In sum, there are a number of problems with the commonly assumed definition of epistemic peerhood. The main problem with many of the requirements for peerhood is that they are too strict. Many of them will rarely, if ever, obtain in cases of real-world disagreement. It is even less likely that more than one of the requirements will obtain at the same time. Note, however, that:

It doesn't follow from the claim that there's no wide-ranging problem about [strict epistemic] peer disagreement that there's no widespread problem about disagreement of any kind. Moreover, even upon learning that acknowledged peer disagreement is rare, one may have a lingering sense of puzzlement or dismay in the face of disagreement. Could there really be no problem here? That seems too good to be true. But if [strict epistemic] peer disagreement isn't the problem, what is? (King 2012, 266)

${ }^{79}$ See also Goldberg 2016 and Barnett and Li 2016.

${ }^{80}$ In private correspondence Ballantyne insists that his argument need not lead to broad scepticism because it does not apply to every subject. He argues that it is less likely that in fields such as chemistry and physics that in nearby worlds there is peer disagreement. Thus, his argument does not apply with the same epistemic force to every discipline. It would take a much larger discussion to evaluate this claim.

${ }^{81}$ It is worth noting that Licon 2013 claims that the existence of modal disagreement is reason in itself to think the equal weight view is mistaken. I think that one can only derive this conclusion if one assumes beforehand that scepticism is false. But that begs-the-question against the equal weight view in the first place.

${ }^{82}$ Counterfactual disagreement with one's counterfactual self is discussed in Ballantyne 2014. 
In the next sections I examine two reformulations of peerhood and the significance of disagreement which attempt to address this question. To conclude this chapter I offer a different way to formulate the problem of peer disagreement. My approach uses expanded notions of peerhood and evidence, such that they obtain in many cases of real-world disagreement, unlike the strict notion of peerhood discussed thus far.

\section{Two Reformulations of Peerhood and of the Problem of Disagreement}

The above worries for the strict notion of epistemic peerhood appear to have prompted certain philosophers to reformulate the appropriate way of understanding the significance of peer disagreement. In this section I discuss two such proposals. First, Nathan King argues that the debate should not rely on any concept of peerhood. Second, Jennifer Lackey argues for a broader understanding of epistemic peerhood. The motivation that lies behind both of these views appears to be the desire to take the existence of real-world disagreement on controversial issues more seriously, along with the realization that the strict notion of epistemic peerhood makes doing so impossible.

\section{King's Reformulation of the Problem: Total Epistemic Situation}

Nathan King suggests that those advocating that peer disagreement requires conciliationism should shift focus away from what is disclosed in cases of disagreement, and instead focus on what remains unclear. He explains that what the existence of disagreement might show an agent is that her epistemic situation is less than ideal. For instance, it might be unclear which party has more extensive or representative evidence. Or, it might be unclear which party better responds to the evidence she possesses (King 2012, 267). How an agent assesses her epistemic position and the reason she offers are ultimately about higher-order evidence. In light of this, King explains that: 
$[\mathrm{H}]$ igher-order unclarity comes in at least two varieties, both of which themselves come in degrees. This is what gives us several problems about disagreement, rather than just one. The varieties of unclarity concern, on the one hand, one's actual higherorder attitudes about one's epistemic position with respect to the target belief, and one's reasons for these attitudes, on the other. Call the conjunction of one's evidence, dispositions, and actual performance in evidence assessment one's total epistemic position with respect to the target belief (King 2012, 268)

If this is right, then unless an agent has reason to think her total epistemic position is superior to her opponents, disagreement is epistemically significant. The weight of the significance comes in degrees. What the conciliationist needs are principles that rely on an agent's total epistemic position, as opposed to epistemic peerhood. King suggests that two potential principles are:

(SK1) If $\mathrm{S}$ believes $\mathrm{P}$ and is aware of some other subject $\mathrm{T}$ who believes $\sim \mathrm{P}$, and $\mathrm{S}$ has no reason to think $S$ 's total epistemic position with respect to $P$ renders $S$ more likely to be correct than $\mathrm{T}$, then $\mathrm{S}$ is not rational in believing $\mathrm{P}$.

(SK2) If $\mathrm{S}$ believes $\mathrm{P}$ and is aware of some other subject $\mathrm{T}$ who believes $\sim \mathrm{P}$, and $\mathrm{S}$ has no reason to think $\mathrm{S}$ 's total epistemic position with respect to $\mathrm{P}$ renders $\mathrm{S}$ more likely to be correct than T, then $\mathrm{S}$ does not know P (King 2012, 269).

King argues that it is likely that the antecedents of (SK1) and (SK2) obtain more frequently than the conditions he lists for strict epistemic peerhood. So this formulation of the problem of disagreement is epistemically more significant than one that relies on peerhood. A lot of questions remain, including, for example, what should count as reasons to think an agent's total epistemic position is superior to an opponent's position? Also, ought such reasons to be independent of the dispute in question? If an agent does not have such reasons then what type of epistemic defeat exists for the disputed beliefs? King concludes that:

$[R]$ eflection on the rational significance of higher-order unclarity seems likely to yield results that are relevant to the rational status of our disputed, cherished beliefs. Or at any rate, such reflection seems more likely to yield these results than is continued reflection on the epistemic significance of acknowledged peer disagreement (King 2012, 270). 
In sum, King reformulates the problem of disagreement without relying on the notion of epistemic peerhood, and instead focuses on what disagreement tells us about the nature of higher-order evidence.

\section{Evaluation of King's Reformulation}

What I said earlier in this chapter is consistent with most of King's comments on peerhood. In fact, while King claims that the strict conditions for epistemic peerhood rarely obtain, I suggest that they never obtain in cases of real-world disagreements on complex subjects. King's emphasis on an agent's total epistemic position is a more accurate way to understand how an agent should assess real-world disagreements. However, recasting the debate in terms of an agent's total epistemic position is not going to fundamentally change how we ought to understand the appropriate response to disagreement.

Recall (SK1): If $\mathrm{S}$ believes $\mathrm{P}$ and is aware of some other subject $\mathrm{T}$ who believes $\sim \mathrm{P}$, and $\mathrm{S}$ has no reason to think S's total epistemic position with respect to P renders S more likely to be correct than $\mathrm{T}$, then $\mathrm{S}$ is not rational in believing $\mathrm{P}$ (King 2012, 269). But consider that many of the non-conciliationist arguments (e.g. the special insight view) claim to offer a reason for an agent to think her total epistemic position is more likely to be correct than her opponent's. There are a lot more details needed here, but the lesson is that perhaps not many of the arguments in the epistemology of disagreement literature will change on King's reformulation of the problem of disagreement. Thus, I will proceed to frame my discussion in terms of peer disagreement. If King's account is correct, what I say can be reformulated to apply to disagreement that relies on the concept of total epistemic position rather than on the notion of epistemic peerhood.

\section{Lackey's Reformulation of the Problem: Three New Conditions for Peerhood}


In a discussion of religious disagreement Jennifer Lackey argues that if anything like the strict notion of peerhood is needed to generate the epistemic force of disagreement, then religious disagreement is epistemically insignificant. This is due to the fact that peerhood almost never obtains in cases of religious disagreement (Lackey 2014, 301-302). Recall from Chapter Three Elga's dismissal of the significance of disagreement about complex issues because of a lack of peerhood. Regarding Elga's line of argument, Lackey objects that:

A... problem with Elga's view here is that while he advertises it as 'conciliatory' where 'equal weight' is given to one's own belief and to that of one's opponent, it sanctions a dogmatic 'sticking to one's guns' in nearly all of the cases of disagreement that are of deep importance to us. Disagreements regarding religious, moral, political, and philosophical matters, for instance, almost invariably involve opposing views about a range of related issues that will lead the relevant parties to fail to count one another as epistemic peers. On Elga's view, then no doxastic revision is required in all of these cases. Not only is this a peculiar result for a 'conciliatory' view, it also seems epistemically wrong - surely there are some cases where at least some doxastic revision is rationally required when disagreeing about contentious matters, even when the disagreement involves a host of related questions" (Lackey 2014, 308).

Lackey reformulates a broader conception of peerhood in order to avoid trivializing

disagreement about controversial subjects. She offers the following conditions for reasonable disagreement:

A and B are equally justified in their conflicting beliefs whether $p$ when (i) A and B have been thinking about the subject matter in question for a sufficiently long time and in significant detail, (ii) A and B are both sufficiently intellectually virtuous with respect to whether $p$, and (iii) neither A nor B is in sole possession of evidence that both would (after careful consideration) take to be decisive on the claim in question (Lackey 2014, 313).

When these requirements obtain, then, according to Lackey, reasonable disagreement is possible. She explains that requirement (i) does not entail that both parties have identical evidence. It allows for peers to assess a proposition using different methods and/or from different starting points (Lackey 2014, 313). Requirement (ii) does not imply that both parties must have the same intellectual virtues in the same degrees. Lackey says that "[r]ather, (ii) is satisfied when A and B 
both possess sufficiently many virtues to a significant degree" (Lackey 2014, 313). I understand this to imply that Lackey wishes her account to allow for (slightly) different rankings of intellectual virtues. Finally, according to Lackey's requirement (iii) is meant to rule out the following type of cases:

A and B are both excellent scientists who have devoted years to studying whether $p$. They currently have conflicting beliefs, but this can be explained by the fact that A has made a revolutionary discovery in her lab, which now definitively establishes that her theory is correct. Although B has not yet seen the data, if she were to see it, she would agree that it proves A's theory to be right and her own view to be wrong. In such a case clearly, A and B would not, and should not, regard themselves as equally justified on the question whether $p . "$ (Lackey 2014, 313-314)

Lackey believes that her more permissive account of peerhood is able to take seriously the epistemic significance of religious disagreement, and presumably also that of other realworld disagreements about controversial subjects.

\section{Evaluation of Lackey's Reformulation}

Lackey's requirement (iii) is trivial in that in most cases of disagreement (if not all of them) on controversial subjects such as politics, ethics, and religion, neither party to the dispute will possess decisive evidence. It is far from uncontroversial what would count as decisive evidence in support of a proposition on such a complex subject. In a disagreement over how much is owed on the bill, or which horse won the race, it is possible that one peer has evidence that both ought to deem decisive. For example, maybe one party re-checks the bill with her calculator. Or maybe one party recorded the horse race on a camera phone. But the same cannot be said of other controversial subjects. Thus, while requirement (iii) is true, it is trivial.

One important question regarding Lackey's requirements is how often (i)-(iii) actually obtain. ${ }^{83}$ The answer to this question likely depends on a number of factors, but they probably

\footnotetext{
${ }^{83}$ This question was brought to my attention by Klaas J. Kraay.
} 
obtain frequently in areas such as politics, ethics, and religion. For instance, I think that in philosophy (i)-(ii) obtain very frequently, assuming a fairly permissive interpretation of Lackey's requirements. Consider again the disagreement between van Inwagen and Lewis about incompatiblism. Both have thought about the arguments for a sufficiently long period of time, so (i) obtains. They also appear to both be intellectually virtuous with respect to the question, so (ii) obtains. And as I already mentioned, I think (iii) is going to obtain in almost all cases of disagreement on controversial subjects.

Lackey's three requirements obtain frequently, or at least frequently enough to be considered a viable alternative to the strict notion of peerhood. Remember that part of the motivation for a different way of understanding peerhood is that the strict notion rarely, if ever, obtains. There are, however, serious problems with requirements (i) and (ii). One problem with Lackey's approach is that "to the extent that we loosen the requirements for acknowledged peerhood, it becomes less clear that disagreement with a peer always has the epistemic significance that [conciliationists] claim for it" (King 2012, 265). For example, if small differences in evidence between peers is allowed, then "there may be cases in which a small evidential different between subjects makes a large difference in what it is rational for subjects to believe. A single piece of evidence may in some cases be the key piece" (King 2012, 266).

Thus, while it is true that on Lackey's account there can be reasonable disagreement, her account is so permissive that the epistemic significance of disagreement evaporates. On her account there can be asymmetries between opponents which would justify both parties in maintaining competing views. The worry is whether on this account it is even possible to generate a situation of disagreement that might require belief revision. In the next section I offer a new 
account of peerhood that is permissive enough to obtain in many real-world disagreements, but is also able to maintain the epistemic significance of disagreement required by conciliationism.

\section{The Significance of Disagreement Reformulated}

A different understanding of peerhood is needed in order to understand how to navigate complex real-world disagreements. But such a conception cannot be so permissive as to negate the epistemic significance of peer disagreement. Likewise, it cannot be so restrictive as to negate the importance of real-world disagreement, by making peerhood impossible. In this section I use some sceptical arguments based on the significance of unpossessed evidence in order to motivate a new account of peerhood and the problem of disagreement.

\section{Ballantyne on Unpossessed Evidence}

Nathan Ballantyne writes that "[f]or many topics, evidence we don't have comprises most of the evidence there is, and it is easy to learn there is much relevant unpossessed evidence for nearly anything we care to think. All of this is obvious" (Ballantyne 2015b, 315). The world is overloaded with information. There are vast libraries and archives, much of which is available instantly online. For many important subjects such as ethics, politics, and religion, it is obvious that there is an overwhelming amount of available relevant information. Everyone forms beliefs about these matters based on partial evidence. Consider the following example from Ballantyne:

LIBRARY: You are wandering among rows of bookshelves at the library. These books concern matters about which you hold views. But you've read only a few them. Let's imagine you think that free will and determinism are compatible, having studied a dozen journal articles and a couple of books years ago in graduate school. Scanning the shelves here, you appreciate that there are several dozen titles relevant to the question of whether compatibilism about free will is true. Some books contain arguments against your view. You hadn't considered this mass of work until now and you haven't yet looked at it (Ballantyne 2015b, 315).

Ballantyne suggests that reflecting on the significance of unpossessed evidence often provides an agent with a defeater for her beliefs. Unless there is reason to think that there is a 
defeater for that defeater, the agent ought to reduce confidence about the belief in question. If an agent is confident enough to think she possesses a defeater-defeater, then what Ballantyne says won't apply to the specific belief in question. Still, awareness of the fact that there is relevant evidence an agent does not possess constitutes additional evidence that the agent needs to consider. Once accounted for, this unpossessed evidence often defeats or partially defeats the agent's original beliefs (Ballantyne 2015b, 315-319). Ballantyne offers three distinct arguments in support of his claim about the significance of unpossessed evidence.

\section{A. The Meta-Defeater Argument}

It is possible that an agent learns of unpossessed evidence which contains a defeater for a belief that she currently holds. This constitutes an unpossessed defeater. While there are cases in which it is clear what the unpossessed evidence supports, there are also other cases where it is unclear that the unpossessed evidence supports a particular position (Ballantyne 2015b, 219). Ballantyne first focuses on "cases where our evidence indicates there is unpossessed evidence that is a defeater relative to some body of evidence we don't have" (Ballantyne 2015b, 320). Consider the MetaDefeater Argument:

M1: $\quad$ Evidence of the existence of a defeater for believing $p$ relative to some body of evidence is a (prima facie) defeater for believing $p$ relative to any body of evidence.

M2: I have evidence of the existence of a defeater for believing proposition $p$ relative to some body of unpossessed evidence.

M3: $\quad$ I have no defeater for that (prima facie) defeater for believing $p$.

Therefore,

MC: $\quad$ I have an undefeated defeater for believing $p$ (Ballantyne 2015b, 320).

Ballantyne believes that M1 is uncontroversial. Consider M2. If an agent reads the dust jacket blurb of a book arguing against a philosophical thesis she believes, then there is reason to 
think there is a defeater for that thesis based on unpossessed evidence. M3 is likely to obtain in many real-life examples. Ballantyne claims that "[t]he trouble is that we normally cannot tell whether our evidence is more likely to indicate what's true than the subsets containing evidence we don't have. We should not presume our evidence is superior" (Ballantyne 2015b, 322).

An agent could resist this argument with a defeater-defeater if her evidential situation is unusually strong. Suppose a tobacco company funds a team of research scientists who discover that, contrary to the overwhelming medical consensus, smoking does not cause cancer. Here, even if the agent does not read the results of the study, she possesses a defeater-defeater because of the strong likelihood that the scientists are biased (Ballantyne 2015b, 322). Another defeater-defeater is the idea that in certain cases it is reasonable to hold that if there were a defeater for a particular belief an agent holds, she would already possess it. Finally, an agent might have reason to think for any defeater for a certain belief, there will always be a defeater for that defeater. This would be a case in which, say, for any theory on a particular subject an agent has always discovered a counterexample to the theory in question. But notice that none of these potential defeater-defeaters apply to LIBRARY. Only in extremely rare circumstances would an agent be in such a strong evidential position.

\section{B. The Overlooked Defeaters Argument}

The Overlooked Defeaters Argument focuses on defeaters an agent might have missed relative to the actual evidence she possesses:

O1: If I have reason to think I have very likely missed defeaters for believing $p$, then I have a (prima facie) defeater for believing $p$.

O2: $\quad$ I have reason to think I have very likely missed defeaters for believing $p$.

O3: $\quad$ I have no defeater for that (prima facie) defeater for believing $p$.

Therefore, 
OC: $\quad$ I have an undefeated defeater for believing $p$ (Ballantyne 2015b, 325).

According to Ballantyne $\mathrm{O} 1$ is uncontroversial. If a philosopher is stranded on an island alone she might think up what seem to her to be very plausible arguments. But she knows that if there were other philosophers around to discuss the arguments with that they would likely offer strong objections. Ballantyne also claims that $\mathrm{O} 2$ should be fairly obvious. Consider a philosopher who believes a certain philosophical thesis. It seems likely that if she were to go back and examine all of the books and articles she has read on the topic, she would probably stumble across ideas that change her original opinion (Ballantyne 2015b, 325-326). There could be reason to reject $\mathrm{O} 3$ if an agent thought her evidence for a belief was conclusive. For example, the cogito conclusively establishes that she (or something) exists even though she is aware that she has missed some defeaters to Descartes. Again, Ballantyne stresses that this response is not available in many real life cases, including LIBRARY.

\section{The Doubtful Fairness Argument}

The final argument Ballantyne offers is about the sample of evidence an agent uses to form beliefs. He writes that:

A fair sample of evidence of a particular size is drawn from a body of evidence by a process that makes it equally probable that each possible sample of evidence of that size will be selected. Confrontation with unpossessed evidence can lead to reasonable doubt about our sample's fairness and, in turn, to reasonable doubt about any belief based on our sample (Ballantyne 2015b, 326-327).

Ballantyne suggests that if an agent believes her sample of evidence is unfair in the relevant sense detailed above, then she ought to lower confidence in her beliefs based on that evidence. If she is unsure about whether her sample of evidence is unfair, this too means that she should reduce confidence in her belief. Any doubts about the fairness of an agent's sample of evidence should cause her to doubt whether her sample of evidence is reliable (Ballantyne 2015b, 327-328). 
Consider the Doubtful Fairness Argument:

F1: If I believe proposition $p$ on the basis of some evidence $\mathrm{E}$ and I have either (i) (prima facie) reason to disbelieve that $\mathrm{E}$ is a fair sample or (ii) (prima facie) reason to suspend judgment whether $\mathrm{E}$ is a fair sample, then I have an undermining defeater for believing $p$.

F2: $\quad$ I believe $p$ on the basis of some evidence $\mathrm{E}$ and I have either (i) reason to disbelieve $\mathrm{E}$ is a fair sample or (ii) reason to suspend judgment whether $\mathrm{E}$ is a fair sample.

F3: $\quad$ I have no defeater for the undermining defeater for believing $p$.

Therefore,

F4: $\quad$ I have an undefeated undermining defeater for believing $p$ (Ballantyne 2015b, 328).

In LIBRARY, learning about an extensive body of knowledge should cause an agent to question whether her body of particular evidence is fair. Ballantyne writes:

Notice that the process we've used to select our evidence is haphazard. Perhaps we looked at a couple of books and some articles that were recommended by friends or colleagues, or ones with titles that caught our eye. We didn't sift through the literature systematically, in a way that would give us reason to think our sample of the available evidence was fair. The evidence we have is a matter of the accidents of our personal history (Ballantyne 2015b, 329).

Defeat for the Doubtful Fairness Argument would consist of a reason for an agent to think her sample of evidence is representative of the total evidence for the subject in question. This does not apply to LIBRARY. In such a case there is simply no way to tell whether or not the agent's sample of evidence is representative. The agent has not used a reliable method to gain her evidence that would ensure it is a fair sample. That is, “[w]e don't know enough about the total evidence to know which attitude it makes rational, so we have no grounds to say our sample is representative" (Ballantyne 2015b, 330). Ballantyne concludes that reflection on the significance of unpossessed evidence paints a very bleak picture of an agent's ability to form rational beliefs on many important topics. While he suggests that these arguments imply that in many cases agents should exhibit a 
healthy amount of intellectual humility, it could turn out that he has really offered some powerful considerations in favour of a wide-ranging scepticism.

\section{Why Shared Evidence Is Not Essential to Epistemically Significant Disagreements}

Ballantyne's sceptical arguments are innovative and deserve careful consideration in their own right, but I will not evaluate them here. Ballantyne's ideas are relevant to my discussion, however, because they provide a helpful way to expand the notion of epistemic peerhood while keeping the epistemic significance of peerhood intact. In this chapter I have argued that in cases of complex real-world disagreements, two parties never share exactly the same evidence. King suggests that once this fact is acknowledged it is difficult to generate the normative force from disagreements based on peerhood, because even slight differences in evidence might be enough to explain why two equally reliable parties form different judgments. But reflections on Ballantyne's work show that this is not necessarily the case. There is a formulation of peer disagreement that need not rely on shared evidence or equal cognitive ability. ${ }^{84}$

Consider two peers who disagree about the truth value of a certain proposition $P$. Suppose further that disagreement over the proposition is indicative of a much broader worldview disagreement. Even though the two peers do not share the same body of evidence for their worldviews, there may be no reason for either agent to think that her evidence is superior to her opponent's. Unless an agent possesses a reason to think her evidence is superior, the normative force behind disagreement remains in place, even though there is a lack of shared evidence.

The Meta-Defeater Argument shows that an agent probably does not have reason to think her body of evidence is superior to her opponent's. It is likely that, if an agent had a different body of evidence for her worldview, then she would possess defeaters for her worldview. Defeater-

\footnotetext{
${ }^{84}$ I also mean to include here disagreement over the best method as to how to acquire evidence, not only how to assess a body of evidence. See Kappel 2012, Lynch 2010 and 2012.
} 
defeaters are probably not on offer in this instance because worldviews are even more complicated than the scenario described in LIBRARY. For an agent's evidential situation regarding her worldview is not likely to be unusually strong. This is because it is also not the case that she has reason to think she would already be aware of all of the defeaters for her worldview. She also likely does not have reason to think she will always have a defeater for any potential defeater for her worldview. ${ }^{85}$ Setting aside Ballantyne's sceptical conclusion, at the very least these reflections demonstrate that in most cases an agent lacks a reason to think the evidence for her worldview is superior to her opponent's. Thus, even in real life disagreements where two opponents never have the same evidence, the existence of disagreement remains epistemically significant. This is so even if disagreements about particular propositions are indicative of more complex disagreements about worldviews or fundamental frameworks.

The Doubtful Fairness Argument also provides a reason for an agent to doubt that her evidence is superior to her opponent's. For an agent likely does not have reason to think that the body of evidence she has for her worldview is representative of the total evidence for that worldview. If Ballantyne is correct that in LIBRARY there is no way to know whether or not an agent's sample of evidence is representative, then this worry applies to more complicated cases of belief such as competing worldviews with numerous interconnected beliefs. An agent typically does not gather the evidence for her worldview in a way that ensures her evidence is a fair sample of the total evidence. Again, setting sceptical conclusions aside, the Doubtful Fairness Argument is another reason to think an agent will typically lack a reason to hold that her evidence is superior to her opponents. Without such a reason, the significance of peer disagreement remains intact.

\footnotetext{
${ }^{85}$ In Warranted Christian Belief Alvin Plantinga (2000) argues that religious experience could serve as a defeater-defeater in the sense required here. Plantinga's position is highly controversial and relies on an externalist account of justification. I will not evaluate Plantinga's reformed epistemology here, nor do I wish to enter into the externalist/internalist debate about justification.
} 


\section{The Significance of Disagreement Reformulated}

With the above discussion in mind, in what follows I propose a broader concept of peerhood that will obtain often in cases of real-world disagreements. This formulation is able to account for both simple disagreements over isolated propositions and complex disagreements over propositions that are deeply tied to an agent's overall worldview:

\section{Sceptical Epistemic Peerhood:}

Two agents should be treated as peers if and only if:

1. Each agent lacks a dispute independent reason to think that each of their bodies of evidence is superior to that of each of their opponents.

2. Each agent lacks a dispute independent reason to think they have assessed their body of evidence more accurately than each of their opponents.

3. (1) and (2) obtain and there are no other relevant epistemic asymmetries between the agents.

I call this conception Sceptical Epistemic Peerhood (from here on 'SEP') because it focuses on the idea that in many cases an agent ought to be sceptical of whether she possesses superior evidence or assessment skills than her opponent. In such cases she should treat her opponent as a peer. ${ }^{86}$

(1) is supported by the considerations I gathered above from Ballantyne's arguments about many agents' evidential situations when forming beliefs. Regarding (2), recall that King rejected the dispositional requirement in the strict notion of peerhood. He argued that even if it is allowed that two peers can assess the evidence differently, it is unlikely they will be exactly equally accurate. And any difference in accuracy can count as a relevant asymmetry. But while (2) clearly allows for different dispositions to be taken towards evidence, notice that my account avoids the worry King has about the dispositional requirement. For (2) to obtain, an agent simply needs to lack a positive reason for thinking that she is better than her opponent at assessing evidence,

\footnotetext{
${ }^{86}$ Priest 2016 is a rare instance of discussion about how superiors should react to disagreement with inferiors.
} 
regardless of the particular method used to assess the evidence. In many cases an agent will not be well positioned to discover what method her opponent uses to evaluate evidence, nor to know the accuracy of the method in question. (3) is just the requirement that there be no other relevant epistemic asymmetry in the dispute which could be appealed to in order to justify reasonable peer disagreement.

One clause requiring more explanation in SEP is the 'dispute independent reason' clause. Suppose two agents, Agent A and Agent B disagree about the truth value of $P$. Agent A cannot appeal to superior evidence or reasoning abilities about $P$ to downgrade Agent B from peerhood status. This would unfairly beg-the-question against Agent B since the very topic under dispute is whether $P$. A dispute independent reason is just that; a reason independent of the dispute. In the case of evidence, it may well be difficult to ever arrive at a dispute independent for downgrading one's opponent in real-life disagreements, although it would in principle be possible. And it is possible. Agent A knows something about Agent B's method or ability to acquire evidence in general, which in itself, doesn't have anything to do with the disagreement over $P$. Agent A might downgrade Agent B on the basis of poor evidence because of what she knows in general about Agent's B method of acquiring evidence. It's independent of the dispute in the sense while it applies to $P$ (since Agent B presumably has evidence for $P$ and all of her evidence is somehow tainted), but the worry doesn't arise from the disagreement. The same applies with respect to cognition (i.e. evidence assessment). If I'm arguing with a four-year-old about whether $P$ (supposing $P$ is at all complex) I will, given common knowledge about developmental psychology, know her ability to assess the evidence about matters of any complexity in general isn't very good. Hence, I have a dispute independent reason for downgrading a four-year-old. In cases where no 
such dispute independent reason exists, it is simply begging-the-question against one's opponent to downgrade them. ${ }^{87}$

\section{Objections to Sceptical Epistemic Peerhood}

\section{SEP does not account for degreed notions of peerhood}

Some suggest that the notion of epistemic peerhood only needs the concept of reliability (Bundy 2011, 288; Enoch 2010, 956; Elga 2007, 499). ${ }^{88}$ It does not matter whether two opponents have similar (or identical) evidence or cognitive abilities. Two opponents are peers simply if and only if they have the same track records with respect to arriving at the truth. There are various ways to understand the details of this formulation, but they all reduce to a truth-tracking criterion. This conception also generates a degreed notion of peerhood. For instance, one's opponent might have a slightly worse track record, but it does not follow that one should therefore completely dismiss her as peer. ${ }^{89}$ Thus, a possible objection is that my rejection of the strict peerhood and proposal of SEP does not consider this degreed notion.

Reply:

While a degreed truth-tracking formulation of peer is more nuanced than the strict notion of peerhood, there are still problems with this formulation. Assessing one's reliability is no straightforward matter. Truth-tracking assumes that there is a clear way to verify whether an agent is correct. But, as argued in the previous chapter, on many complex topics there is no easy way to confirm what is true. Furthermore, part of what I argue in this chapter is that the strict notion of peerhood simply does not obtain in cases of disagreement. And it is far from clear that this point will not also apply to the truth-tracking criteria. Given all of the factors that contribute to what

87 Thanks to Christopher Tindale for prompting me to clarify this point.

88 These citations are from Gelfert 2011, 509-510. 2009.

${ }^{89}$ For further discussion of degreed notions of epistemic peerhood see Gelfert 2011; Vorobej 2011; Wald 
evidence one has and how one assesses it, it is highly implausible to think that people will be identically reliable. ${ }^{90}$ More importantly, we just do not have a good way to assess reliability. If anything, this consideration lends support to SEP: for if one does not strongly suspect that one's opponent is less reliable than oneself, she ought to treat her opponent as an epistemic peer (or superior). ${ }^{91}$ Thus, it could turn out that SEP is consistent with, and amenable to, a truth-tracking formulation of peerhood.

\section{SEP is too inclusive}

Another objection is that SEP is not really about epistemic peer disagreement, since it is so broad that almost anyone could plausibly turn out to be a peer.

Reply:

This is a feature, not a bug, of SEP.

3. SEP is so inclusive it entails scepticism

Following up on the first objection, one might worry that SEP leads to a wide-ranging scepticism. It might prove so difficult for an agent to know when she has superior evidence and/or assessment skills that any instance of disagreement might pose a sceptical threat. While Lackey's view made it too easy to avoid conciliationism, SEP makes it nearly impossible to avoid it. The epistemic significance of disagreement cannot be this drastic.

Reply:

First, this is a feature of SEP, not a bug. It promotes a healthy type of epistemic humility. Second, there are still many cases of disagreement where, even with SEP as the account of peerhood, there in degrees.

${ }^{90}$ There is no non-arbitrary way to restrict how fine grained a notion of peerhood is once one accepts it comes

${ }^{91}$ See Worsnip 2014 and Pittard 2017 for discussion of conciliatory views that require updating on the basis of one's prior assessment of one's own and one's peers reliability on the dispute in question. See also Schoenfield 2015. 
are good reasons to downgrade an opponent as a peer. In many cases an agent will have reason to think that her evidence is superior to her opponent's evidence. Likewise, she will often have reason to think that she is better at assessing such evidence. Thus, SEP might increase the scope and weight of epistemic disagreement, but it does not necessarily entail scepticism. ${ }^{92}$

\section{Conclusion}

Definitions of epistemic peerhood in the literature are often vague and incomplete. Typically, the literature assumes that two opponents must be exact, or near exact, evidential and cognitive equals in order to be considered epistemic peers. But this definition never obtains in cases of real-world disagreements. What is needed is an account of peerhood that is broad enough to apply to many real-world cases of disagreement but narrow enough to retain the epistemic significance of such disagreements. Lackey's reformulation of peerhood allows for reasonable disagreement but is so permissive that it is unclear on her account if disagreement could ever pose a serious epistemic challenge to a disputed belief. King's reformulation of peerhood is more promising in that it is able to maintain the epistemic significance of disagreement in many real-world cases of disagreement. In many cases a peer will not be in a good position to know whether or not her total epistemic position is superior to her opponent's. My account of Sceptical Epistemic Peerhood is not at odds with King's suggestion. I relied on arguments from Ballantyne to motivate the claim that unless an agent has reason to think that her evidence is superior to her opponent's, and she is better able to assess her evidence, then she must take seriously the existence of disagreement.

With SEP in mind, the following two questions about disagreement become important:

\section{Propositional Disagreement Question:}

When two parties disagree over a proposition and (1)-(3) of SEP obtain, how are they rationally required to respond to the disagreement?

\footnotetext{
${ }^{92}$ Sherman 2015 provides a reason to doubt SEP is true (at least in certain instances), but I will not discuss his account here.
} 
Since many real-world disagreements over isolated propositions are indicative of more complex worldview disagreements, a further question is:

Worldview Disagreement Question:

When two parties have a fundamental worldview disagreement and (1)-(3) of SEP obtain, how are they rationally required to respond to the disagreement?

In Chapters Five and Six I discuss an answer to the Propositional Disagreement Question. In these chapters I offer the Benefits to Inquiry Argument which supports a restricted version of nonconciliationism. In Chapter Seven I offer an answer to the Worldview Disagreement question. I offer the Benefits to Worldview Disagreement Argument which provides a way for there to be reasonable worldview disagreement between two epistemic peers. 
Part II. A Limited Version of Non-Conciliationism: The Benefits to Inquiry Argument 


\section{Chapter Five: The Benefits to Inquiry Argument}

\section{Introduction}

In Chapter Three I suggested that there are important differences between simple and more complex cases of disagreement. Much of the literature on disagreement is incorrect to treat all cases of disagreement similarly. In Chapter Four I argued that the standard strict notion of epistemic peerhood rarely obtains in cases of real-world disagreement. This does not, however, justify dismissing the epistemic significance of such disagreements. Rather, Sceptical Epistemic Peerhood is able to (i) obtain in many cases of real-world disagreement and (ii) keep the epistemic significance of such disagreements required for conciliationism intact.

In this chapter I explore and develop an important argument in the epistemology of disagreement literature, initially gestured towards by Catherine Z. Elgin. This argument advances the idea that there are possible future epistemic benefits to be gained if an agent continues to develop and defend her beliefs in the face of peer disagreement, particularly within research contexts. These potential epistemic benefits justify a researcher remaining steadfast in the face of peer disagreement. After outlining the broad contours of the argument, I explore some empirical evidence in support of Elgin's claim. Specifically, I examine an economic model developed by Scott Page which demonstrates that in certain scenarios, peer disagreement tends to enhance epistemic practices such as problem solving and prediction making. I also outline some ideas found in psychology regarding bias and motivated reasoning which also lend empirical support to Elgin. I believe that this is one of the most promising arguments for non-conciliationism, albeit a limited version of it, and as such it will be my focus for the rest of this project.

\section{The Benefits to Inquiry Argument}


In this section I outline an argument in support of non-conciliationism which claims that there are epistemic benefits to remaining steadfast in the face of peer disagreement, at least within research contexts. Research environments contain one or more individuals working towards the common goal of obtaining true belief or knowledge (or a related epistemic good) in a particular field, or finding an answer to a particular question. Obtaining truth ought to be understood so as to include research that focuses on technological or medical advancements. Philosophy departments, biomedical laboratories, and NASA are all paradigmatic research environments. While there are cases in which it is unclear whether an agent is a researcher, or whether an agent is in a research context, it is sufficiently clear in enough cases to proceed with the argument. At the very least, what I will argue applies to cases where it is obvious that an agent is a researcher within a research environment. 93

Elgin argues that if a philosopher refrains from using $P$ or not $P$ as a premise in an argument, simply because there are peers who disagree about $P$, this greatly limits the premises that the philosopher can utilize in argumentation. Elgin focuses on the doxastic stance of acceptance rather than belief. This is because, on the assumption that doxastic involuntariness is true, one cannot will herself to revise her beliefs in the face of peer disagreement (Elgin 2010, 6065). In light of this, Elgin says we can ask whether we should accept a proposition once we become aware of peer disagreement about that proposition. She says that "to accept that $\mathrm{p}$ is to adopt a policy of being willing to treat $\mathrm{p}$ as a premise in assertoric inference or as a basis for action where our interests are cognitive" (Elgin 2010,64). Elgin suggests that to suspend judgment in the face of disagreement means that one must refrain from using $P$ or not- $P$ as a premise. Given the vast amount of disagreement, this greatly limits the premises that philosophers can use. Thus,

\footnotetext{
${ }^{93}$ I assume that truth is correspondence. To succeed this argument must also assume that scientific realism is true.
} 
"[s]uspending acceptance in the face of peer disagreement... would probably be excessively cognitively costly" (Elgin, 2010, 65). Continuing to accept a proposition and use it as a premise in the face of disagreement can lead to epistemic benefits. While Elgin frames her discussion in terms of acceptance, I will follow most of the literature in continuing to talk of belief. Likewise, in the objections sections I will examine whether one can really reap all of the epistemic benefits from disagreement if one merely accepts $P$ as opposed to believing it. Likewise, while Elgin's argument is with specific reference to how, in philosophy, it might be epistemically beneficial to continue to defend certain claims despite peer disagreement, I believe that her argument generalizes to many other fields of inquiry.

\section{Change in View}

Elgin does not develop this intriguing idea about the benefits to inquiry in considerable depth, so I want to offer a few suggestions. ${ }^{94}$ As an initial point of clarification, Elgin should frame her argument with respect to inference, not deduction. Elgin's claim is about belief revision. That is, it is a view about when an agent should revise her beliefs given the existence of peer disagreement. ${ }^{95}$

Gilbert Harman suggests that such principles of belief revision "concern the actual changes to be made, the changes that are actually 'part of' the reasoned revisions, saying such things as that one should make minimal changes in one's view that increase its coherence as much as

\footnotetext{
${ }^{94}$ Elgin 2018 describes the appropriate response to disagreement as prompting philosophers to engage further with one another. She seems to think that this is what philosophers in fact do, and what they ought to be doing. In this later piece Elgin does maintain her earlier stated position that there are epistemic benefits to be gained from disagreement, but here she explicitly disavows conciliationism and non-conciliationism. This is because neither requires a serious engagement with their opponent. For instance, the conciliationist thinks one needs to conciliate in the face of disagreement, but this doesn't necessarily demand that peers directly engage with each other's ideas. Still, nothing she says in this recent piece contradicts what she says in her earlier work on disagreement.

${ }^{95}$ To be precise, Elgin's argument is about acceptance rather than beliefs. But the point I make here about revision and change of view remains the same. I will discuss the doxastic attitude of acceptance in Chapter Six. For a book-length discussion of acceptance see Elgin 2017, where she uses this idea to justify the rationality of scientific inquiry.
} 
possible while promising suitable satisfaction of one's ends" (Harman 1986, 2). He also notes that reasoned change in view is often conflated with "argument for, or proof of, a conclusion from premises via a series of intermediate steps" (Harman 1986, 3). Consider that:

Clearly, argument or proof is not at all the same sort of thing as reasoning in the sense of reasoned change in view. There is a clear difference in category. Rules of argument are principles of implication, saying that propositions (or statements) of such and such a sort imply propositions (or statements) of such and such other sort. (Harman 1986, 3)

Modus ponens, for example, is not a rule about belief revision. The rules of logic are not rules about how an agent should revise her beliefs (Harman 1986, 3). In arguments, an agent is always accumulating conclusions, while inference might involve subtracting beliefs. Harman concludes that discovering rules of inference or rules of reasoning is very different from discovering rules of deduction. Thus, Elgin's argument is best understood as based on principles about reasoning or inference, but the language of premise, conclusion, and argumentation that she uses fails to make this distinction clear.

\section{Community and Individual Benefits}

It is also important to distinguish between the epistemic benefits to the group and epistemic benefits to an individual. A research community could benefit from an individual remaining steadfast in the face of disagreement, but that does not mean that every individual researcher will benefit. Likewise, an individual researcher could benefit, but not the research community. Ideally, both the individual and community will receive epistemic benefits in both the short and long term for remaining steadfast. Minimally, a successful argument along Elgin's lines requires that the individual will benefit in the long run, if she is to be rational in remaining steadfast in the face of peer disagreement. This so on the assumption that an individual should not sacrifice truth (i.e. her 
own epistemic health) for the sake of a community benefiting epistemically (i.e. gaining true beliefs). A fuller treatment of Elgin's ideas would fill in the details of following chart:

\begin{tabular}{|l|l|l|l|l|}
\hline & $\begin{array}{l}\text { Short Term } \\
\text { Benefits }\end{array}$ & $\begin{array}{l}\text { Short Term } \\
\text { Costs }\end{array}$ & $\begin{array}{l}\text { Long Term } \\
\text { Benefits }\end{array}$ & $\begin{array}{l}\text { Long Term } \\
\text { Costs }\end{array}$ \\
\hline $\begin{array}{l}\text { Individual } \\
\text { Research }\end{array}$ & & & & \\
\hline $\begin{array}{l}\text { Group } \\
\text { Research }\end{array}$ & & & & \\
\hline
\end{tabular}

Elgin needs it to be the case that the long-term benefits outweigh the short term costs and long terms costs. ${ }^{96}$

\section{The Giving Up Principle}

It is also important to note that Elgin is not endorsing an unthinking dogmatic position that never requires an agent to change views:

This position does not require denying that the overarching epistemic goal is accepting or believing only what is true. It simply notes that, where there is a significant chance that my opponent's view is true, if I want to believe only what is true, I would be well served by not foreclosing inquiring prematurely. If I can recognize my opponent's view is rational and might... be right, then I have reason to hope that she retains her position, develops it, and either comes ... to see the error of her ways or... develops an argument that will demonstrate to me the error of mine (Elgin 2010, 68).

Thus, on Elgin's account, the ultimate goal of research is still truth, rather than supporting unreasonable dogmatism.

In order to turn Elgin's suggestion into a fuller treatment of how to respond to peer disagreement, there needs to be a principle which informs an agent when she should eventually give up the position she has chosen to defend in the face of disagreement. Perhaps Elgin thinks that peer disagreement constitutes no such reason to give up defending a proposition. But in the above quotation she is careful to insist that it needs to be possible for an agent to change her mind

\footnotetext{
${ }^{96}$ Of course, the short term benefits outweighing the short and long term costs is advantageous too. I will say more about epistemic consequentialism in Chapter Six.
} 
given good reason. Specifically when, however, should an agent accept such reasons and not continue to develop her original position? Elgin's account should include a principle which specifies when an agent should give up a belief:

The Giving Up Principle (GUP): $\quad$ An agent is irrational to continue to believe proposition $P$ when reasons she is aware of ought to convince her that her belief in $P$ is mistaken.

While this principle is vague and needs to be developed further, it is a plausible initial constraint that Elgin's argument requires in order to avoid licensing unreasonable dogmatism. Notice that when it comes to the disagreement in question, that what will constitute good reasons will vary depending on whether the disagreement is simple or complex.

At this point a further important qualification to the argument is needed. The rationality of a researcher remaining steadfast in the face of disagreement does not depend on the actuality of epistemic benefits. Rather, it only depends on the probability of epistemic benefits. This is because in many cases it is simply impossible for a researcher to predict the epistemic results of her labour. The potential for epistemic benefits is enough to justify remaining steadfast in the face of peer disagreement. In order to better understand the intuitive force of Elgin's suggestion, consider the following real life examples when remaining steadfast resulted in epistemic benefits. ${ }^{97}$

\section{Four Real Life Examples}

\section{Case 1: Ignaz Semmelweis and Bacteria}

In the mid-19 $9^{\text {th }}$ century, hospitals in Europe and America were disease and death-filled places. Childbirth in hospitals by male doctors replaced home births with mid-wives (Downs 1982, 227). But this greatly increased cases of puerperal fever, and while it "had long been known in the medical profession... its causes remained a dark mystery" (Downs 1982, 228). Ignaz Semmelweis

${ }^{97}$ De Cruz and De Smedt 2013 discuss a case study of disagreement in paleoanthropology and appear to endorse something similar to the Benefits to Inquiry Argument, at least with respect to scientific research. 
(1818-1865) was a doctor in Europe during the first half of the $19^{\text {th }}$ century. He became concerned with discovering the cause and prevention of puerperal fever which contributed to mortality rates of over $20 \%$ among pregnant women. Against the medical consensus of his day, Semmelweis became convinced that there was a way to prevent puerperal fever (Zoltán 2019). He began to observe a connection between rates of the puerperal fever and medical students who had been involved in medical procedures, including examining corpses, before child delivery. When he ordered that all medical students wash their hands in chlorinated lime before child delivery, cases of puerperal fever dropped in his division to $1.27 \%$.

Semmelweis' ideas were, however, generally met with scepticism and hostility from the medical community. Semmelweis published his findings in a book called The Etiology, Concept, and Prophylaxis of Childbed Fever (Semmelweis 1861). But though "[h]e sent it to all the prominent obstetricians and medical societies abroad... the general reaction was adverse. The weight of authority stood against his teachings. He addressed several open letters to the professors of medicine in other countries, but to little effect" (Zoltán 2019). Eventually, Semmelweis experienced a mental breakdown, partly due to his frustration with not being able to convince any of his peers about the truth of his ideas.

Semmelweis faced overwhelming peer disagreement about his belief in the causal connection between hand washing and mortality rates. During his lifetime it was impossible to prove the connection because bacteria remained undetectable. But surely Semmelweis was rational to remain steadfast in his belief, even though individual short and long term costs were adverse. If conciliationism is true, then Semmelweis rationally ought to have revised his beliefs about the connection between hand washing and mortality rates. He would have had to either give up his belief in the causal connection between hand washing and mortality, or reduce his credence. And 
given that so many of his peers disagreed with him, he would have had to greatly reduce his confidence in the connection between hand-washing and the fever. He probably would never have written his book or pushed his ideas with such vigour. Yet while Semmelweis suffered greatly, he is in many ways an epistemic exemplar. By remaining steadfast in his beliefs about hand-washing, the group (i.e. the medical community, but in this case also all of humanity) benefitted in the long term from his continued and rigorous defense of his ideas in the face of disagreement. The Semmelweis case is a clear example of how remaining steadfast in the face of peer disagreement can lead to positive epistemic results for the group in the long term. It also led to at least some short term benefits, given that infant mortality rates dropped in his division.

Indeed, the discovery that puerperal fever is contagious was marked by fundamental disagreements in America too. For instance, in 1875 Alexander Gordon speculated in A Treatise on the Epidemic of Puerperal Fever that there was a connection between who was delivering the child and whether they got the fever. However, "[m]any of the leading doctors, medical school teachers, and nurses of the period, on the other hand, ridiculed the notion that they might be guilty of transmitting the deadly disorder" (Downs 1982, 228).

Later in 1843, Doctor Oliver Wendell Holmes published a paper titled "The Contagiousness of Puerperal Fever" in The New England Quarterly Journal of Medicine and Surgery. This was the first paper which indicated a change of consensus amongst physicians in America about the fact that the disease was communicable. The paper "presents a long array of facts in support of the contention that the disease was contagious, was usually transmitted by the doctor or the nurse, and was due to a specific infection" (Downs 1982, 229). Holmes contradicted the standard view found in Dewees' Treatise on the Diseases of Females which asserted that puerperal fever was absolutely not contagious. Robert B. Downs explains that: 
Predictably, the conservatives and traditionalists reacted violently and adversely to the Holmes thesis. Such a forthright, forceful statement challenging fixed ideas was certain to arouse the antagonism of those whose teachings had been for years diametrically opposed to the concept of the contagiousness of puerperal fever (Downs 1982, 231).

Holmes remained steadfast in the face of numerous attacks and continued to defend the claim that the fever is contagious. Downs notes that " $[\mathrm{h}]$ is arguments had been prepared with such care that before long they became accepted facts among enlightened members of the medical profession" (Downs 1982, 232). These efforts lead to beneficial results, and Downs concludes that "[ $\mathrm{t}] \mathrm{o}$ Semmelweis... belongs the major credit for our first knowledge of the means to eliminate the horrible pestilence of puerperal fever" (Downs 1982, 233).

In applying the lessons from Chapters Three and Four to this example it's first worth observing that this is what I refer to as an 'unclear' case that is neither obviously simple nor complex. This disagreement was, in principle, subject to empirical confirmation. However, it wasn't subject to confirmation at the time of the disagreement (only years later when microscopes powerful enough to detect bacteria were invented). The disagreement also involved special expertise, since ordinary adults do not have medical competence. Thus, we can say this disagreement is one between alethic experts.

What's perhaps more difficult to see is how SEP applies to Semmelweis. For one might object that while it's unclear what Semmelweis thought about his colleagues' assessment skills, he clearly thought he had superior evidence. Indeed, his opponents didn't appear to recognize his evidence as evidence. The worry here is that if Semmelweis held his evidence was superior to his opponents then he could downgrade them from peerhood status. While it's true he would then be rational to remain steadfast this doesn't help further my ends. I want to know whether it's rational to remain steadfast when one's opponents really are peers. But according to SEP, Semmelweis is 
indeed epistemic peers with his opponents (at least given what we know about the example). For he doesn't have dispute independent reasons to downgrade either his opponent's evidence or cognitive abilities. For the evidence in question is at the very heart of the debate. For Semmelweis to appeal to it as a reason to downgrade his opponents would be to beg-the-question against them. According to SEP, Semmelweis is in a disagreement with peers. Or, at the very least he requires a dispute independent reason for thinking otherwise.

\section{Case 2: Galileo and Heliocentrism}

Galileo Galilei (1564-1642) was an Italian astronomer who fundamentally changed and shaped the course of contemporary astronomy. Galileo was able to construct some of the first powerful telescopes that could be used to observe the moon and discover other planets. Galileo came to agree with Copernicus that the Sun was at the centre of the universe. Downs explains that:

Prior to Galileo, Copernican ideas had had little impact on European thought. The theories advanced by Copernicus some seventy-five years earlier were viewed as mere hypotheses, a fact that led the church authorities to regard the Copernican discoveries as too inconsequential to ban. Galileo, however, soon changed the attitude from indifference to one of intense concern." (Downs 1982, 101)

The Catholic Church insisted that Galileo not write or teach Copernican theory because it was considered theologically heretical. Though he was eventually allowed to defend the theory hypothetically, an inquisition was brought against him. He was tried for heresy and lived the rest of his life under house arrest (Van Helden 2014). His belief in heliocentricrism, however, ultimately turned out to be true.

It might be argued that none of the scientists or church authorities were genuinely Galileo's epistemic peers, so he had no need to worry about peer disagreement. While this may be the case, a lesson remains. If there had happened to be an epistemic peer who disagreed with Galileo about heliocentrism, the epistemic benefits gained in this case make plausible the idea that he would 
have been rational to remain steadfast. If Galileo had given up his research because of peer disagreement, there would have been a great epistemic loss. The group (i.e. astronomers and physicists) benefited in the long term from Galileo's research. ${ }^{98}$

\section{Case 3: Charles Darwin and Natural Selection}

Charles Darwin (1809-1882) famously expounded the theory of evolution by natural selection.

The details of Darwin's life and work are well known. For years Darwin did not publish his findings for fear of religious persecution. The Origin of the Species published in 1859 was met with mixed reviews. Though some parts of evolutionary theory were accepted, the theory of natural selection was viewed with suspicion. Downs also notes that:

If the revolutionary new theory were valid, the biblical story of creation could no longer be accepted. Church authorities immediately viewed the Darwinian thesis as dangerous to religion, and roused a storm of opposition. In The Origin of Species, Darwin intentionally softpedaled any discussion of man's beginning, because the thought that any emphasis on this phase of evolution would cause his entire theory to be rejected (Downs 1982, 225-226).

Darwin's follow up to the Origins was a book called The Various Contrivances by which British and Foreign Orchids are Fertilised by Insects. In this work he defended the theory of natural selection against critics. Another defense includes Darwin's book The Descent of Man, and the Selection in Relation to Sex. I will not detail any more of this well-known story here. But the lesson should be clear: Darwin was rational to continue to defend the theory of natural selection even in the face of peer disagreement. The theory of natural selection has been one of the most, if not the most, formative theories in shaping the contemporary scientific landscape (Desmond 2019).

These four cases are clear examples of a researcher remaining steadfast in the face of peer disagreement, and of this steadfastness leading to epistemic benefits for the group in the long run.

\footnotetext{
${ }^{98}$ It is an open question whether Galileo intentionally provoked the church, but such details are not relevant to the example.
} 
If the above researchers had been spineless in the face of peer disagreement, the group would have lost out on numerous epistemic benefits. These individuals were epistemically rational to remain steadfast in the face of peer disagreement.

\section{Case 4: Gerard Gierlinski and Human-Like Footprints}

A more recent, and perhaps less clear, example of disagreement in a research community occurred when in 2002 paleontologist Gerard Gierlinski accidentally discovered what he took to be humanlike footprints on the Greek island of Crete. In 2010 Gierlinski decided to formally study the footprints, consulting numerous experts from around the world. They concluded, contrary to the standard view, that the footprints belonged to human relatives and are 5.6 million years old. This conclusion is shocking because, if correct, the footprints are 2 million years older than the footprints in Africa, which is widely believed to be the birth place of the human species. If Gierlinksi and his team are correct, then the story of human evolution is completely different from the standard one currently on offer. He believes his findings deserve further exploration.

Almost all paleontologists (and scientists more broadly) are committed Africanists who believe the human species arose in Africa. Because of this, Gierlinski's work has been met with almost universal scorn. Per Ahlberg was the member of Gierlinski's team responsible for publishing their findings. It took six and a half a years and many rejections to get their research published. Ahlberg has published numerous papers in prestigious scientific venues such as Nature and Science. He claims to have never before experienced so much trouble getting his work published. For instance, many referees flatly denied that the footprints could be related to humans, despite expert opinion to the contrary. Ahlberg is sceptical the review process was fair, and claims many referees were just trying to bury the paper. 
Eventually, the work was published in an article called "Possible hominin footprints from the late Miocene (c.5.7 Ma) of Crete?" It was published in 2017 in the Proceedings of the Geologists' Association which is not considered a top venue, particularly for this type of research. Since its publication the paper has received attention from the mainstream media, and it seems that the scientific community is more willing to seriously consider the data. Indeed, since its publication most of the scientific community has accepted that the alleged footprints are in fact footprints. Ahlberg believes the original standard for getting the paper published was so high because the scientific community are already committed Africanists. An agnostic about human origins would have been more willingly to publish the work. The jury is still out on the legitimacy of the claims made by Gierlinski and his team. However, it seems clear that the scientific community is better off (i.e. more likely to arrive at the truth) if they consider Gierlinski's ideas. ${ }^{99}$ While the final conclusion about this research is still unknown, the community of inquirers is more likely to get at the truth if there are dissenting voices in the community. This shows us that fostering the existence of cognitive diversity is also a valuable research method.

\section{Empirical Support}

Presumably, the claims made here are subject to empirical scrutiny and could be researched and defended as such. A researcher could examine a variety of disciplines, in a variety of settings and note the disciplines in which researchers tend to act as non-conciliationists concerning beliefs and compare their research success (i.e. their ability to gain knowledge and understanding) to the disciplines where researchers do not act as non-conciliationists concerning beliefs. While empirical studies with the epistemology of disagreement explicitly in view have not been

99 I discovered this story in a news article. Much of the information is from the article: https://newsinteractives.cbc.ca/longform/human-footprints-greece?cnis=01d7e7d5-8294-4320-bd25-

$1463 \mathrm{e} 0 \mathrm{aa} 309 \mathrm{~b} * \mathrm{C} * 1195 * 0 * 0 * \mathrm{~A}$. See Gierlinski et al. 2017 for the published results. 
conducted, there is at least some empirical evidence on offer that supports the idea that remaining steadfast in the face of disagreement yields positive epistemic results. First, economist Scott Page has created economic models to show the epistemic benefits of diverse groups, especially with regard to tasks such as problem solving and prediction. Second, some psychological literature suggests that there are epistemic benefits to be gained when researchers disagree, at least given certain constraints. In what follows I briefly outline some of these ideas.

\section{Scott Page's Economic Models}

In The Difference: How the Power of Diversity Creates Better Groups, Firms, Schools, and Societies, Scott Page argues persuasively that in many scenarios, diverse groups are better at problem solving and prediction making than homogenous groups. This provides evidence for the claim that there are long term epistemic benefits to be gained if an agent remains steadfast in her beliefs in the face peer disagreement. Disagreement contributes to the cognitive diversity that, according to Page, enhances the success of epistemic tasks such as problem solving and prediction. ${ }^{100}$ Page says that he "will show with modest rigor how diverse perspectives, heuristics, interpretations, and mental models improve our collective ability to solve problems and make accurate predictions" (Page 2004, XX).

Page begins his analysis by examining the mental tools agents use in problem solving and prediction, including the concepts of perspectives, interpretations, heuristics, and predictive models (Page 2004, 7). By 'perspective' Page refers to the ways in which agents understand the world. They "are representations that encode objects, events, or situations so that each gets its own unique name" (Page 2004, 25). If members of a group perceive a problem in precisely the same

${ }^{100}$ Page provides some technical economic models in support of his claims which I will not outline here. See also James Surowiecki 2004. Surowiecki argues that within certain parameters groups are wiser than individuals. See also Moshman and Geil 1998. 
way, they are more likely to find the problem unsolvable. Page explains that a unique perspective can often make solving what appears to be an intractable problem easy. He uses heuristics to refer to different mental tools an agent can use to solve problems. Heuristics are found within perspectives and help guide a person in finding a potential solution or course of action (Page 2004, 52-53). Page explains that "perspectives are ways of seeing solutions, and heuristics are ways of constructing solutions, ways of moving around the space of possibilities" (Page 2004, 71). Interpretations create "a map from objects, situations, problems, and events to words. In an interpretation, one word can represent many objects [while a] predictive model is an interpretation together with a prediction for each set or category created by the interpretation" (Page 2004 71, 92). A heuristic model is meant to provide a course of action while a predictive model informs one about what will happen.

Perspectives, heuristics, interpretations, and predictive models all combine to make up a person's total framework. Frameworks are the tools that people use to solve problems (Page 2004, 101). Page says his thesis is that "collections of diverse individuals outperform collections of more individually capable individuals" (Page 2004, 159) when the following four conditions are met:

Condition 1: The Problem is Difficult: No individual problem solver always locates the global optimum [i.e. best solution].

Condition 2: The Calculus Condition. The local optima of every problem solver can be written down in a list. In other words, all problem solvers are smart.

Condition 3: The Diversity Condition. Any solution other than the global optimum is not a local optimum for some nonzero percentage of problem solvers.

Condition 4: Good-Sized Collections Drawn from Lots of Potential Problem Solvers. The initial population of problem solvers must be large and the collections of problem solvers working together must contain more than a handful of problem solvers (Page 2004, 162). 
He claims that while these are not the only conditions when diversity will trump ability, but when these conditions are met diversity will always win out. That is, when these conditions are met, a diverse group of problem solvers will always outperform a collection of individually more talented, but homogenous, problem solvers (Page 2004, 162, 165). ${ }^{101}$ Of course, much more remains to be discussed regarding Page's work, but by now the implications for Elgin's theory are clear: Page's conditions support the claim that remaining steadfast in the face of peer disagreement will lead to epistemic benefits, at least in certain contexts.

\section{Counteracting Confirmation Bias}

There is also some psychology literature which lends support to the suggestion that disagreement is epistemically beneficial. For example, Duarte et al. argue that the discipline of social psychology is overwhelmingly politically liberal. It turns out that this widespread agreement likely negatively impacts the research being conducted by social psychologists. This is because liberal values and assumptions are often embedded into research questions and observations. Researchers also tend to only focus on research topics that are likely to reinforce liberal values, while avoiding topics that might support a different political perspective (Duarte et al, 2015). They explain that:

[I]n a politically homogeneous field, a larger-than-optimal number of scientists shine their flashlights on ideologically important regions of the terrain. Doing so leaves many areas unexplored. Even worse, some areas become walled off, and inquisitive researchers risk ostracism if they venture in... Political homogeneity in social psychology can restrict the range of possible research programs or questions. It may also deprive us of tools and research findings we need to address pressing social issues (Duarte et al. 2015, 5).

While homogenous political ideology among researchers might not negatively impact research outputs in every research field, these examples points to the broader lesson that widespread agreement would likely be an epistemic hindrance to many other fields as well.

${ }^{101}$ It is an open question whether this is necessarily the case. That is, it is an open question whether this is true in every possible world. 
Duarte et al. note that the existence of cognitive diversity is more important than personal identity diversity for epistemic benefits (Duarte et al 2015; Menz 2012; Williams and O'Reilly 1998). While I do not dispute this claim, in Chapter Seven I explore whether cognitive ability might be (partly) dependent on personal identity. ${ }^{102}$ Duarte et al. suggest that the benefits of cognitive diversity are most easily had when "organizations are pursuing open-ended exploratory goals (e.g., scientific discovery) as opposed to exploitative goals (e.g., applying well-established routines to well-defined problems)" (Durate et al. 2015, 7; Cannella, Park and Hu 2008). This implies that the Benefits to Inquiry Argument might be more or less successful depending on the specific research questions being explored by a group of inquirers.

The well-known phenomena of confirmation bias is that "[p]eople tend to search for evidence that will confirm their existing beliefs while also ignoring or downplaying disconfirming evidence" (Duarte et al. 2015, 7). Psychologists have demonstrated that confirmation bias is difficult to avoid in almost any setting. For example, studying critical reasoning only leads to temporary suppression of biases in college students. Academics with high IQs are prone to offer more reasons in favour of their own views, rather than being more open to opposing ideas than lay people with lower IQs and less education (Duarte et al. 2015, 8). Thus, "people are far better at identifying the flaws in other people's evidence-gathering than in their own, especially if those other people have dissimilar beliefs" (Duarte et al. 2015, 8; Mercier and Sperber 2011; Sperber et al. 2010).

In a community where social cohesion is the main goal, widespread agreement, along with the existence of confirmation bias, is beneficial. However in a scientific research community where the end is epistemic (i.e. true belief, understanding, knowledge, etc.) widespread agreement

${ }^{102}$ In other words, it is not clear that these really can be separated. The answer is subject to empirical scrutiny. 
coupled with confirmation bias "can be devastating for scientific communities by leading to widely-accepted claims that reflect the scientific community's blind spots more than they reflect justified scientific conclusions" (Duarte et al. 2015, 8). Duarte et al. also note that the widespread political agreement in social psychology entails that blind peer review is less likely to be a fair process which is able to detect errors and judge the merits of research fairly (Duarte et al. 2015, 8). For because of confirmation bias:

[C]ertain assumptions, theories, and findings can become the entrenched wisdom in a field, not because they are correct but because they have consistently undergone less critical scrutiny. When most people in a field share the same confirmation bias, that field is at a higher risk of reaching unjustified conclusions. The most obvious cure for this problem is to increase the viewpoint diversity of the field. Nobody has found a way to eradicate confirmation bias in individuals... but we can diversify the field to the point where individual viewpoint biases begin to cancel each other out (Duarte et al. 2015, 8).

One might respond that if almost every agent is subject to confirmation bias in almost every situation, this can hardly count as empirical evidence against widespread agreement in a particular research discipline. But if there were more political disagreement in a field like social psychology, to use the current example, then confirmation bias could be (partially) eliminated. If agents suffer from confirmation bias but disagree with one another, the bias will be less likely to negatively impact research outcomes.

Psychologists have also explored the positive epistemic impact that a dissenting minority can have on group decision-making. Majority based decision-making often creates strong pressure for group conformity and thus leads to groupthink (Duarte et al. 2015; Fiske, Harris and Cuddy 2004). A dissenting minority is able to disrupt group cohesion norms. This is epistemically beneficial if those group norms are problematic. For instance, in science such minority disagreement is epistemically beneficial because it causes scientists to think more deeply about their research (Duarte et al. 2015; Crano 2012). Thus, "[t]he many benefits of these processes have 
been borne out by research on minority influence, which shows that the deeper thought produced by dissent can lead to higher-quality group decisions" (Duarte et al. 2015 8; Crisp and Turner 2011; Moscovici and Personnaz 1980; Nemeth 1995; Nemeth, Brown and Rogers 2001).

Duarte et al. provide reasons to think that social psychology would epistemically benefit from more political disagreement in the field. If their conclusions are correct, and if those conclusions can be generalized and applied more broadly, then there is reason to think cognitive disagreement is epistemically ideal. Confirmation bias is problematic in individual reasoners, but not if they are in cognitively diverse groups where such biases begin to cancel each other out.

\section{The Argumentative Theory of Reasoning}

While the existence of cognitive diversity is one way to help combat the negative epistemic impact of confirmation bias, there is additional empirical support for my argument. Depending on the evolutionary function of human reasoning, there is another way to understand confirmation bias and motivated reasoning that shows humans are not actually poor reasoners, and this account also promotes the epistemic benefits of peer disagreement. Hugo Mercier and Dan Sperber argue in favour of the argumentative theory of human reasoning. This theory claims that the purpose of reasoning is to create arguments intended to persuade an opponent. In their most recent book, The Enigma of Reason they expand their theory to reason more broadly and hence defend what they call the interactionalist account of reason (2017). This view is, however, far from uncontroversial. For it directly opposes the dual process account of reasoning which is the received wisdom on human reason. The dual process account argues for two cognitive systems; type 1 (fast) and type 2 (slow). Daniel Kahneman's book, Thinking, Fast and Slow is the best-known defense of this view (2011). When humans use type 1 reasoning, they make mistakes, but when they use type 2 they reason well. Since Mercier and Sperber oppose the standard account, this section should be 
understood as supplementary evidence for my argument. My argument doesn't depend on the truth of the argumentative theory of reasoning, but it would be good news if it turned out to be true.

Mercier and Sperber explain that reason isn't about thinking better on one's own, it is about our interactions with others. Humans "produce reasons in order to justify our thoughts and actions to others and to produce arguments to convince others to think and act as we suggest. We also use reason to evaluate not so much our own thought as the reasons others produce to justify themselves or convince us" (Mercier and Sperber 2017, 7). The main evolutionary functions of reason are to (i) produce reasons to justify something to ourselves and; (ii) produce reasons to justify ourselves to others. This isn't surprising given the highly social and cooperative nature of human. Humans aren't very good at producing arguments, but they are good at evaluating arguments. This is because it is an adaptive advantage to be careful about who we trust.

Due to the fact that it is often difficult to ensure honest communication, listeners must evaluate the communicator and the content of her message. Reasoning by producing arguments is one way for a communicator to gain the trust of her listeners. Thus, argumentation enables effective communication. Arguing helps establish effective group cooperation. Mercier and Sperber conclude that the argumentation theory fits better than classical theories of reasoning given the current available data (Mercier and Sperber 2011, 60).

Mercier and Sperber assert that when reasoners are motivated to evaluate an argument (i.e. when the outcome of the argument directly impacts them), the evaluation is often accurate. The more context provided in situating the argument, the more likely that the evaluation will be accurate. If evidence is available, agents will typically appeal to it when constructing an argument. When agents have a belief challenged, they are more likely to create better arguments in support of that belief than if it had remained unchallenged (Mercier and Sperber 2011, 62). Motivated 
reasoning occurs when an agent proactively seeks arguments in support of her beliefs because they anticipate needing to argue for the beliefs in question. If an agent reflects on the controversial nature of a belief she holds, "[i]t makes sense to look for arguments for our opinions before we find ourselves called upon to state them. If the search for arguments is successful, we will be ready. If not, then perhaps it might be better to adopt a weaker position, one that is easier to defend" (Mercier and Sperber 2011, 66). ${ }^{103}$

Mercier and Sperber confirm some of the ideas in Page's work when they suggest that reasoning produces the best results in the context of group discussions. Interestingly, their research suggests that if one person in a group knows the truth, then she will almost always be able to convince the other group members of the truth. With Page, they also suggest that group performance is superior to the individual performance of the group's best member. Thus:

[I]n many cases, no single participant had the correct answer to begin with. Several participants may be partly wrong and partly right, but the group will collectively be able to retain only the correct parts and thus converge on the right answer. This leads to the assembly bonus effect, in which the performance of the group is better than that of its best member (Mercier and Sperber 2011, 63). ${ }^{104}$

The interactionist account of reason also better explains the existence of cognitive biases. For humans are not seeking confirmation in general constantly. Rather, they are seeking confirmation of their own individual views. For it is only difficult to come up with counterexamples to one's own arguments, not arguments in general. This type of bias is best called the 'myside bias'. However, all of this is just what we should expect on the interactionist approach to reason. Confirmation bias is a feature of human reasoning, not a bug (Mercier and Sperber 2017, 205-219).

${ }^{103}$ See also Molden \& Higgins 2005

${ }^{104}$ See also Blinder and Morgan 2000; Laughlin et al. 2002; 2003; 2006; Lombardelli et al. 2005; Michalesen et al. 1989; Sniezek and Henry 1989; Stasson et al. 1991; Tindale and Sheffey 2002. 
Many experiments purport to show that when participants are asked to evaluate an argument, they simply defend the position they already believe to be true. Reasoning is employed only to confirm our initial pre-reflective intuitions about the argument in question. Mercier and Sperber claim this is exactly what to expect on the argumentative theory of reasoning (Mercier and Sperber 2011, 65). They note that:

When one is alone or with people who hold similar views, one's arguments will not be critically evaluated. This is when the confirmation bias is most likely to lead to poor outcomes. However, when reasoning is used in a more felicitous context - that is, in arguments among people who disagree but have a common interest in the truth - the confirmation bias contributes to an efficient form of division of cognitive labor (Mercier and Sperber 2011, 65).

Thus, provided that group members can eventually be convinced by the truth, groups are epistemically better off if individual members pursue different hypotheses on their own rather than a single hypothesis at the same time.

According to Mercier and Sperber, motivated reasoning cannot be mere wishful thinking, since otherwise participants in various studies would dismiss evidence or arguments rather than attempt to undermine them. They explain that:

All these experiments demonstrate that people sometimes look for reasons to justify an opinion they are eager to uphold. From an argumentative perspective they do this not to convince themselves of the truth of their opinion but to be ready to meet the challenges of others. If they find themselves unprepared to meet such challenges, they may become reluctant to express an opinion they are unable to defend and less favorable to the opinion itself, but this is an indirect individual effect of an effort that is aimed at others (Mercier and Sperber 2011, 66).

Mercier and Sperber conclude that while reasoning can lead to irrational beliefs, this is not necessarily due to the fact that humans are poor reasoners. Rather, it is because the function of reasoning is to create arguments in order to justify current beliefs and actions. However, their argumentative theory of reasoning "puts such well-known demonstrations of 'irrationality' in a novel perspective. Human reasoning is not a profoundly flawed general mechanism; it is a 
remarkably efficient specialized device adapted to a certain type of social and cognitive interaction at which it excels" (Mercier and Sperber 2011, 72).

While this is only a brief glance at the relevant psychological literature, it does have some interesting implications for the Benefits to Inquiry Argument. If the interactionist account of reasoning is correct, the existence of confirmation bias should be expected. This provides reason to think that, in the face of peer disagreement, an agent should remain steadfast and continue to defend her view, since doing so is the main evolutionary function of reasoning. Such argumentation leads to better communication, which is the purported adaptive advantage behind argumentation. And adaptations work best when they perform the task they evolved to do. This, then, is an adaptive reason to remain steadfast in the face of disagreement (Mercier and Sperber 2011).

Additionally, consider that it is epistemically more important if both opponents remain steadfast rather than revising, because the subsequent dialogue is likely to reveal each other's confirmation biases about the arguments in question. In light of the argumentative theory of reasoning, then, the best strategy for getting at the truth is for the two opponents in a dispute to evaluate each other's arguments, rather than evaluating their own arguments (and specific reasons in their arguments. If both parties revised right away in the face of disagreement, then the opportunity to discover one another's biases is lost. ${ }^{105}$ In sum, an agent is better off to let her opponents evaluate her arguments because of her biases in favour of her own arguments. Again, this suggests she should remain steadfast in the face of peer disagreement, while allowing her opponent's to check her reasoning. ${ }^{106}$

105 Thanks to Nick Griffin for bringing this point to my attention.

106 This is not to imply that because $\mathrm{x}$ is adaptive that $\mathrm{x}$ is necessarily rational. I am not claiming that one should remain steadfast because it is adaptive. Rather, given that it is adaptive, it comes as no surprise that there are epistemic benefits to disagreement. The argumentative theory of reasoning confirms my hypothesis. 
Mercier and Sperber address a number of potential objections to the interactionalist account of reason. I will survey the two most prominent here. The first objection is that their account, while alleged to be universal, only applies to WEIRD people. WEIRD stands for people from Western, Educated, Industrialized, Rich, Democratic countries (Mercier and Sperber 2017, 278-279). Most of the experiments that support and confirm the interactionist approach are conducted on WEIRD people. Mercier and Sperber acknowledge that:

The importance given to argumentation among WEIRD people could be another freak trait inspired by the ancient Greek's reliance on argumentation in science, politics, and legal institutions. In most Western cultures the existence of disagreements is seen as a normal aspect of human interaction, one that should be organized rather than suppressed and that can have positive effects [...] Universities in particular are supposed to encourage the practice of debate. Couldn't it be, then, that seeing argumentation as beneficial is a cultural bias, and that reason - at least reason as we have described it with its justificatory and argumentative functions - is a culturally acquired skill rather than an evolved, universal trait? Could, for instance, people in other cultures be excellent solitary reasoners but terrible arguers? Or not be reasoners at all? (Mercier and Sperber 2017, 279).

However, according to Mercier and Sperber, reasoning is not culturally relative. It exists across cultures provided that it is properly motivated (Mercier and Sperber 2017, 280). For instance, in Japan it is considered rude to argue as it shows a lack of care for social cohesion. But this fact doesn't show that Japanese people cannot reason when situated in the appropriate context (Mercier and Sperber 2017, 280-281). Likewise, it is a myth that there is little argumentation in Asian culture in general. The writings of Confucius and other Chinese philosophers are full of intense debate (Mercier and Sperber 2017, 281-282). Finally:

To say that reason is a universal mechanism does not imply that it works in exactly the same manner in all places or that specific societies can affect reason only in the superficial, merely cosmetic ways. Reason is deployed in a variety of cultural practices and institutions that may inhibit some of its uses, enhance others, and provide socially developed cognitive tools that complement and extend naturally evolved abilities (Mercier and Sperber 2017, 286). 
Likewise, even if Mercier and Sperber's response to this objection fails, it wouldn't completely defeat the interactionist account of reason. Rather, it would simply narrow its scope to WEIRD people. Likewise, it would have to be understand as a cultural phenomenon, rather than something that evolved.

The second objection to Mercier and Sperber's account is that there are numerous cases of solitary geniuses who made great contributions to knowledge while working in isolation from other humans. Mercier and Sperber write that "[i]f scientific progress is achieved by lone geniuses building revolutionary theories, even if these geniuses fail to convince their colleagues to share in their vision, then science, the most successful of our epistemic endeavors, violates all the predictions of our interactive approach to reason" (Mercier and Sperber 2017, 317). However, Mercier and Sperber object that this is simply not true. Closer inspection reveals that even alleged solitary geniuses almost always had interlocutors of some kind. For instance, Planck complained he would never convince his peers; he said they would have to wait for a new generation of scientists to accept his ideas. However, Planck's ideas were accepted in his lifetime; he did indeed convince his peers (Mercier and Sperber 2017, 318-319). Mercier and Sperber conclude that:

Revolutions in science proceed in a gentle manner. There is no need to chop off senior scientists' heads; they can change their minds through 'unforced agreement'. Ten years after Darwin had published The Origin of Species, three-quarters of British scientists had been at least partly convinced. Barely more than ten years after a convincing theory of plate tectonic was worked out, it had been integrated into textbooks (Mercier and Sperber 2017, 319).

They insist that a close inspection of how science progresses confirms the interactionist approach to reason.

Mercier and Sperber nicely sum up their position:

In our interactionist account, reason's bias and laziness aren't flaws; they are features that help reason fulfill its function. People are biased to find reasons that support their point of view because this is how they can justify their actions and convince others to 
share their beliefs. You cannot justify yourself by presenting reasons that undermine your justification. You cannot convince others to change their minds by giving them arguments for the view you want them to abandon or against the view you want them to adopt. And if people reason lazily, it is because, in typical interactions, this is the most efficient way to proceed. Instead of laboring hard to anticipate counterarguments, it is generally more efficient to wait for your interlocutors to provide them (if they ever do) (Mercier and Sperber 2017, 331).

The psychological literature on these and related topics is vast. The literature itself, and in particular the data from specific psychological experiments, is open to multiple competing interpretations. Thus, it is important not to overstate the empirical support gathered in this section. However, if Mercier and Sperber are correct then there is direct empirical support for the claim that remaining steadfast can lead to epistemic benefits. In sum, this is intended as supplementary evidence, not the evidence for the argument.

\section{Connections to Mill's Political Philosophy}

The Benefits to Inquiry Argument has some noteworthy connections to Mill's classic text, On Liberty. Throughout On Liberty Mill defends the harm principle, which is:

[T] hat the sole end for which mankind are warranted, individually or collectively, in interfering with liberty or action of any of their number, is self-protection. That the only purpose for which power can be rightfully exercise over any member of a civilized community, against his will, is to prevent harm to others... The only part of the conduct of any one, for which he is amenable to society, is that which concerns others. In the part which merely concerns himself, his independence is, of right, absolute. Over himself, over his own body and mind, the individual is sovereign" (Mill $1859,80,81)$.

Mill argues that this type of liberty is grounded in utility. He claims humanity is more likely to progress with this liberty in place. According to Mill, liberty comprises of "absolute freedom of opinion and sentiment on all subjects practical or speculative, scientific, moral, or theological" (Mill 1859, 83). In Chapter Two of On Liberty, 'Of the Liberty of Thought and Discussion', Mill touches on many ideas related to the benefits gained by the existence of disagreement. Mill 
believes that disagreement and a critical exchange of ideas is more likely to get at the truth in the long run. Mill argues that:

[T] he peculiar evil of silencing the expression of an opinion is, that it is robbing the human race; posterity as well as the existing generation; those who dissent from the opinion still more than those who hold it. If the opinion is right, they are deprived of the opportunity of exchanging error for truth: if wrong, they lose, what is almost as great a benefit, the clearer perception and livelier impression of truth, produced by its collision with error" (Mill 1859, 87).

Thus, disagreement can help to reinforce the truth of a belief. Mill argues that it is impossible to be sure that the belief one attempts to silence is false, and even if one were sure, it would still be wrong to silence it (Mill 1859, 88). Attempting to supress a belief rests on an assumption of infallibility. Unless an agent claims that her beliefs are infallible, she should be open to opposing views. Mill suggests that there are very few topics that his line of reasoning does not apply. He argues that:

The peculiarity of the evidence of mathematical truths is, that all the argument is on one side. There are no objections, and no answers to objections. But on every subject on which difference of opinion is possible, the truth depends on a balance to be struck between two sets of conflicting reasons. Even in natural philosophy, there is always some other explanation possible of the same facts; some geocentric theory instead of heliocentric, some phlogiston instead of oxygen; and it has to be shown why that other theory cannot be the true one: and until this is shown, and until we know how it is shown, we do not understand the grounds of our opinion. But when we turn to subjects infinitely more complicated, to morals, religion, politics, social relations, and the business of life, three-fourths of the arguments for every disputed opinion consists in dispelling the appearances which favour some opinion different from it (Mill 1859, 104).

Mill's argument applies to almost every field of inquiry including controversial beliefs about politics, ethics, and religion. He believes that disagreement will help an agent to better understand and appreciate her own views. It helps to sharpen the reasons an agent has for her particular beliefs (Mill 1859, 110). The Socratic dialectics were negative discussions used to challenge received opinion. Without the ability to utilise criticism, this important method of getting at the truth is lost. 
Mill claims that this type of liberty would help make the world a better place because it would free it from various superstitious and religious dogma that in his day often went unchallenged. ${ }^{107}$ As mentioned at the beginning of this section, this is not a project in the history of philosophy. However, Mill rightly deserves credit for clearly pointing to the epistemic benefits of disagreement. ${ }^{108}$

\section{The Benefits to Inquiry Argument and Toy Cases}

Notice that the Benefits to Inquiry Argument nicely reinforces the distinction between simple and complex cases of disagreement. The Benefits to Inquiry Argument is unlikely to ever justify remaining steadfast in simple cases of disagreement. ${ }^{109}$ Disagreements about which horse won the race, or how much is owed on the bill, are not within research contexts and are not going to lead to epistemic benefits in the future. But in the more complicated cases of disagreement discussed, such as the meteorologist or medical diagnoses cases, it is less obvious that remaining steadfast will not lead to epistemic benefits in the future. As should be clear, this is not meant to imply that the argument will apply in every case of complex disagreement. However, it does show that my argument is consistent with affirming conciliationism in the simple cases, while simultaneously rejecting it in complex cases. In other words, the Benefits to Inquiry Argument yields the intuitively correct results about the different cases of disagreement we've discussed thus far.

\section{Conclusion}

${ }^{107}$ Mill also writes: "Not the violent conflict between parts of the truth, but the quiet suppression of half of it, is the formidable evil: there is always hope when people are forced to listen to both sides; it is when they attend only to one that errors harden into prejudices, and truth itself ceases to have the effect of truth, by being exaggerated into falsehood. And since there are few mental attributes more rare than that judicial faculty which can sit in intelligent judgment between two sides of a question, of which only one is represented by an advocate before it, truth has no chance but in proportion as every side of it, every opinion which embodies any fraction of the truth, not only finds advocates, but is so advocated as to be listened to" (Mill 1859, 117).

${ }^{108}$ It's an open historical question whether Mill was the first person to make note of this fact. Either way, he probably is the most prominent philosopher to do so.

109 Thanks to Nick Griffin for bringing this to my attention. 
With the above discussion of Elgin and the relevant empirical literature in the background, I offer a new argument in defense of non-conciliationism in research contexts.

\section{The Benefits to Inquiry Argument:}

1. If agent $S$ reasonably believes that there are future epistemic benefits to be gained from continuing to believe proposition $P$ in the face of epistemic peer disagreement within a research context $R$, then $S$ is rational to be a non-conciliationist about $P$ in the context of $R$.

2. $S$ believes $P$ within the context of $R$.

3. There is at least one epistemic peer of $S$ 's who believes not-P within the context of $R$.

4. $S$ reasonably believes that there are future epistemic benefits to be gained from continuing to believe $P$ within the context of $R$.

Therefore,

5. $S$ is rational to be a non-conciliationist about $P$ within the context of $R$.

I have spent most of this chapter defending premise (1). The four examples of disagreement, Page's models, the psychological literature on counteracting cognitive bias, and the idea of the argumentative theory of reasoning all support (1). (2) to (4) are the conditions needed for the antecedent of (1) to be true in any given scenario. There needs to be peer disagreement (otherwise there would be no problem) and a reasonable belief that future epistemic benefits can obtain. The conclusion (5) follows from (1) through (4). Notice that as it stands the Benefits to Inquiry Argument only justifies a limited form of non-conciliationism. It applies only to researchers about inquiry beliefs within research environments. In Chapter Six I outline and respond to a number of objections to the Benefits to Inquiry Argument, including claims from David Christensen and Richard Feldman which suggest that my line of argument is problematic because it conflates practical reasons with epistemic reasons. In Chapter Seven I explore whether the Benefits to Inquiry Argument can be used to justify non-conciliationism about non-inquiry beliefs. 


\section{Chapter Six: Objections to the Benefits to Inquiry Argument}

\section{Introduction}

In this chapter I outline and respond to a number of objections to the Benefits to Inquiry Argument. I begin with what I take to be the weakest objections and conclude with the strongest objections. The most promising objection to the Benefits to Inquiry Argument is that it conflates practical reasons with epistemic reasons. I respond to this by arguing that future epistemic benefits should indeed be considered benefits of epistemic reasoning. The objection succeeds only if synchronic epistemic reasons are the only type of epistemic reasons included in one's account of epistemic rationality. But an all-things-considered epistemic rationality will include both synchronic and diachronic epistemic reasons.

\section{Initial Objections to the Benefits to Inquiry Argument}

\section{Agents Ought to Defer to Group Majority}

One initial objection to the Benefits to Inquiry Argument is that it does not take seriously enough the weight of the majority. When a majority of agents agree on the truth value of a proposition, an agent ought to give significant weight to this fact (Pettit 2006a, 156-157). ${ }^{110}$ For if a group majority believes $P$, then it ought to sway the minority to believe $P .^{111}$

Reply:

A majority opinion should hold epistemic weight in certain situations. If there is a majority expert consensus on the truth value of a proposition, it should count as significant evidence for a non-

110 This is an objection that Pettit raises, but ultimately rejects.

111 This is essentially the heart of the argument for conciliationism found in Matheson 2015a. He holds that rational belief should be based on the results of an epistemic election, but since we cannot know the results of an epistemic election we should be sceptics in the face of peer disagreement. 
expert on the topic of the proposition. ${ }^{112}$ However, the same is not true for non-expert consensus, or for an expert who disagrees with the expert-consensus. Consider that:

This strategy will be intuitively abhorrent to many, suggesting as it does that in appropriate circumstances we ought to defer routinely to the majority, abdicating our own construal of the substantive evidence available on some disputed question. It may seem to recommend not so much testimonial sensitivity as testimonial timidity, even servility (Pettit 2006a, 157).

The Benefits to Inquiry Argument provides a good reason not to defer to majority opinion, especially in research contexts where every agent is an expert. ${ }^{113}$ Finally, for majority expert opinion to be epistemically significant, experts must form their judgments independently of one another, and it is not the case that their judgments are always formed in this way. ${ }^{114}$

\section{There isn't the relevant sort of epistemic success in non-empirical fields}

The objector might offer a rejoinder that convergence indicates the existence of other epistemic success terms such as justification, warrant, or coherence. The lack of convergence in philosophy and related non-empirical fields points to a lack of achievement of such success terms. This means that philosophy isn't a field of inquiry, at least not one that falls within the purview of the Benefits to Inquiry Argument. Colin McGinn argues that humans did not evolve to be good at philosophy since such abstract reasoning isn't an adaptive advantage. The contingent process of evolution resulted in our sort of brain, but had different adaptations occurred we would have a different brain.

David Chalmers explains McGinn’s idea:

It is sometimes suggested that there is a Darwinian explanation for the lack of progress in philosophy. The rough idea is that we did not evolve to be good at philosophy, since in our evolutionary environment there were no selection pressures that favored philosophical ability or anything that strongly correlates with it (Chalmers 2015, 28). ${ }^{115}$

112 This is somewhat controversial. Some might argue that unless the expert judgments are formed independently of one another, they do not constitute additional evidence.

113 This is a reason to doubt that Matheson's argument for the epistemic election is correct.

${ }^{114}$ I acknowledge that the independence requirement is controversial, but I will not defend it here.

115 See also McGinn 1993. 
In other words, we simply didn't evolve to be good at philosophy. It's unreasonable to expect truth-convergence in the field. And so it's unreasonable to think that the Benefits to Inquiry Argument will apply to it.

Reply:

One way to reply to this is simply to maintain that philosophers should focus on different, less robust epistemic ends. Chalmers says that "[d]espite this lack of convergence, it is hard to deny that the insights of Plato and Aristotle, Hume and Kant, Frege and Russell, Kripke and Lewis have involved significant philosophical progress" (Chalmers 2015, 12). While philosophical arguments rarely lead to agreement, they often lead to more sophisticated disagreement. He explains that those who hold a view "learn what extra commitments they need to take on to avoid the [counter] arguments [to their views]. Bad versions of a view are rejected and sophisticated versions are developed in their place. This leads to a sort of eliminative progress where areas of philosophical space are eliminated" (Chalmers 2015, 18). So it might be countered that this objection unfairly attributes a goal to philosophy and other non-empirical disciplines that they could never be expected to fulfill. Non-empirical fields shouldn't be expected to make progress if progress is measured in terms of expert (truth) convergence over time. Rather, philosophy should be measured by its ability to help us ask more precise questions. It also helps us to tease out intuitions and assumptions that are normally hidden. Finally, philosophy should be measured by how well it provides structure to our worldview. Structure is valuable if it is good, beautiful, or explanatory, not just true. So truth convergence should not be the measure of philosophical progress. Or at the very least it should not be the sole measure of progress.

Still, one might wonder about this reply because so many philosophers do in fact take themselves to be arguing for truths. It might take a radical revision of the field's self-understanding 
for this sort of reply to succeed. Chalmers gestures at the idea that we may need more time to answer the big philosophical questions, but he doesn't develop the idea in very much detail (to be fair, he isn't trying to develop it). For instance he writes that:

[W] may eventually answer philosophical questions without radical cognitive enhancement. We may need to develop new methods, increased discipline, new sorts of insights, and perhaps there will need to be a conceptual revolution or two, but none of this will lie outside human capacity. It may turn out that there is a curve of increasing philosophical sophistication such that past a certain point on the curve, major progress is possible. We are not there yet, but we are working our way toward it (Chalmers 2015, 31).

Chalmers concludes his piece on progress in philosophy rather optimistically by saying that "we are still learning to do philosophy well. To see how far it can take us, we have to keep doing philosophy" (Chalmers 2015, 31). In what follows I will briefly attempt to build on this optimism. ${ }^{116}$

John L. Schellenberg writes that "Evolutionary time is of an extent almost beyond fathoming - that's why scientists call it 'deep'... Stephen Jay Gould, put it this way: 'an abstract, intellectual understanding of deep time comes easily enough - I know how many zeroes to place after the 10 when meaning billions. Getting it into the gut is another matter"' (Schellenberg 2013, 3). Schellenberg continues:

[O]ne needs to think hard about the fact that the perhaps 200, 000-year history of $H$. sapiens is wedged between three and a half billion years of evolutionary development on one side - life's past - and another billion on the other - life's potential future. Consider especially the second figure. A billion years is a period of time ridiculously longer than the 50, 000 years of thinking and feeling that, on a generous estimate, our species has put into religion so far. What developments in religiously-relevant thought and feeling might Earth see in so much a time?... Even if we restrict ourselves to the possible future of our own species, the numbers are staggering. H. sapiens, though manifesting its religious inclinations and symbolic powers a bit earlier, has at most 6,000 years of organized and systematic religious inquiry to its credit (Schellenberg 2013, 3).

${ }^{116}$ Additionally, one might claim that the very fact that other disciplines emerge from philosophy that more obviously make (epistemic) progress is actually indicative of philosophy's success. I won't explore this response here, but it is another way to side-step this worry. 
Scientists believe that in its infancy the sun was 30 percent less luminous or hot than its current state. In a widely cited paper K. P. Schroeder and Robert Connon Smith (2008) argue that if the sun increases in luminosity by 10 percent then biological life will be impossible on earth. They predict that this will happen in approximately 1 billion years. This estimate is widely accepted by the scientific community (Schellenberg 2013, 14). King-Fai Li's (2009) research team from Caltech suggests that this won't happen for 2.3 billion years. Recent discoveries seem to point in the direction that 1 billion is a conservative figure (Schellenberg 2013, 14-15). Schellenberg suggests that while we often account for the deep past, we usually fail to consider the consequences of the deep future. The first line in the following diagram represents how we typically understand deep time, while the second represents how to account for the deep future:

4.5 billion yrs-------------------------US

----------------3.5 billion yrs----US----1.0 billion yrs----------------'

Schellenberg further writes:

A deep time perspective on inquiry, in which we trade our human timescales for those of the universe, should have a decided impact. In particular, it's going to seem rather plausible that it might take a lot longer for human intelligence to get anywhere really interesting than we had thought. Many deep layers of matured thought, developed only after much difficult collaboration over unbelievably long periods of time, may need to be laid down before we are in a position to see the deep truth of things (if we ever are) (Schellenberg 2013, 47).

In light of deep time and the fact that the human species is little over 200, 000 years old (from the Middle Paleolithic Period), it's apparent that we're still intellectually immature. For instance, Lucy's brain is a third the size of our brains. It's possible that with enough time humans will evolve and/or acquire the requisite skills to be better at philosophy. It's possible that because we're so

${ }^{117}$ This is modified from Schellenberg 2013, 20. 
early in our history we don't yet see very much convergence in philosophy, but we will in the future. Perhaps with enough time there will be a lot of convergence like there has been in the sciences. That this is a possibility makes it possible that in the future the Benefits to Inquiry Argument will apply to philosophy in the same way that it currently does to the more empirical disciplines.

\section{The Benefits to Inquiry Argument violates the Independence Principle}

Recall that one prominent idea in favour of conciliationism is the independence principle. This principle requires that an agent find a dispute-independent reason to downgrade one's opponent in a dispute. Without such a reason, remaining steadfast would be to beg the question against one's opponent. The simple idealized cases used by conciliationists are designed, in part, to generate intuitions in favour of independence. The Benefits to Inquiry Argument violates the independence principle because it appeals to reasons (albeit future ones) that are not independent of the dispute itself.

Reply:

It isn't clear that the Benefits to Inquiry Argument does in fact violate the Independence Principle. As I will highlight below, the cases of epistemic peer disagreement in question are with respect to synchronic reasons. But the reasons appealed to by the Benefits to Inquiry Argument are diachronic reasons. So they are different from the reasons that the researchers are initially disputing over. One might reply that there will be cases where the diachronic reasons are also under dispute so they can't be appealed to as independent of the disagreement. But this seems no more than an ad hoc response, since the Benefits to Inquiry Argument is meant to address disagreements between researchers who disagree right now. Finally, even if the Independence Principle is 
violated by the argument, this could simply be a reason to reject the Independence Principle. The Benefits to Inquiry Argument is, after all, an argument against conciliationism.

\section{Doxastic Attitudes Other than Belief}

Another objection is that the epistemic benefits of remaining steadfast are available to researchers who do not stick to their beliefs in the face of disagreement. Consider that there are a variety of weaker doxastic stances which a researcher can plausibly take toward a proposition. Disagreement might make belief irrational, but it does not impact the rationality of researchers pursuing a disputed line of research. In what follows I outline a number of these attitudes and show how a researcher might adopt one of them toward her research. My survey does not aim at completeness, but it should be fairly representative of the weaker available doxastic alternatives to belief. Finally, there may be overlap between these attitudes; nothing in what I say precludes these attitudes from

coming in degrees. I conclude this section by showing why the Benefits to Inquiry Argument is best understood as an argument about rational belief, rather than about a weaker doxastic stance. But first, here are some more details about this objection.

It might be objected that a researcher need only entertain or speculate that a proposition is true, rather than believe a proposition is true, in order to enjoy the relevant epistemic benefits derived from disagreement. Speculating or entertaining can be understood as occurring when a researcher speculates that $P$ is the likeliest amongst a group of options, but she does not have enough evidence to justify belief in $P$ (Barnett 2019a, 113-115). Further, suppose that when a researcher entertains or speculates about a proposition, she chooses only to use it within the confines of an experiment or theorizing. She does not believe and hence act as if it is true with respect to all of her research, or life outside of her research, since it lacks the appropriate level of justification for rational belief. She is merely imagining what things would be like if that 
proposition turned out to be true within the context of her research. Philosophers routinely entertain propositions in this way. Philosophers might entertain many different propositions to help explore arguments, objections, and counter-examples to various ideas. The inquirer who simply speculates about a proposition could even conduct meaningful research on a proposition she believes to be false. Consider, for example a philosopher who defends presentism:

Even though one might repeatedly assert and defend P, with all sincerity and honesty, one may not actually believe $\mathrm{P}$ - to any degree at all. For instance, I could be a presentist (roughly: only presently existing and atemporal objects exist in the core sense of existence) even though I don't believe that presentism is true. That may seem odd to a non-philosopher, but it will be familiar to any professional philosopher. My commitment to presentism might well fall short of belief. I may defend it, call myself 'a presentist', and suspect that the current public evidence is in its favor, but I need not believe it's true. There's no requirement that I be sure enough to actually believe it. So there is no epistemically blameworthy belief in presentism because there is no belief in presentism even in the presentist (Frances 2010, 443).

Thus, entertaining or speculating about a proposition may be rational in the face of disagreement, regardless of whether or not it is rational to believe the proposition in question.

One significant difference between the Benefits to Inquiry Argument and Elgin's initial suggestion is that she claims that arguments in the epistemology of disagreement should be phrased in terms of acceptance, rather than belief. This is because belief is involuntary and acceptance is voluntary (Elgin 2010). Thus, it does not make sense to speak of 'remaining steadfast' or 'suspending judgment' with respect to beliefs. In the presentation of the Benefits to Inquiry Argument above, I chose to ignore this distinction because even if belief is involuntary, assessing the rationality of beliefs remains possible. But the distinction between belief and acceptance can be used to offer another possible doxastic stance which is different from entertaining or speculating.

Consider L. Jonathan Cohen's canonical formulation of acceptance: 
[T] accept the proposition or rule of inference that $\mathrm{p}$ is to treat it as given that $\mathrm{p}$. More precisely, to accept that $\mathrm{p}$ is to have or adopt a policy of deeming, positing, or postulating that $\mathrm{p}$ - i.e. of including that proposition or rule among one's premises for deciding what to do or think in a particular context, whether or not one feels it to be true that p" (Cohen 1992, 4).

This definition of acceptance is stronger than entertaining. Cohen notes that "acceptance is not the same as supposition, assumption, presumption, or hypothesizing [or entertaining], in the standard senses of those terms... acceptance implies commitment to a pattern, system, or policy - whether long or short term - of premising that $\mathrm{p}$ as a basis for a decision" (Cohen 1992, 13). This is distinct from supposing or entertaining because when a researcher accepts a proposition she adopts it within her research on a specific question, but also within her broader research framework and life as well. She is acting as if the proposition is true, even though she realizes she does not have enough justification to believe that the proposition is true.

Yet another doxastic attitude to take which differs from belief is that of insulated reasoning.

David Chalmers explains that:

[A] level-crossing principle... is a principle by which one's higher-order beliefs about one's cognitive capacity are used to restrain one's first-order beliefs in a subject matter... We can imagine a cognizer - call him Achilles - who is at least sometimes insensitive to this sort of level-crossing principle. On occasion, Achilles goes into the mode of insulated cognition. When in this mode, Achilles goes where first-order theoretical reasoning takes him, entirely insulated from higher-order beliefs about his cognitive capacity. He might acquire evidence that he is unreliable about mathematics, and thereby come to believe 'I am unreliable about arithmetic', but he will go on drawing conclusions about arithmetic all the same (Chalmers quoted in Barnett 2019a, 119-120).

In defending the practise of philosophizing in the face of disagreement, Zach Barnett says that insulated reasoning is reasoning that is insulated from certain types of evidence (e.g. disagreement) (Barnett 2019a, 120). Barnett suggests bracketing-off the higher-order evidence when conducting philosophy (Barnett 2019a, 120-123). He explains that:

Higher-order evidence leads one to doubt one's own direct thinking about some core body of evidence. But there can often be a kind of seeming produced by that direct 
thinking - whether or not one trusts it. Even after one acquires evidence that the direct thinking is not reliable, the direct thinking does not tend to vanish; it will still be there, and it may even be correct. And when the direct thinking is still there, we will be in a position to advocate for the conclusion it produced in a way that bears important hallmarks of sincerity: The position will seem right to us in a psychologically gripping way, and we will have something substantial to say in support of it, which we can see no flaw in. In short, because disagreement is a species of higher-order evidence, it seems plausible that bracketing disagreement will tend to support the kind of sincerity that [conciliationism] seemed to place in jeopardy (Barnett 2019a, 123-124).

The main reason for appealing to these weaker doxastic stances is to show that the Benefits to Inquiry Argument only makes it rational to continue to hold a doxastic attitude weaker than belief about a proposition in the face of peer disagreement. The argument fails to show that it is rational to maintain belief in a proposition in the face of peer disagreement as opposed to one of the weaker doxastic stances mentioned above. Thus the existence of peer disagreement remains a defeater for the rationality of believing the proposition in question, even if a weaker doxastic attitude toward the proposition is rationally permissible.

Reply:

There are two main responses to this objection. First, it is far from obvious that the epistemic benefits can be obtained unless a researcher really believes the propositions she is investigating. For instance, Goldberg observes that speculation might not be strong enough in philosophy because those holding philosophical positions typically are more motivated to persist in defense of the views when challenged, than is one who merely speculates that p" (Goldberg quoted in Barnett 2019a, 115). Barnett explains that Goldberg "suggests that speculation should be taken to be a necessary condition on having a philosophical view, not a sufficient one" (Barnett 2019a, 115). The more tenacious stance of belief might be required in order to gain the most epistemic benefits of remaining steadfast in the face of peer disagreement. For example, when an agent 
supposes that a proposition is true, as opposed to believes it to be true, she is much more open to revision about that proposition.

Also consider what Stalnaker says about the tentative nature of acceptance:

To accept a proposition is to treat it as a true proposition in one way or another - to ignore, for the moment, the possibility that it is false... A person may accept a proposition for the moment without the expectation that he will continue to accept it for very long. If a person expects a particular one of his beliefs to be overturned, he has already begun to lose it, but an assumption he makes maybe quite explicit temporarily, and he may presume that something is true even when expecting to be contradicted (Stalnaker quoted in Engel 2000, 10).

In other words, adopting a weaker doxastic attitude might turn out to be a hindrance to successful inquiry. Beliefs are much harder to change and this is likely better for inquiry if the Benefits to Inquiry Argument is correct. In the face of disagreement, an agent will continue to defend a proposition much more vigorously if she believes rather than only entertains or accepts it as true.

Recall Semmelweis and his belief in the connection between hand washing and infant mortality rates from Chapter Five. If Semmelweis had taken a weaker doxastic stance than belief to this idea, he would have been much more open to revision. He may have been swayed by the vast amount of peer disagreement he faced over hand washing. It is plausible to think that he would not have pursued his ideas with such fervor if he did not really believe them. Thus while it is true that in some cases it is likely that the epistemic benefits can be gained without genuine belief, there are cases where belief is required to obtain all of the potential epistemic benefits. Therefore, in at least some cases believing will yield better research results (i.e. be more truth conducive), than a weaker doxastic stance.

It also turns out that in many cases the inquirer really does believe the ideas she defends. Note that if belief comes in degrees then an agent need not be certain about a proposition to believe that proposition. Everything that I say here is consistent with understanding beliefs as coming in 
degrees. ${ }^{118}$ The objector might insist that this is mere speculation on my part about the psychology

of researchers. But consider what Peter van Inwagen says about speculative physics:

Even in the most austere and abstract parts of science, even in high-energy physics, the current queen of the sciences, where there is some real plausibility in the thesis that investigators typically hold some more tentative attitude than belief toward the content of the controversial theories they champion, it is possible to find clear examples of [belief]. To find them, one need only direct one's attention away from the content of the theories to the judgments that physicists make about the theories, their judgments about such matters as the usefulness of the theories, their 'physical interest', and their prospects. A former colleague at Syracuse University, an internationally recognized quantum-gravity theorist, has told me, using a simple declarative sentence that contained no hedges whatever, that superstring theory would come to nothing. Many prominent physicists (Sheldon Glashow, for example) agree. They really believe this. And many prominent physicists (such as Steven Weinberg and Edward Witten) vehemently disagree. They really believe that superstring theory has provided the groundwork within which the development of fundamental physics will take place for a century (Peter van Inwagen 1996, 148-149).

Finally, there is empirical support for the claim that it is more epistemically beneficial to actually believe what one is defending, at least in certain cases (Matheson 2015c, 140). Matheson nicely summarizes some empirical literature (some of which was mentioned in Chapter Five) that suggests it is beneficial when inquirers genuinely believe what they are researching as opposed to taking a more tentative stance. He writes:

Mercier (2011)... suggests that we tend to seek out arguments that confirm our antecedently held beliefs. Such confirmation bias is a detriment to both individuals and like-minded groups. In addition Dawson et al. (2002) provide evidence that we are better at finding falsifying data regarding arguments and opinions with which we disagree. So, groups with genuinely dissenting parties will do better in terms of placing appropriate checks and balances on the reasoning and arguments deployed in the group. This conclusion is confirmed with work by Schulz-Hardt et al. (2002). They found that groups with genuine disagreement performed better than those where the disagreement was merely contrived by using various 'devil's advocate' techniques. Evidence suggests that we reason better with respect to beliefs that we actually have than we do with respect to 'devil's advocate' beliefs. So, groups with genuine dissent do better at avoiding both belief bias and confirmation bias (Matheson 2015c, 140141.

${ }^{118}$ The spectrum of credence in a proposition needed for belief might be .51 to 1 . 
Importantly, these different doxastic attitudes fail to address the conciliationist challenge. Conciliationism challenges the rationality of belief in the face of disagreement, not a weaker doxastic stance. These weaker doxastic stances are not sufficient for knowledge. ${ }^{119}$ It may well be the case that maintaining a weaker doxastic attitude different from belief is rational in the face of disagreement. Indeed, part of the motivation for Barnett's proposal is to explain how one could continue to do philosophy sincerely given the truth of conciliationism. Such proposals, however, do not show (and are not intended to show) that it is epistemically rational to continue to believe a proposition that has been challenged by an epistemic peer. The Benefits to Inquiry Argument is intended as a (limited) response to conciliationism and hence its target is the rationality of belief.

In sum, a weaker doxastic stance may prevent an agent from obtaining the full epistemic benefits of remaining steadfast in the face of disagreement. There are cases where some or all of the epistemic benefits only obtain if the inquirer genuinely believes what she is defending. Likewise, it turns out that many researchers really believe, rather than entertain, the propositions they defend. There is also important empirical evidence to support the claim that genuine belief is more beneficial to group inquiry than hypothetical disagreement. ${ }^{120}$ Finally, these weaker doxastic stances do not actually answer the conciliationist challenge since they are not about rational belief.

\section{Gaining evidence for proposition P versus a beneficial method for group inquiry}

There is a difference between an inquirer who knows that she will get more evidence for $P$ in the future and an inquirer who knows that maintaining her belief that $P$ is generally an epistemically beneficial methodological approach for group inquiry. Ignoring this distinction may allow an

119 This might be controversial but it seems to be an implicit assumption in the disagreement literature. The focus of the disagreement literature reduces to the question of whether peer disagreement impacts one's ability to have knowledge.

${ }^{120}$ For the purposes of my project the distinctions drawn here are sufficient. For more nuanced treatments of the difference between believing and accepting see Cohen 1992 and Engel 2000. 
inquirer to claim that remaining steadfast about $P$ is rational even though she has no specific reason to believe she will gain diachronic epistemic reasons in support of $P .^{121}$

Reply:

The Giving Up Principle is supposed to prevent an agent from dogmatic irrationality. Having said that, while the second benefit mentioned in the above objection isn't as strong as the first, it is still an example of purported epistemic benefits. The methodological practice of fostering disagreement is epistemically beneficial to group inquiry. The fact that this argument has the potential for abuse by agents does not mean we should abandon it.

\section{Difference between individual and group inquiry}

There is an important difference between disagreements between individuals and disagreements between groups. An individual inquirer might have a diachronic epistemic reason to remain steadfast in the face of peer disagreement. Disagreement between groups, however, is another matter. Consider that many scientific projects that groups work on result in failure. The worry is that there might be epistemic benefits for individuals who remain steadfast, but the epistemic benefits might be less forthcoming when it comes to a group of inquirers remaining steadfast because they disagree with another group of inquirers. ${ }^{122}$

Reply:

This objection could point to an important qualification needed in the Benefits to Inquiry Argument. It could turn out that the argument only applies to intra-group disagreement and not inter-group disagreement. However, the scope of the argument need not be limited in this way if the failed group research projects contribute in some way to the epistemic success of the small

121 Thanks to Klemmens Kappel for bringing this objection to my attention.

122 Thanks to Sandy Goldberg for bringing this objection to my attention. 
number of successful group projects. Disagreement between groups might help inquiry even if most of the groups turn out to be incorrect. ${ }^{123}$

\section{Tenacity and the Possibility of Epistemic Loss}

Suppose that one acknowledges it is possible that there could be epistemic benefits gained by maintaining belief in the face of disagreement. It still could be objected that the Benefits to Inquiry Argument fails to seriously consider that remaining steadfast in the face of disagreement could result in epistemic losses. Tenaciously defending a belief, rather than merely entertaining or accepting it, could lead to epistemic benefits, but it could also result in epistemic harm. And even the less tenacious stances of entertaining or accepting a proposition could lead to epistemic harm. Maybe the Giving Up Principle (GUP) proposed in the Chapter Five can be used to distinguish between cases in which it is more likely that epistemic benefits obtain rather than epistemic losses, but not enough was done in that discussion to explain how this principle functions. Sufficient information was not provided in order to demonstrate how an agent can accurately judge when a belief is unlikely to yield epistemic benefits if pursued and hence should be given up in the face of disagreement. Finding a precise account of GUP will be a difficult task, if not impossible. ${ }^{124}$ Reply:

Admittedly, GUP and its application as stated in Chapter Five are vague. Evaluating specific propositions with respect to predicting epistemic benefits is an incredibly difficult task. It is difficult to see how a researcher could know whether (or reasonably believe that) maintaining a belief in the face of disagreement will yield negative, neutral, or positive epistemic results. While this objection does not defeat the claim that epistemic benefits justify certain beliefs, it does show

${ }^{123}$ Thanks to Chris Dragos for suggesting this reply.

${ }^{124} \mathrm{I}$ am indebted to an anonymous referee report on an article closely related to this chapter for bringing this objection to my attention. 
that a more detailed explanation is required in order to explain how an agent could identify those beliefs. Recall that part of what I have argued in favour of thus far is that complex disagreements are best understood as broader worldview disagreements. Later in Chapter Eight I argue that it is easier to provide a plausible set of criteria by which to evaluate the truth of worldviews than can be offered to evaluate individual propositions. In other words, GUP is easier to apply to cases of complex disagreements, than it is to apply to simpler disagreements over propositions more isolated from an agent's overall worldview. Thus, this objection is more or less powerful depending on the specific details of the disagreement case in question (i.e. how closely it is connected to an agent's worldview). ${ }^{125}$ Notice how maintaining this distinction yields the intuitively correct results when evaluating different cases of disagreement. The Benefits to Inquiry Argument may be difficult to apply to simple cases of disagreement partly because it is difficult to apply GUP. But the Benefits to Inquiry Argument is not meant to defend remaining steadfast in cases of simple disagreements like Christensen's Restaurant Bill case. Thus, this objection helps to show that the Benefits to Inquiry Argument yields the intuitively correct result about the different cases of disagreement.

\section{Feyerabend Permissivism}

Related to the above objection is the worry that the Benefits to Inquiry Argument is too permissive because it can justify almost any belief by way of appeal to future epistemic benefits. In Against Method Paul Feyerabend argues for extremely permissive epistemic anarchism with respect to the scientific method. Feyerabend argues that "[s]cience is an essentially anarchic enterprise: theoretical anarchism is more humanitarian and more likely to encourage progress than its lawand-order alternatives" (Feyerabend 1988, 5). One way to interpret this is that he takes the

125 See chapters Eight for more details. 
epistemic benefits of disagreement to their very extreme. He suggests that people often too easily ignore the highly contingent manner in which they form beliefs. The contingent historical, social, political, religious, cultural, etc., setting one is in greatly impacts the beliefs that one forms. Feyerabend suggests that:

It is clear, then, that the idea of a fixed method, or of a fixed theory of rationality, rests on too naïve a view of man and his social surroundings. To those who look at the rich material provided by history, and who are not intent on impoverishing it in order to please their lower instincts, their craving for intellectual security in the form of clarity, precision, 'objectivity', 'truth', it will become clear that there is only one principle that can be defended under all circumstances and in all stages of human development. It is the principle: anything goes" (Feyerabend 1988, 19).

The objection is that GUP and its application are so vague that the Benefits to Inquiry Argument cannot avoid aligning itself with Feyerabend's 'anything goes' rationality. It justifies an extremely permissive epistemic anarchism. Also, while the argument clearly applies to inquiry related beliefs, it is unclear whether it is intended to also apply to the method of inquiry. The question remains as to what one should do in the face of disagreement over method.

Reply:

While I will not discuss Feyerabend's provocative account in detail, his principle of 'anything goes' rationality has hardly been met with universal praise. It's true that some disagreement is epistemically beneficial. And Feyerabend is likely justified in claiming that science has been given an undeservingly high epistemic status. But from these facts, it hardly follows that 'anything goes' with respect to rationality. The fact that the Benefits to Inquiry Argument applies only to research contexts and has GUP is supposed to protect it from this type of objection. Likewise, the argument says that the agent in question needs to reasonably believe there are epistemic benefits in the offing.

As with the epistemic loss objection, this worry rightly demands more clarification about the scope of the Benefits to Inquiry Argument. GUP is supposed to protect the argument against 
licensing an 'anything goes' rationality. While its application may be vague, it is surely not so vague as to allow any belief to count as rational. The argument focuses on inquiry beliefs, but it can also be used to justify a researcher employing a different method of inquiry. Disagreement over the appropriate method also leads to possible epistemic benefits. Notice, too, that disagreement over method is more likely to be a complex than a simple disagreement. As noted above, it will be shown later that GUP is easier to apply in such cases.

\section{Epistemic Rationality versus Practical Rationality}

The most serious objection to the Benefits to Inquiry Argument is based on the distinction between epistemic rationality and practical rationality. Epistemic rationality is "the kind of rationality which one displays when one believes propositions that are strongly supported by one's evidence and refrains from believing propositions that are improbable given one's evidence" (Kelly 2003, 612). Practical rationality is "the rationality which one displays in taking the means to one's ends" (Kelly 2003, 612). The objection is that the Benefits to Inquiry Argument only demonstrates that believing a proposition in the face of disagreement can be practically rational and fails to show that it is epistemically rational.

This objection is anticipated in some of the early literature on disagreement. For example,

David Christensen writes that:

It's quite plausible that knowledge is best advanced by people exploring, and attempting to defend, a variety of answers to a given question. Perhaps, human psychology makes this easier to do when investigators actually have a lot of confidence in the hypotheses they're trying to defend. Certain sorts of inquiry might well work best when a variety of investigators have irrationally high levels of confidence in a variety of pet hypotheses. So there may well be important epistemic benefits to certain patterns of irrational belief. But I would argue that the patterns of belief are no more epistemically rational for all that (Christensen 2007, 216).

Likewise, Richard Feldman appears to share Christensen's worry: 
This skeptical conclusion [that we should suspend judgment in the face of peer disagreement] does not imply that people should stop defending the views that seem right to them. It may be that the search for the truth is most successful if people argue for the things that seem true to them. But one can do that without being epistemically justified in believing that one's view is correct (Feldman 2011, 157).

Both Christensen and Feldman seem to allow that the Benefits to Inquiry Argument establishes that an agent has practical reasons to continue to believe and defend a proposition in the face of disagreement. But such reasons offer no defense for the epistemic rationality of maintaining belief in the face of disagreement.

\section{Reply:}

My reply to this objection is divided into six different sections, as there are a variety of different topics I need to address.

\section{Preliminaries}

First, it is important to remember that the benefits appealed to in the Benefits to Inquiry Argument are epistemic. True, the argument does recommend a particular course of action with respect to researchers; it recommends that a researcher ought to continue to believe and inquire into the truth value of a proposition over which there exists peer disagreement. But the reason for this recommendation is that there are future epistemic benefits in the offing.

Second, one might contest that while the epistemology of disagreement is about epistemic rationality, the term 'rational' is often used in different ways, or simply goes undefined throughout much of the literature. Nicholas Wolterstorf explains that:

[T] he term 'rational' is a word of many meanings. What is it being used to mean in the debate between conformists and nonconformists?... [This lack of clarity i]nitially... appears to be a serious flaw in the discussion. On further reflection I am inclined to think, however, that it is not. The [conciliationist] holds that if those who regard each other as epistemic peers disagree, then they lack an epistemic merit such that the lack of that merit makes it imperative that each party revise his or her beliefs so that the merit is then present. It would be interesting to know what exactly the merit is thought to be that is being picked out with the term 'rational'. But the important point is that 
the lack of that merit, whatever it be, is held to generate the belief-revision imperative" (Wolterstorf 2014, 320).

Thus, the best way to understand Christensen and Feldman is that they are claiming that future epistemic benefits will not make a currently contested belief possess whatever merit is necessary for epistemic rationality. It is not necessary to detail what this merit is in order to successfully formulate this objection.

Third, the success of this objection depends on the answer to the following question: Can future epistemic benefits ever count as the proximate epistemic justification for a current belief? If 'yes' it is difficult to see how this objection could succeed. For an affirmative answer implies that the Benefits to Inquiry Argument could be used to rationally justify inquiry beliefs, at least in principle. For this to be an objection that covers every belief that might be epistemically justified based on the Benefits to Inquiry Argument, Feldman and Christensen must answer 'no' to the question. They must hold that it is impossible for future epistemic benefits to ever count as the proximate epistemic justification for a current belief. I will show that this relies on drawing a sharp distinction between synchronic reasons and diachronic reasons. ${ }^{126}$ For Christensen and Feldman, epistemic rationality is only about synchronic reasons, and never about diachronic reasons.

\section{Epistemic Teleology}

Brian Talbot argues that if believing a proposition leads to true beliefs, regardless of whether or not that proposition is true, then the belief in the proposition in question is epistemically justified. While Talbot's target is broader than the Benefits to Inquiry Argument, his argument provides reasons for affirming that future epistemic benefits can count as the current proximate epistemic justification for a belief. The following also shows that in order to succeed, the Benefits to Inquiry Argument needs to assume that epistemic teleology is true.

126 This distinction is found in Holley 2013; Lougheed and Simpson 2017; Matheson 2015a; $2015 \mathrm{c}$. 
Talbot's argument rests on three claims which epistemologists will not easily want to give up: "epistemic oughts are normative, epistemic oughts have a source, and the source of epistemic oughts is an end that has true belief as a necessary component" (Talbot 2014, 599). Believing $P$ on the basis of future epistemic benefits does not imply that an agent needs to believe against the current evidence for $P$. It need only be the case that she lacks evidence or that there is not currently enough evidence on offer to otherwise consider $P$ to be epistemically rational (Talbot 2014, 600). Note that this does not mean disagreement could not stop an agent from believing $P$. But the evidence against $P$ based on peer disagreement could be counterbalanced by other evidence.

Talbot argues that epistemic teleology entails that future epistemic benefits can provide current proximate epistemic justification. Since there are sometimes beliefs an agent ought to believe, it follows that epistemic justification is normative. The source of such epistemic oughts is the end of acquiring true belief. Talbot explains that "whether or not one epistemically ought to believe such and such is a function of the epistemic reasons for and against the life of some epistemic norms and rules" (Talbot 2014, 602). Rules or norms help explain how strongly the belief in question needs to be supported by evidence in order to be epistemically justified. There are different possible sources from which epistemic rules might arise. They could arise from the goal of believing truths or avoiding falsehoods. They could also arise from goals such as acquiring interesting truths, or knowledge, or understanding, or wisdom. Perhaps these goals arise in social or group contexts (Talbot 2014, 602). Talbot explains that:

These accounts have something in common: on each of them, epistemic reasons and rules arise from some end, whether this end is a goal, or an aim, or a value. Further, there is another shared theme. On the accounts I listed, true belief plays some important role in the epistemic end. Specifically, on each account I've noted, having true beliefs is necessary in order to achieve the end (Talbot 2014, 602). 
In other words, it is widely held that some true beliefs are necessary in order to achieve whatever epistemic end is desired. Talbot continues to claim that:

Belief [in future epistemic benefits, for example,] promotes true belief, and promoting true beliefs will promote things that have true belief as a necessary component. This means that relative to the epistemic end there is something that counts in favor of, or that there are reasons for, belief [based on future epistemic benefits. I] magine that the epistemic goal were to form true beliefs just on the basis of [current] evidence. Since [future epistemic benefits] are not [current] evidence, it might seem that belief [based on future epistemic benefits] cannot be consistent with this epistemic end. However, the belief that $\mathrm{p}$ can lead to having other beliefs that are supported by evidence (Talbot 2014, 603-604).

One objection to Talbot's argument is that there are accounts of epistemic consequentialism that do not entail that future epistemic benefits can count as proximate epistemic justification. Talbot considers Marian David's subjunctive truth goal, which is that "for every p, if I were to believe that $\mathrm{p}$, then $\mathrm{p}$ would be true, and if $\mathrm{p}$ were true, then I would believe p" (David 2001, 166). On David's account, then, it could be argued that future epistemic benefits are not epistemic reasons. But Talbot contends that this is not so on David's account. He argues that if an agent accepts David's subjunctive truth goal then it follows that "one has the sub-goal to believe all propositions that are true. This is because all things that are true satisfy the antecedent of 'If $p$ were true, believe p.'... We'll get similar results for any subjunctive goal that can be furthered by actually believing what is true" (Talbot 2014, 605).

Another objection to Talbot's account is the worry that if epistemic consequentialism is true, then maybe there are epistemic rules that forbid future epistemic benefits to ever count as epistemic reasons. For example, a rule ensuring a particular epistemic end might be "[b]elieve only what is [directly] supported by one's evidence" (Talbot 2014, 605). Talbot counters that there cannot be a hard and fast rule that future epistemic benefits never count as epistemic reasons. This is because following that as an unbreakable rule will sometimes make an agent worse off with 
respect to whatever epistemic end she is pursuing. And sometimes this will be quite obvious (Talbot 2014, 607). Note that GUP is a relevant constraint that might help account for this worry. With epistemic consequentialism in mind, one way of understanding GUP is that when it is violated, appealing to future epistemic benefits is inappropriate because doing so will not promote an agent's desired epistemic end (e.g. true belief, interesting belief, understanding, wisdom, knowledge, etc.).

Another thought-provoking idea is one recently suggested by Crispin Wright. He argues that denying that future epistemic benefits can ever count as proximate epistemic justification entails that there can never be epistemically rational inquiry. ${ }^{127}$ I will not discuss this argument here, but if it is true then Wright's claim serves to strengthen the Benefits to Inquiry Argument (Wright 2014). This discussion gives reason to think epistemic teleology and the truth of epistemic teleology supports the Benefits to Inquiry Argument.

\section{Against Epistemic Teleology: The Epistemic Separateness of Propositions}

It is a very important question whether the Benefits to Inquiry Argument is consistent with Talbot's claim that, while future epistemic benefits are not direct evidence, they "can lead to having other beliefs that are supported by evidence" (Talbot 2014, 604). That is, is believing that $P$ based on the possibility of future epistemic benefits is epistemically rational because it will lead to knowledge (or related epistemic goods) of $P$, or of other propositions, or of both $P$ and other propositions? Intuitively, for $P$ to be epistemically justified by future epistemic benefits, the benefits in question must be about $P$. If the benefits are only about some other proposition(s), it is difficult to grasp how $P$ could gain any epistemic justification in such a scenario. Acquiring other epistemic benefits alongside $P$ in such a scenario is an epistemic bonus, but not necessary for the

${ }^{127}$ If we had all of the synchronic reasons for $P$ why would we ever need to conduct inquiry about $P$ ? 
epistemic justification of $P$. In this sense the Benefits to Inquiry Argument is stronger than anything proposed by Talbot.

Since the Benefits to Inquiry Argument assumes epistemic consequentialism, there is an objection lurking nearby. Selim Berker argues that epistemic consequentialism makes certain unwelcome trade-offs, which are obviously epistemically irrational, turn out to be epistemically rational. Berker explains that epistemic teleology assumes that:

[T]rue beliefs have epistemic values as ends, false beliefs have epistemic disvalue as ends, and nothing else has epistemic value or disvalue as an end. Or to formulate things in terms of goals instead of ends: according to this theory of final epistemic value, our only ultimate epistemic goals are (i) the accumulation of true beliefs and (ii) the avoidance of false beliefs (Berker 2013, 360).

Berker claims that this type of "[v]eritism is, in many ways, the default theory of final value for epistemic teleologists" (Berker 2013,360). In the same way that teleological ethical theories allow for trade-offs between good and bad consequences, epistemic teleology allows for "trade-offs between the positive goal of believing a proposition if it is true and the negative goal of not believing that same proposition if it is false" (Berker 2013, 363). While this point has been appreciated in the literature, Berker argues that:

[W] hat has not... been sufficiently appreciated is the degree to which veritistic theories also need to allow for trade-offs between our epistemic goals with respect to different propositions: they must balance the positive goal of believing one proposition if it is true against the positive and negative goals associated with believing all other propositions, and they must balance the negative goals of not believing one proposition if it is false against the positive and negative goals associated with believing all other propositions. But such trade-offs... are beyond the pale" (Berker 2013, 363).

To show what veritistic theories are committed to, Berker offers the following story:

Suppose I am a scientist seeking to get a grant from a religious organization. Suppose, also, that I am an atheist: I have thought long and hard about whether God exists and have eventually come to the conclusion that He does not. However, I realize that my only chance of receiving funding from the organization is to believe in the existence of God: they only give grants to believers, and I know I am such a bad liar that I won't be able to convince the organization's review board that I believe God exists unless I 
genuinely do. Finally, I know that, were I to receive the grant, I would use it to further my research, which would allow me to form a large number of new true beliefs and to revise a large number of previously held false beliefs about a variety of matters of great intellectual significance. Given these circumstances, should I form a belief that God exists? Would such a belief be epistemically rational, or reasonable, or justified (Berker 2013, 364)? $?^{128}$

Berker argues that it should be obvious that in this story the scientist's belief in God would fail to be epistemically reasonable. And yet the trade-off of one false belief would maximise epistemic value because it would lead to more true beliefs and fewer false beliefs overall. Berker argues that while there are many different nuanced veritistic theories, they are all subject to modified counterexamples of the one quoted above (Berker 2013). He concludes that:

[W] hen determining the epistemic status of a belief in a given proposition, it is epistemically irrelevant whether or not that belief conduces (either directly or indirectly) toward the promotion of true belief and the avoidance of false belief in other propositions beyond the one in question. Veritistic epistemic teleology, in flouting this fact ignores what we might call "the epistemic separateness of propositions" (Berker $2013365)$.

Elsewhere, Robert Mark Simpson and I observe that "modelling epistemic rationality on decision theory, Hilary Greaves arrives at a similar conclusion, suggesting some element of our intuitive notion of epistemic rationality is ultimately incompatible with a consequentialist formulation of epistemic norms of belief" (Lougheed and Simpson 2017, 154). Greaves worries that if it is rational to endorse a belief on the basis of epistemic utility overall, then epistemic bribes are permissible. According to Greaves there is

No theory that recovers the obviously correct result that an agent (epistemically) should retain credence 1 [i.e. certainty] in propositions for which she has conclusive evidence, even in the face of 'epistemic bribes'. The reason this is difficult to recover... is, heuristically, that a decision-theoretic utility function always assesses epistemic utility globally, and hence will always be open to the move of increasing overall expected utility by making a sacrifice of a relatively small number of propositions; our intuitive notion of epistemic rationality, meanwhile, does not seem to exhibit this willingness (Greaves quoted in Lougheed and Simpson 2017, 154-155).

${ }^{128}$ Berker takes this story from Fumerton 2001, 55. It is originally found in Firth 1998a, 326; 1998b, 261. 
Both Berker and Greaves are pointing to the fact that the intuitive notion of epistemic rationality "entails that what one ought to believe about a given proposition is entirely determined by one's reason for thinking that particular proposition is true or false" (Lougheed and Simpson forthcoming). Doing otherwise leads to unwelcome trade-offs or the possibility for epistemic bribes.

\section{Synchronic Epistemic Rationality versus Diachronic Epistemic Rationality}

Elsewhere, in a co-authored article, I argue that Berker and others who agree with his assessment are incorrect to think such epistemic trade-offs are beyond the pale. There are good reasons to hold that the epistemic separateness of propositions can be violated in certain cases. But suppose in the scientist case offered above by Berker that the following will obtain:

(i) Epistemically good outcomes will ensue, e.g. a significant number of people will come to have true beliefs about a significant number of non-trivial propositions, provided that agent $\mathrm{A}$ believes $\mathrm{P}$;

(ii) Whatever countervailing, epistemically bad outcomes will ensue as a result of A believing $\mathrm{P}$ are negligible and/or clearly outweighed by these epistemically good outcomes; and

(iii) A has a reasonable beliefs that conditions (i) and (ii) hold (Lougheed and Simpson 2017, 152).

Simpson and I argue that if it really is the case that believing $P$ now makes significant epistemic benefits down the line likely - then believing $P$ in light of these epistemic reasons is rational epistemically rational right now (at the time of the disagreement).

Berker wrongly focuses solely on the epistemic value of avoiding false beliefs, while ignoring the epistemic value of possessing true beliefs. He is also only concerned with an individual's beliefs in isolation, rather than in the context of holding beliefs in a community of epistemic agents. Simpson and I argue that Berker turns a norm like "[b]elieve only what is [directly] supported by one's evidence" (Talbot 2014, 605) into an overly narrow and single mindedly focused position. Consider a slightly modified version of Berker's example: 
Permissive Scientist: The same conditions obtain as in the previous case $-\mathrm{S}$ must be a theist in order to win funding that will result in major epistemic benefits, etc. - except that, while $\mathrm{S}$ does not believe in God, her judgement about the evidence's probative force, vis-à-vis God's existence, is such that she sees both theism and non-theism as rationally permissible stances on the question of God's existence (Lougheed and Simpson 2017, 156).

The point of this example is to demonstrate that:

[I]f there is something epistemically unacceptable about S's favouring of theism in Permissive Scientist, the unacceptability can't be due to S's belief conflicting with her appraisal of the evidence's probative force, nor due to $S$ having disingenuously willed herself to believe, since neither factor figures in the scenario. It may be a rationalitydefeating feature of a belief - perhaps a decisively rationality-defeating feature - that it conflicts with the agent's assessment of the probative force of the evidence. However, it is consistent with this to allow that, wherever this disqualifying condition doesn't hold, beliefs that are informed by a strategic consideration of what's likely to maximize [diachronic] epistemic reasons are, or at least can be counted as, epistemically rational (Lougheed and Simpson 2017, 156).

To account for diachronic reasons in one's assessment of what is rational to believe does not, then, necessarily fly in the face of epistemic rationality. Thus:

To characterize [diachronic] epistemic reasons for belief as epistemic reasons is not to say that people should delusionally gull themselves into having beliefs that conflict with their views about the evidence's probative force. It's just to say that where an agent identifies some spectrum of rationally permissible doxastic attitudes in response to some body of evidence, and where she has some ability to influence what doxastic attitude she holds among that range of options, then, to the extent that she has reason to believe that her holding doxastic attitude $X$ will have better global epistemic consequences than holding doxastic attitude $\mathrm{Y}$, she has a reason - one that may be aptly characterized as an epistemic reason - to favour $\mathrm{X}$ over $\mathrm{Y}$ (Lougheed and Simpson 2017, 157).

Admittedly, there is an important distinction between beliefs that are epistemically justified by current epistemic reasons and those beliefs only justified by future epistemic benefits. It is likely this idea that motivates Feldman, Christensen, and Berker to reject future epistemic benefits as proximate epistemic justification. While I do not want to resist the legitimacy of making a distinction between the types of justification about those different beliefs, I do not think this distinction should be understood in terms of practical versus epistemic rationality. Rather, I claim 
that this distinction is best understood as reflecting two kinds of epistemic rationality: synchronic epistemic rationality and diachronic epistemic rationality. An all-things-considered account of epistemic rationality would include both synchronic and diachronic epistemic reasons.

\section{Diachronic Epistemic Reasons Exhibit Interpersonal Normative Parity}

There is also a positive argument on offer for thinking that diachronic epistemic reasons are not merely practical reasons. For diachronic epistemic reasons "exhibit a type of "interpersonal normative parity' that is characteristic of epistemic reasons for belief in general, but not of pragmatic reasons" (Lougheed and Simpson 2017, 160). Consider that "[w]here R is a pragmatic reason for $\mathrm{A}$ to believe $\mathrm{P}$, this by itself does not make it the case that $\mathrm{R}$ is also a pragmatic reason for person B to believe P. R's normative force only carries over like this if it happens that B shares the aims or interests by virtue of which R has its pragmatic normative force for A" (Lougheed and Simpson 2017, 160). However:

By contrast, where evidence E constitutes a bona fide epistemic reason for A to believe $\mathrm{P}$, it also, ceteris paribus, constitutes an epistemic reason for $\mathrm{B}$ to believe $\mathrm{P}$. Or to express this in a more qualified way, where evidence $\mathrm{E}$ is an epistemic reason for $\mathrm{A}$ to believe $\mathrm{P}$, the question of whether $\mathrm{E}$ is also an epistemic reason for $\mathrm{B}$ to believe $\mathrm{P}$ doesn't hinge on what A's and B's respective aims and interests are, nor the extent to which they coincide (Lougheed and Simpson 2017, 160).

Diachronic reasons exhibit interpersonal normative parity which practical reasons do not. That is, "[i]n circumstances where more truths will be believed in domain D provided that someone believes $\mathrm{P}$, both $\mathrm{A}$ and $\mathrm{B}$ are given an [diachronic] epistemic reason to believe $\mathrm{P}$. And this interpersonal normative parity obtains even if it happens to be the case that $\mathrm{A}$ is deeply concerned about the prevalence of true belief in domain D, whereas B doesn't care at all about this" (Lougheed and Simpson 2017, 160).

Talbot notes that synchronic and diachronic rationality achieve their normative force from exactly the same place: their epistemic end (e.g. true belief, justified belief, interesting belief, 
wisdom, knowledge, etc.) (Talbot 2014, 609). Thus, the account I provide offers a way to preserve Christensen's et al intuition that there is a distinction between beliefs justified by current epistemic reasons and those only justified by possible future epistemic benefits. But the account offered here is also able to preserve the intuition that future epistemic benefits are epistemic reasons, rather than merely practical reasons. The distinction between synchronic and diachronic epistemic rationality helps to explain why violating the epistemic separateness of propositions is acceptable in certain scenarios, specifically when one believes future epistemic benefits are in the offing.

\section{A Category Mistake: Epistemology is not concerned with diachronic reasons}

Matheson believes that appealing to diachronic reasons ultimately answers a different question about disagreement that is not being asked by Feldman and Christensen (along with not being asked in the rest of the literature). According to Matheson, an argument such as the Benefits to Inquiry Argument:

[F]ails to give an answer to the all-epistemic things-considered version of our question [i.e. what should we believe in the face of disagreement?] since it does not tell us how to weigh answers to the synchronic version of the questions with the answers to the diachronic version of the question, and it is compatible with there being no way of combining these answers at all. That is, it may be that there simply is no all-epistemicthings-considered perspective, but only the disambiguated epistemic perspectives. (Matheson 2015c, 144).

Thus, Matheson suggests that the synchronic question of what I ought to believe right now in the face of disagreement might be an entirely separate question from the diachronic question of what I ought to believe based on future considerations. Conciliationist views in the epistemology of disagreement to which the Benefits to Inquiry Argument offers a response are only intended to inform agents about synchronic reasons, not an all-things-considered rationality which also includes diachronic reasons. 
Thus, one might worry that the Benefits to Inquiry Argument is guilty of a category mistake. It simply answers a question in an entirely separate category, which is distinct from the questions about disagreement the rest of the literature seeks to answer (as outlined in Chapter One). Perhaps even more worrisome is that epistemologists in general are only concerned with synchronic reasons. And so it is futile to discuss diachronic reasons. Matheson explains that:

While 'justification', 'rational', and their cognates are far from univocal, it is plausible (at least historically) epistemologists have been examining epistemic justification (at least when seen as what helps put us in a position to know at the time in question) and have been concerned with answering the synchronic version of our question [i.e. of what to believe in the face of disagreement]... While we can see that both versions of the question are properly epistemic, and both are concerned with what is epistemically rational or justified for me to believe now, the diachronic answer does not provide the type of epistemic justification required for knowledge - at least not knowledge at the time in question (Matheson 2015c, 145).

He continues to claim that non-conciliationist views may be epistemically justified, but not in "the sense of epistemic justification that traditional epistemologists have been concerned with" (Matheson 2015c, 145).

There are at least two main ways to respond to Matheson's worry. The first response is to concede that the Benefits to Inquiry Argument does not justify remaining steadfast in the face of disagreement because questions about what it is rational to believe in the face of disagreement are asking about synchronic epistemic rationality. While I have explicated an argument in response to conciliationist worries, it simply does not apply in the appropriate sense to the disagreement literature. This is true even if one agrees with Matheson that diachronic reasons are properly epistemic. This response is consistent with the Benefits to Inquiry Argument being worthy of serious philosophical consideration, but it does concede the argument fails to directly address the initial questions set out at the beginning of this project. 
The second and more promising response is to reject the idea that the Benefits to Inquiry Argument commits a category mistake. Part of my defense of diachronic reasons is to argue that they are properly epistemic. Implicit in that defense is the claim that future considerations are indeed relevant to what an agent believes currently. Why think that synchronic and diachronic reasons need to be separated? As argued earlier, there are good reasons to think that the separateness of propositions can be violated. Matheson is indeed correct that the history of epistemology is concerned primarily with synchronic reasons. ${ }^{129}$ But that is no reason not to hold that epistemologists, whether intentionally or not, have missed an important component of knowledge. It does not follow from the fact that epistemic justification has typically been construed as only about synchronic reasons that epistemic justification must be (only) made up of such reasons. Likewise, it does not follow from the fact that there is no good account on offer about how to weigh and combine synchronic reasons with diachronic reasons in order to give an allthings-considered account of reasons, that it is therefore impossible to give such an account. The researcher who disagrees with her peers over the truth value of $P$ has a synchronic reason to believe that continuing to inquire about $P$ right now is epistemically rational partly because of the diachronic reason of the potential for future epistemic benefits.

This is a topic which, as Matheson himself notes, has not received a lot of attention from epistemologists. In sum, while it is true that epistemologists have been primarily concerned only with synchronic reasons, it does not follow that they ought not to be concerned with all-thingsconsidered epistemic reasons. The answer to the question of what I ought to believe right now in the face of epistemic peer disagreement ought to be answered by considering both synchronic and diachronic reasons. Nothing in this answer precludes the fact that giving an all-things-considered

${ }^{129}$ Of course, I am only referring to the Western philosophical canon. Also, while this claim can be verified, providing a comprehensive defense of it is well beyond the scope of my project. 
account of reasons may be very difficult. The one thing that would prevent defeating this response is for Matheson to show that such an account cannot be given, but that is a claim that would have to be defended. ${ }^{130}$ To do otherwise would be to beg the question against the legitimacy of an allthings-considered epistemic rationality, and hence the Benefits to Inquiry Argument. In the following section I propose a tentative account of all-things-considered epistemic rationality.

\section{All-Things-Considered Epistemic Rationality}

\section{All-Things-Considered Epistemic Rationality}

Here's one proposal for showing how an all-things-considered account of epistemic rationality is at least possible. Contra Matheson, there are some cases where diachronic and synchronic can plausibly combine to form an all-things-considered perspective. I've already shown that this is sometimes possible when a researcher reflects on her total epistemic position. One suggestion for an all-things-considered epistemic rationality is that agents should give equal weight to both synchronic and diachronic epistemic reasons, all else being equal. Further assume that higherorder evidence and first-order evidence should be given equal weight, all else being equal. It would be arbitrary to give different weights to these reasons without a principled reason. Once the synchronic and diachronic questions have been distinguished from one another, it is difficult to see what such a principle would be without being guilty of choosing to only answer one of the questions, or of arbitrarily favouring one of the answers to one of the questions over the other.

One way to understand how to include both types of reasons in an account of epistemic rationality is to understand beliefs in terms of credences. Suppose the researcher has a very high credence that $P$. Her colleague, on the other hand, has a very low credence that $P$ (or a very high credence that not-P). According to (some) versions of conciliationism, she should now have a

${ }^{130}$ Indeed, much more remains to be said here. Providing a detailed account of an all-things-considered epistemic rationality that includes both synchronic and diachronic reasons is its own dissertation project. 
middling credence in $P$. At the very least, she should now be 'on the fence' about whether $P$. But since I want to know whether it is all-things-considered rational to believe $P$, the researcher must also factor in her, say, very high credence that she will obtain positive epistemic results by continuing to believe $P$. Given her initial belief that $P$, the counterevidence of disagreement about $P$ (synchronic reasons), and the future epistemic benefits of continuing to believe $P$ (diachronic reasons), her credence about $P$ should still be high. In any case, it should be higher than it would be otherwise if she did not have such a credence about future epistemic benefits.

Notice that this result does not discount the higher-order evidence of peer disagreement and hence does not require rejecting conciliationism out of hand. It simply accounts for the additional evidence provided by diachronic reasons. Notice too, that if the researcher had a lower credence in the probability of obtaining future epistemic benefits that her credence in $P$ might drop low enough to preclude rational belief (i.e. a credence lower than .5). This shows why the Benefits to Inquiry Argument is only a limited response to conciliationism; it will not apply to every case of disagreement. Admittedly, different cases will vary in complexity, but the general procedure I have described above in principle applies to any case of disagreement.

Again, it also yields the intuitively correct results with respect to the different cases of disagreement. For instance the simple cases like the disagreement about whether the dean is in the quad, it's difficult to see how diachronic reasons could help one of the parties. So diachronic reasons cannot be used to mitigate the force of the (defeating) synchronic reasons offered by the existence of disagreement in such a case.

While there are a plethora of kinds of synchronic evidence, it is unclear whether the same can be said of diachronic reasons. Making accurate predictions about what will lead to positive epistemic results is difficult. Diachronic reasons seem most clearly available in research scenarios 
where examples abound of positive epistemic results from continuing to research a proposition despite some evidence against it. Such reasons are, however, less clearly available in cases where an agent is not conducting inquiry. But nothing in this analysis suggests that every proposition can be supported by diachronic reasons. When a proposition cannot be supported with such diachronic reasons, the all-things-considered reasons about that proposition will simply reduce to the synchronic reasons. This proposal is consistent with this fact. Based on the above discussion, the three different types of rationality look something like this:

All-Things-Considered-Rationality: Agent $S$ is all-things-considered epistemically rational to believe $P$ at time $T$ if and only if she gives equal weight to the synchronic and diachronic reasons she possesses for $P$ at $T$ and such reasons combine to justify $S$ 's belief that $P$.

Synchronic Rationality: $\quad$ Agent $S$ is synchronically epistemically rational to believe $P$ at time $T$ if and only if she gives total weight to the synchronic reasons she possesses for $P$ at $T$ and such reasons justify $S$ 's belief that $P$.

Diachronic Rationality: $\quad$ Agent $S$ is diachronically epistemically rational to believe $P$ at time $T$ if and only if she gives total weight to the diachronic reasons she anticipates to possess at some future time Tn and such reasons justify $S$ 's belief that $P$.

One might object that diachronic reasons on their own are not reasons at all. But imagine a case where an agent possesses only diachronic reasons for $P$ and no synchronic reasons for or against $P$. The temptation to reject diachronic reasons appears only when one thinks of reasons as exclusively synchronic. The account of all-things-considered rationality I have presented is better able to settle the seemingly conflicting intuitions about whether a proposition is justified. The following chart summarizes the equal weight view with respect to synchronic and diachronic reasons:

\begin{tabular}{|l|l|l|}
\hline \multicolumn{3}{|l|}{ All-Things-Considered Epistemic Rationality } \\
\hline Type & Synchronic & Diachronic \\
\hline Time & Present & Future \\
\hline
\end{tabular}




\begin{tabular}{|l|l|l|l|l|}
\hline Level & First-Order & Higher-Order & First-Order & Higher-Order \\
\hline Weight & .25 & .25 & .25 & .25 \\
\hline
\end{tabular}

\section{Objections}

In this section I will briefly examine some objections to my proposal for an all-things-considered epistemic rationality.

\section{A. Diachronic Reasons are not Possessed Reasons}

One objection to my proposed account of all-things-considered epistemic rationality is that diachronic reasons are not possessed by the agent at the time they are considered. The agent does not possess the content of the reasons in question. If the agent did possess the content of the reasons then they would just amount to synchronic reasons. ${ }^{131}$

Reply:

This objection amounts to a merely verbal dispute with the account of rationality I've offered above. One could index synchronic reasons to different times and the result is consistent with my account of all-things-considered epistemic rationality. Rather than referring to them as diachronic reasons one could say they are synchronic reasons indexed to future times. Agent $S$ might not possess the content of evidence $E$ at time $T_{1}$ but she has reason to believe that $E$ will support $P$. She need not possess the content of $E$ at $T_{1}$ if she is justified in believing that at some future time, $\mathrm{T}_{\mathrm{n},}$ E will support $P$. In such a case she has 'evidence of evidence' for $P$ and that is evidence in itself for $P$. Alternatively, one can understand $E$ as a synchronic reason for $P$ at $T_{n}$. Finally, from a logical point of view, reasons are timeless. It would be unprincipled to privilege reasons at $T_{1}$ over reasons at $T_{n}$ since they are both reasons. There would need to be an argument on offer for doing otherwise.

\section{B. Privileging Epistemic Perspectives}

131 Thanks to Nathan Ballantyne for bringing this objection to my attention. 
One non-arbitrary reason to favour the reasons at $T_{1}$ over those at $T_{n}$ is that from the first-person perspective of the inquirer she only knows the content of the synchronic reasons for $P$. It's true that 'evidence of evidence is evidence', but the inquirer doesn't possess the content of the evidence. This is a difference between the two sorts of reasons, even if the inquirer is justified in thinking she has good diachronic reasons for $P$. This isn't a reason to disregard diachronic reasons, but it is a reason to think they should not be given equal weight with synchronic reasons. Synchronic epistemic reasons should be accorded more weight than diachronic epistemic reasons because their content is possessed by the inquirer. ${ }^{132}$

Reply:

Suppose a juror has good reasons to think that she will gain a deciding piece of evidence when the trial continues next week. Right now she has good reasons to believe that the defendant is guilty. Further suppose the juror has reason to think the evidence she will get next week will be strong evidence supporting the defendant's innocence. In this scenario while the juror doesn't possess the content of evidence supporting the defendant's innocence she does know which verdict the total evidence supports. It would be a mistake to give more weight to the evidence of which she currently possesses the content.

Having said that, it is easy to imagine cases where one doesn't know what the future reasons will support. Imagine that the juror knows she will gain some decisive piece of evidence next week, but she doesn't know which verdict that piece of evidence will support. In such a case it is still wrong to give more weight to her synchronic reasons that the defendant is guilty. Why? Because the evidence she knows is forthcoming may not support that verdict. Finally, even if it is true that different weights should be accorded to synchronic and diachronic reasons, this doesn't

132 Thanks to Paul Faulkner for bringing this objection to my attention. 
require giving up my more general claim that diachronic reasons should count as epistemic reasons. Unless one wants to say that in every scenario synchronic reasons will always swamp diachronic reasons, then it's possible for the Benefits to Inquiry Argument to be sound in certain cases of disagreement. Thus, even if synchronic reasons should be accorded more weight than diachronic reasons, it's still possible that the Benefits to Inquiry Argument will apply in a number of cases of disagreement.

\section{Conclusion}

In this chapter I examined several possible objections to the Benefits to Inquiry Argument. I spent the most time addressing what I take to be the most serious objection which is that the argument demonstrates believing a proposition in the face of disagreement based on the possibility of future epistemic benefits is practically rational, but not epistemically rational. Talbot argues that any plausible form of epistemic justification is inherently teleological in nature. He further argues that if epistemic consequentialism is true, it necessarily follows that future epistemic benefits count as proximate epistemic justification. The most promising objection to Talbot's epistemic consequentialism is that it violates the epistemic separateness of propositions. There are ways of understanding the Benefits to Inquiry Argument that do not violate the epistemic separateness of propositions, but Berker might object that inasmuch as the Benefits to Inquiry Argument is consequentialist, it necessarily allows for the possibility of violating the epistemic separateness of propositions.

Berker worries that if the epistemic separateness of propositions is violated then terrible trade-offs between believing falsehoods in order to gain truths are permissible. According to Berker such trade-offs are always beyond the pale. I countered that not all such trade-offs are necessarily epistemically irrational. Berker wrongly obsesses over the epistemic value of avoiding 
falsehoods, while placing no emphasis on the importance of gaining truths. Admittedly, though, there is an important difference between beliefs that are epistemically justified based on synchronic reasons and those beliefs only epistemically justified based on future reasons. This distinction, however, is best construed as that of between synchronic and diachronic epistemic reasons, not as one of between practical and epistemic reasons. This is because future epistemic benefits have broad interpersonal normative parity in the same way as other epistemic reasons, not practical reasons.

A lot more remains to be said about the topics discussed here. What I hope to have shown in this section is that, minimally, there is a plausible philosophical defense of the claim that future epistemic benefits can sometimes count as the proximate epistemic justification for a belief. Thus, there is a plausible response to the objection raised by Christensen and Feldman that arguments like the Benefits to Inquiry Argument can only preserve practical rationality, but not epistemic rationality. I have offered an account of all-things-considered epistemic rationality in order to show that synchronic and diachronic reasons do not necessarily have to come apart. While the details of this account might be contested, so long as diachronic reasons are epistemic reasons and matter in assessments of all-things-considered epistemic reasons, the Benefits to Inquiry Argument is sound, at least in certain cases of disagreement. 


\section{Chapter Seven: The Benefits to Non-Inquiry Argument}

\section{Introduction}

In this brief chapter I explore the scope of the Benefits to Inquiry Argument. Specifically, I examine whether it can be used to justify remaining steadfast in the face of disagreement with respect to non-inquiry beliefs held outside of research environments. If non-inquiry beliefs cause an agent to hold certain inquiry beliefs, then those non-inquiry beliefs may well fall within the scope of the Benefits to Inquiry Argument. As it stands, however, I suggest that this expansion cannot be rationally endorsed because it leads to absurd results. Nevertheless, with more empirical information in the future, it might be possible to endorse. I conclude by exploring some of the implications of expanding the argument if indeed such an expansion turns out to be possible.

\section{The Benefits to Non-Inquiry Argument}

Here is a standardized version of the argument I want to explore in this chapter. Since its truth is dependent on the truth of the Benefits to Inquiry Argument, it is really a continuation of the initial argument.

\section{The Benefits to Non-Inquiry Argument:}

1. If agent $S$ reasonably believes that there are future epistemic benefits to be gained from continuing to believe proposition $P$ in the face of epistemic peer disagreement within a research context $R$, then $S$ is rational to be a non-conciliationist about $P$ in the context of $R$.

2. If agent $S$ believes $P$ because she believes proposition $Q$ in a non-research context $O$, and there is epistemic peer disagreement about $Q$, then $S$ is rational to be a non-conciliationist about $Q$ in the context of $O$.

3. $S$ believes $P$ within the context of $R$ (and within the context of $O$ and $Q$ ).

4. $S$ believes $Q$ within the context of $O$.

5. $\mathrm{S}$ believes $\mathrm{P}$ because she believes $Q$.

6. There is at least one epistemic peer of $S$ 's who believes not-P within the context of $R$. 
7. $S$ reasonably believes that there are future epistemic benefits to be gained from continuing to believe $P$ within the context of $R$.

8. There is at least one epistemic peer of $S$ ' $S$ who believes not- $Q$ within the context of $O$. Therefore,

9. $S$ is rational to be a non-conciliationist about $P$ in the context of $R$.

And,

10. $S$ is rational to be a non-conciliationist about $Q$ in the context of $O$.

Premises (1), (3), (6), (7), and conclusion (9) are the Benefits to Inquiry Argument that was defended in Chapters Five and Six, so I will not say more about those premises in this chapter. Premise (2) is the main premise in need of defense, along with premise (5), which is part of the antecedent of (2). In the next section I will outline the conditions that would need to obtain in order for (2) and (5) to be true. Whether such conditions ever obtain is ultimately an empirical question that I do not purport to answer in this project. However, I will suggest that as it stands (2) and (5) cannot be rationally believed.

\section{Defense of Premises (2) and (5)}

I begin this section by defending premise (5), which is: $S$ believes $P$ because she believes $Q$. Recall that $P$ is a belief that occurs within the context of research. $P$ is intended to represent a proposition about a particular research problem or question that a researcher is working through. $Q$, on the other hand, is a proposition which may not be directly related to $P$ or any specific research problem and not held within a research context. So $P$ is what I will call an inquiry belief and $Q$ is what I will call a non-inquiry belief. But how could an agent's beliefs in these two propositions be connected to each other such that a researcher believes $P$ because she believes $Q$ ? How could belief 
that $Q$ cause belief that $P$ ? In order for the connection between belief that $Q$ and belief that $P$ to be established, it merely has to be the case that $Q$ (partly) causes the belief that $P$.

Suppose that Sally is a researcher who is studying the long-term effects of regular marijuana use on the brain. She is particularly interested in the effects of marijuana use on mental health. She wants to know whether long-term use has a positive, negative, or neutral impact on various areas of mental health, including anxiety and depression. Her currently limited knowledge and research suggests that there is some correlation between long-term marijuana use and increased levels of anxiety. Sally therefore comes to believe the truth of the following proposition: Long-term marijuana use causes increased levels of anxiety. Proposition $P$ in the above argument can represent her belief about marijuana. This is straightforward enough so far. But to the extent that the Benefits to Inquiry Argument applies to non-inquiry beliefs the example has to be expanded. Suppose Sally believes that marijuana causes anxiety because she associates drug use with negative mental health outcomes. We can say that Sally believes the truth of the following proposition: Drug use is associated with negative mental health outcomes. Further suppose that this belief is not based on any of her research. This can be represented by proposition $Q$ in the above argument. If $Q$ causes $P$, then there is an inquiry belief which is dependent on a non-inquiry belief. $Q$ could be represented by any belief, and could be unrelated to $P$.

Recall that premise (2) states: If agent $S$ believes $P$ because she believes proposition $Q$ outside of a non-research context $O$, and there is epistemic peer disagreement about $Q$, then $S$ is rational to be an non-conciliationist about $Q$ in the context of $O$. The first part of the antecedent is explained in the above discussion of what it would take for (5) to be true. The second part of the antecedent is that there is peer disagreement over $Q$, the non-inquiry belief. The consequence is that it is rational to be a non-conciliationist about $Q$ in $O$. 
Note that even in attempting to expand the scope, this argument does not necessarily apply to non-researchers. It is a researcher who believes $P$. And her belief in $Q$ is only justified because it causes her belief that $P$. Thus, as I have presented the argument, it still only applies to noninquiry beliefs that researchers hold. One way to include non-inquiry beliefs of non-researchers would be to show that they impact the non-inquiry beliefs held by researchers. For if non-inquiry beliefs of non-researchers impact the non-inquiry beliefs of researchers (and in turn their inquiry beliefs), then such beliefs might also fall within the scope of the Benefits to Inquiry Argument. While this is clearly a logical possibility, the truth of this conditional is ultimately subject to empirical scrutiny. As it stands, it is not rational to believe that it is true.

\section{Objection: Including Non-Inquiry Beliefs Makes the Argument Too Permissive}

The most worrisome objection to the Benefits to Non-Inquiry Argument is that in allowing noninquiry beliefs it becomes far too permissive. It ends up licensing beliefs that are totally disconnected from inquiry beliefs and in some cases will license belief in propositions which are obviously false. In the example I offer above about Sally, her non-inquiry belief is still somewhat related to the inquiry belief in question. But consider the following example:

\section{Basketball Beliefs and Research}

Suppose Sally's non-inquiry belief is that 'Lebron James is the best basketball player of all time'. So $Q$ now represents a belief about Lebron James. Further suppose that it is this basketball belief which causes her inquiry belief about marijuana, $P$. Sally now encounters epistemic peer disagreement about $Q$. Perhaps her epistemic peer argues that either Michael Jordan or Bill Russell is the greatest basketball player of all time. If the Benefits to Non-Inquiry Argument is true, then Sally is rational to continue to believe $Q$ in the face of disagreement because her belief that $Q$ causes her belief that $P$. And there are epistemic benefits to be gained from believing $P$. But this is an absurd defense of $P$.

This example demonstrates the highly counterintuitive results of attempting to expand the Benefits

to Inquiry Arguments. As it stands, nothing is in place to preclude $Q$ from being completely 
disconnected from $P$. Likewise, nothing precludes $Q$ from being obviously false. Even if such beliefs are partly responsible for an agent's research beliefs it's bizarre to include them in the argument. For instance, consider the proposition, 'Kirk Lougheed is the best basketball player of all time'. This proposition is obviously false, but as it stands it appears that the Benefits to NonInquiry Argument would protect such a belief if it caused the relevant inquiry belief for Sally.

Given what we currently know, this objection successfully shows that the Benefits to Inquiry Argument cannot be expanded to include non-inquiry beliefs. Or more precisely, a lot more information about how belief formation occurs is required. There needs to be some principled way of bracketing off both beliefs that are extremely unrelated to the inquiry belief in question, and also beliefs that are obviously false. Perhaps future research in epistemology, psychology, and cognitive science will be able to help address this objection in a satisfying way, but for now this objection should make us weary of endorsing the Benefits to Non-Inquiry Argument. For the rest of this chapter I will explore the potential implications of the Benefits to Non-Inquiry Argument on the assumption that it turns out to be sound. But again I stress that I have not in fact successfully defended the argument.

\section{Non-Inquiry Beliefs, Different Cases of Disagreement, and Worldview}

In this section I explore one potential implication of the Benefits to Non-Inquiry Argument. If the argument turns out to be sound (which may be shown to be the case in the future), what would follow from this fact? The implication of the Benefits to Inquiry Argument I wish to discuss regards the distinction between simple and complex cases of disagreement. This is a distinction that I have stressed throughout this project. It turns out that including non-inquiry beliefs leads to the intuitively correct result with respect to the simple and more complex cases of disagreement. Disagreements about how much is owed on the bill, who is in the quad, and which horse won the 
race do not involve inquiry beliefs or non-inquiry beliefs that cause inquiry beliefs. So while such beliefs are clearly non-inquiry beliefs they do not fall within the subset of non-inquiry beliefs meant to be included in the Benefits to Non-Inquiry Argument. Hence, the simple cases do not fall within the scope of the argument, even when they include non-inquiry beliefs. Thus, even though the Benefits to Non-Inquiry Argument may defend non-conciliationism about certain non-inquiry beliefs, it does not for the beliefs in the simple cases of disagreement.

Disagreements between meteorologists and doctors, however, are different. First, it is less clear that these beliefs are non-inquiry beliefs. Meteorologists are essentially conducting weather research in order to make predictions. Doctors too, appear to be conducting a kind of research when trying to accurately diagnose a patient. Moral and religious disagreements perhaps do fall outside of a research context (assuming the disagreement is not between moral philosophers). But again, this yields the intuitively correct results when reflecting on the cases. Part of the lesson from the moral example was that it is unclear whether conciliation is required. So in a case where a researcher's inquiry beliefs were indeed caused (partly) by her moral non-inquiry beliefs, those beliefs would fall within the scope of the Benefits to Inquiry Argument. This is the intuitively correct assessment of the cases.

As argued earlier, disagreement about complex cases are more likely to be deeply connected to an agent's worldview. Complex disagreements about inquiry beliefs are often closely connected to an agent's worldview. Also complex disagreements about non-inquiry propositions are often closely connected to an agent's worldview and hence perhaps more likely to impact that agent's inquiry beliefs. As noted earlier, some of the complex disagreements really amount to disagreements between worldviews. This is the case with personal identity non-inquiry beliefs too. One topic I have yet to explore in detail is the nature of worldview disagreement: When an agent 
comes to realize that disagreement over $Q$ or $P$ depends upon broader worldview disagreement, what is the appropriate rational response? Presumably, a worldview disagreement implies that there is a large list of propositions two agents disagree about, rather than disagreement over an isolated proposition. Does the Benefits to Inquiry Argument still apply in such cases?

A worldview is made up of the core set of beliefs found in the centre of an agent's web of beliefs. There is a sense in which, if an agent's worldview were to change, then their identity would change. Suppose two agents who disagree about $Q$ or $P$ come to realize that these beliefs are near the centre of their respective web of beliefs. In other words, the belief that $Q$ or not- $Q$ is connected to many of their other beliefs. So in discovering a disagreement over one proposition the two opponents have really discovered that they disagree over a large set of propositions. Since there are so many beliefs in question and they are near the centre, it is best to understand this as a worldview disagreement. The Benefits to Inquiry Argument may still apply in such a case inasmuch as each of the beliefs in question are either inquiry beliefs or non-inquiry beliefs that cause inquiry beliefs for a researcher. I make no claims about the interrelatedness of beliefs in a case that amounts to a broader worldview disagreement. Presumably they will differ from individual to individual. Inasmuch as the conditions obtain then there is a sense in which the Benefits to Inquiry Argument may be able to justify remaining steadfast in the face of broader worldview disagreement.

\section{Conclusion}

In this chapter I examined the scope of the Benefits to Inquiry Argument by exploring possible defenses of the Benefits to Non-Inquiry Argument. Non-inquiry beliefs fall within the scope of the argument inasmuch as they cause inquiry beliefs held by agents in research contexts. As it stands, however, expanding the argument in this way leads to unwelcome results. It could be used to 
defend irrelevant or irrational beliefs. However, it remains possible that future advancements in epistemology, psychology, and cognitive science will make it rational to endorse the Benefits to Non-Inquiry Argument. Finally, the argument appears to yield the intuitively correct results when thinking about the differences between simple and complex cases of disagreement. 


\section{Chapter Eight: Worldview Disagreement}

\section{Introduction}

In this chapter I explore the nature of worldview disagreement: When an agent encounters epistemic peer disagreement over a proposition, and she subsequently comes to discover that she has a fundamental worldview disagreement with her opponent, what does rationality require of her? In such a case she has discovered that she disagrees with her opponent about many more beliefs than initially thought. Pointing out that a disagreement is a worldview disagreement is highlighting the fact that many more propositions are under dispute than what was initially thought when the disagreement was first discovered.

The concept of peerhood is somewhat problematized when applied to the nature of worldview disagreement. One might think that it is possible to be epistemic peers with an opponent when it comes to certain parts of one's worldview, but not to others. This fact might allow an agent to downgrade her opponent when it comes to a certain subset of beliefs under dispute. This strategy is, I think, consistent with my account of Sceptical Epistemic Peerhood, but this is not what I am interested in discussing in this chapter. Rather, I am interested in cases where two agents discover a disagreement they have about one proposition really amounts to a broader worldview disagreement about numerous propositions. In such cases there is no obvious way to extricate oneself from the sceptical threat of the disagreement (e.g. downgrading one's opponent in many

of the relevant disputed subject areas). How should the opponents respond to the discovery of worldview disagreement? In what follows I offer the Due Diligence Argument which purports to answer this question.

\section{The Due Diligence Argument}


I argue that an agent is obligated to re-evaluate her worldview when she encounters peer disagreement:

\section{The Due Diligence Argument:}

(1) If agent $S$ encounters epistemic peer disagreement over proposition $P$ and subsequently discovers that disagreement over $P$ entails a disagreement over her worldview $W$ (a set of propositions including $P$ ), then in order to rationally maintain $W$ she should examine whether $W$ is theoretically superior to the competing worldview. ${ }^{133}$

(2) If $S$ evaluates the theoretical virtues of $W$ then $S$ will get the benefit of better understanding and appreciating the epistemic status of $W .^{134}$

(3) S discovers an epistemic peer who believes not-P.

(4) S subsequently discovers that the disagreement about whether $P$ entails a disagreement between two competing worldviews $W$ and $W^{*}$.

Therefore,

(5) In order to rationally maintain $W$ she should examine whether $W$ is theoretically superior to $W^{*} \cdot{ }^{135}$

Therefore,

(6) $S$ needs to evaluate the theoretical virtues of $W$.

Therefore,

(7) $S$ will better understand and appreciate the epistemic status of $W$. [(2) and (6) MP]

I want to focus on the idea that disagreement will help an agent to better understand and appreciate the epistemic status of her own worldview. While this line of argument may be true with respect to individual propositions, it is particularly interesting to consider the benefits this can have with

${ }^{133}$ Simpson speculates that a similar principle may be true: [W] hen someone believes [a worldview W], she should evince a robust kind of personal commitment to [W]. This means being prepared to defend [W] by stating the case in [W's] favour, but it also means - perhaps more importantly - making it one's business to rebut the arguments and reasons that others adduce in their cases against [W]. When an individual [believes W], on this view, this makes her a committed stakeholder in the discourse about [W]. She cannot just think of herself as a spectator waiting to see how the case for or against [W] pans out and adjust her views as necessary (Simpson 2013, 570).

${ }^{134}$ Namely, its truth or falsity.

${ }^{135}$ Graham Oppy gave me the idea to formulate this in terms of worldviews. 
respect to worldview. If worldviews are understood as partly providing the agent with a metaphysical, epistemological, and moral framework by which to understand the world, then disagreement about a worldview can help enable an agent to have a more accurate picture of the world.

Notice that $P$ need not be a proposition about research or held in a research context. It is simply a proposition that is located near the centre of the agent's web of beliefs. It is interconnected to many other propositions and hence should be considered an important part of her worldview. When $\mathrm{S}$ encounters a peer who believes not- $P$ and subsequently discovers her peer's worldview is $W^{*}$ there now exists a disagreement between the truth of $W$ or $W^{*}$. Of course, this is not to say that two competing worldviews cannot agree about the truth value of many propositions. But the two worldviews cannot both be true in totality since they disagree about the truth value of proposition $P .^{136}$ In the real-life disagreements I am interested in, there will be numerous disagreements that are ultimately worldview disagreements. Finally, I do not deny that a worldview can contain certain doxastic attitudes that are not reducible to propositions. But in order to make meaningful evaluations the comparisons have to be between competing truth values of propositions. Notice that the Due Diligence Argument does not require that an agent necessarily modify her beliefs in the face of disagreement. But she does have an obligation to examine the theoretical virtues of $W$. This may or may not lead to a change in particular beliefs, enough of which may constitute a change in worldview.

The most promising way to understand worldview evaluation is by taking the best version of the worldview in question and subjecting it to objective criteria. Two peers always have different

${ }^{136}$ Since I am considering lists of propositions here it is possible that the rightness of a worldview can come in degrees. A worldview could be more accurate than another even if not every proposition it takes to be true is in fact true. 
bodies of evidence for their worldview. But from this it does not follow that their worldviews cannot be scrutinised using objective criteria. When a worldview disagreement occurs between two agents, they ought to consider the best idealized version of each worldview. This means using the best public evidence and reasons in support of the view in question. The best version of the worldview in question should be subjected to the evaluative criteria I outline later in this chapter.

Premise (1) is the first controversial premise. It is the consequent of (1) that warrants the most explanation in the argument. Why think that the rationality of $W$ depends on its theoretical virtues? I have two primary responses to this question. First, consider that worldviews are, at least in part, explanations of the features of the universe. Worldviews are comprehensive theories about the universe. They are theories of everything. For every (or almost all) facts in the universe, a worldview will have an explanation of the fact in question. ${ }^{137}$ Second, there could be other things required of $S$ in order to rationally maintain $W$. To my mind, understanding worldviews as theories is the simplest and most accurate way to compare competing worldviews. But I do not deny it might be necessary to employ other methods. Thus, I claim that examining the theoretical virtues of $W$ is necessary for the rationality of $W$, though perhaps not also sufficient.

The other controversial premise is (2). Why think that if $S$ evaluates $W$, she will better understand and appreciate the epistemic status of $W$ ? While (2) is not as controversial as (1), it does require further explanation. In the next section I motivate the argument by discussing its connection to the Benefits to Inquiry Argument. It will help to explain (2). I conclude by offering criteria for how an agent might evaluate worldviews which also explains (1).

\section{Motivating the Due Diligence Argument}

${ }^{137}$ The language of facts is possibly misleading. For instance, some worldviews will deny that there are any moral facts. But there is still the fact of the existence of certain moral intuitions that the worldview will have to explain. This will involve telling a story that accounts for the existence of moral intuitions while showing how this is consistent with there being no moral facts. 
There are interesting connections between the epistemic benefits of disagreement I have already discussed in this project and the Due Diligence Argument. As discussed in Chapter Five, there are important connections between my argument and Mill's political philosophy. I want to focus on Mill's idea that disagreement will help an agent to better understand and appreciate her own views. While this may be true with respect to individual propositions, it is particularly interesting to consider the benefits this can have with respect to worldviews. If worldviews are understood as encompassing the metaphysical, epistemological, and moral framework by which an agent understands the world, then disagreement about a worldview to the extent that provokes reflection will help an agent to have a sharper and more refined picture of the world.

There are different reasons that show why these considerations are distinct from those already discussed in relation to the Benefits to Inquiry Argument. There is no explicit or formal connection to inquiry beliefs or research environments. While reflecting on one's worldview is perhaps a type of informal research, it is not research in the sense relevant to the Benefits to Inquiry Argument. However, because there is research (if only informal research) and epistemic assessment occurring, the benefits associated with worldview evaluation do not run into the same problems I mentioned associated with the Benefits to Non-Inquiry Argument. Likewise, the agent in question who is examining her worldview is not necessarily going to make discoveries about the truth value of a specific proposition $P$ in the future. Likewise, she might not get the benefit of believing true propositions in addition to $P$ in the future. Rather, if she examines her worldview and becomes either more or less confident in the truth of her worldview, then this presumably amounts to an epistemic benefit. ${ }^{138}$ After evaluating her worldview, in some cases the agent in question will be rationally required to change her entire worldview. Presumably, this constitutes changing a number

${ }^{138}$ This is easy to see if one thinks of beliefs as coming in credences. 
of beliefs near the centre of her web of beliefs, and hence beliefs that are essential to whatever worldview she holds. None of this is inconsistent with the Benefits to Inquiry Argument, but the focus on worldview adds a different, broader, dimension to the ideas discussed thus far.

Recall the Giving Up Principle: An agent is irrational to continue to believe proposition $P$ when reasons she is aware of ought to convince her that her belief in $P$ is mistaken. While I have argued that GUP is true, one worry I discussed is that its specific application is vague. It might be true, but knowing when it applies to a particular proposition may prove to be quite difficult. Of course, connected to this problem is the related worry that the Benefits to Inquiry Argument could be employed to license irrational dogmatism. While I addressed these objections in Chapters Five and Six, one advantage of the Due Diligence Argument is that its application is less vague than the Giving Up Principle. This is because it is easier to provide a set of criteria for worldview evaluation than it is to provide criteria for evaluating isolated propositions. My claim here is not that such criteria are beyond scrutiny, but merely that they are more readily available with respect to worldviews. Also notice that the Due Diligence Argument is consistent with the intuitive responses to the various cases of disagreement mentioned throughout this project. For instance, the Due Diligence Argument may mandate revision in Moral Disagreement and Religious Disagreement, but only after an extensive evaluative process which is not required in the simple cases of disagreement. In what follows I offer some criteria by which an agent can evaluate her worldview and hence an explanation of premise (1) of the Due Diligence Argument.

\section{The Criteria for Worldview Evaluation}

The criteria discussed in this section are not intended to be comprehensive. Rather, they are intended to show why it is more reasonable to pursue worldview evaluation as opposed to evaluating an individual proposition. All of the criteria I list here only give a worldview an 
epistemic advantage over a competing worldview if all else is equal between the worldviews in question.

\section{External Coherence}

External coherence is about how well a worldview coheres with the most up-to-date scientific knowledge (Vidal 2012, 319). Fit with scientific knowledge can be parsed out in many ways, including but not limited to, explanatory scope, fit with current data, simplicity, internal consistency, and predictive power. I will say more about some of these below. ${ }^{139}$

\section{Internal Coherence}

Internal coherence is about how well the propositions within a worldview cohere with one another. If it could be demonstrated that a worldview is logically inconsistent, then one would be irrational to continue to believe the worldview in question. ${ }^{140}$ But logical inconsistency is rarely, if ever, shown to explicitly apply to worldviews. It is more common that tensions exist between particular propositions within a worldview, as opposed to outright logical contradictions.

\section{Explanatory Scope}

The more phenomena that a worldview can explain, the better. All else being equal, a superior worldview will explain more than its competitors. Explanatory scope can be all encompassing or subdivided into different areas. In other words, one worldview might do better at explaining one set of data, but worse than another at explaining a different set of data. All else being equal, the worldview that provides correct explanations on the most topics should be considered superior with respect to explanatory scope. All else will not be equal if certain topics are more important

139 Lovering notes that some common worldview evaluative standards include "logical coherence, selfreferential coherence, simplicity, explanatory power, uniformity (treating like cases alike), comprehensiveness, and parsimony" Lovering 2001, 113.

${ }^{140}$ This is disputed by paraconsistency advocates (e.g. Graham Priest). Some have also objected to coherentist theories of justification on the basis that logical consistency is actually too high a standard to meet. 
than others. Thus, simply tallying the total number of topics each worldview can explain better than its competitors will not necessarily provide the most accurate results. ${ }^{141}$

\section{Fit with current values}

Some worldviews will fit better than others with the current values that exist about the world. ${ }^{142}$

\section{Simplicity}

Simplicity is a theoretical virtue and different worldviews vary in their complexity. There are different types of simplicity, including "descriptive simplicity (how easy it is to state the theory), simplicity of hypotheses, inductive simplicity (e.g. using 'straight rules', or some such), simplicity of postulated laws, formal simplicity, and so on..." (Nolan 1997, 329). As part of simplicity qualitative parsimony is often considered a theoretical virtue. Qualitative parsimony refers to the number of kinds of entities that a theory postulates to explain various phenomena. More controversially, quantitative parsimony might also be considered a virtue. This is the idea that it is better - all else being equal - to postulate a fewer number of entities themselves as part of an explanation (Nolan 1997, 330).

\section{Predictive Power}

A superior worldview will have better predictive power than its competitors.

\section{Additional Criteria}

The initial description of the objective criteria emphasised fit of the worldview with current scientific knowledge. But the objective criteria be broadened in scope. It could plausibly include how well the worldview fits with both empirical facts and non-empirical facts. Discussion of disagreement naturally tends to highlight the differences between worldviews. But there is actually

much more agreement between many competing worldviews than disagreement. The

${ }^{141}$ Graham Oppy brought this distinction to my attention.

142 This will matter a lot to realists about value. 
disagreements are highlighted because they are discussed more than topics of agreement. But there is widespread agreement about many non-empirical facts. How a worldview explains and fits with these non-empirical facts is just as important as how it fits with empirical facts. Consider that it is a non-empirical fact that certain things exist such as: evil, goodness, pain, pleasure, beauty, love. ${ }^{143}$ Certain worldviews will better explain the existence of these facts than others.

\section{Objections to Worldview Evaluation}

\section{Different Epistemic Perspectives}

Lo Guercio argues that in cases of complex disagreement, an agent need not conciliate because she likely has a different epistemic perspective than that of her opponent. Epistemic perspectives include "the faces, the evidence, the relative weight of that evidence, [and] the relevant epistemic goals" (Lo Guercio 2012, 466). He suggests that it is impossible to adjudicate between epistemic perspectives because it is impossible to be outside of any particular perspective.

\section{Reply:}

Inasmuch as there is agreement about how to evaluate two competing worldviews, this objection is not troublesome. I do not deny that different worldviews will have different approaches to what constitutes evidence and how it ought to be evaluated. Yet agents with different worldviews are able to discuss evidence and reasons with those with whom they disagree. There is often enough agreement between different worldviews to be able to make meaningful judgments and comparisons. For instance, it is true that opponents might dispute what counts as superior fit with data, predictive power, or the simplest explanation. But debating the application of these criteria is part of the very process of evaluating different worldviews. In most cases of worldview

\footnotetext{
${ }^{143}$ It is impossible to create a list that will be uncontroversial amongst philosophers. Still, if one is a realist about any other domain outside of science they will have to admit non-empirical facts into their ontology.
} 
disagreement, two parties to a dispute can agree on enough regarding what constitutes evaluative criteria and their application in order to make progress on the evaluation.

\section{Worldviews are too complex}

The project of defining a worldview, let alone evaluating one, is so enormous and complicated that it is unhelpful to shift the disagreement debate from propositions to worldview. Even if it is true that disagreements over certain propositions amount to worldview disagreements, it is of no practical use to shift the debate to worldviews. This is part of the reason why the epistemology of disagreement literature focuses on disagreement about individual propositions.

Reply:

It is true that moving the epistemology of disagreement toward worldviews makes matters more complicated. But the simple cases will not help to advance our understanding of how to treat cases of real-world disagreement.

\section{Is the idea of competing worldviews coherent?}

If worldviews are conceptual schemes, it could be argued that the notion of worldview is incoherent. Donald Davidson notes that:

In order to make sense of the possibility of an alleged alternative conceptual scheme, one would have to know that such a scheme existed. Yet to know this would require successful translation of at least some items from the alternative scheme into one's own. But... insofar as successful translation is possible between two conceptual schemes, the one conceptual scheme cannot be considered a genuine alternative to the other. That is, if one could distinguish one conceptual scheme from another, one would need to know what the other comprised, but if one did know this it would be part (or rendered a part) of one's own conceptual scheme, it would not be a genuine alternative conceptual scheme. Simply (and paradoxically) put, in order for the view that there is a plurality of conceptual schemes to be true, it must be false. This being the case, such

a position is self-referentially incoherent (Davidson quoted in Lovering 2001, 143). ${ }^{144}$

\section{Reply:}

${ }^{144}$ See also Davidson 1973. 
This might demonstrate that the notion of multiple conceptual schemes is self-referentially incoherent, but not that the very idea of a conceptual scheme is incoherent (Lovering 2001, 144). More needs to be said here regarding the coherence of multiple conceptual schemes. Depending on how one defines worldview or conceptual scheme there may be no theoretical limit to how many worldviews that could exist.

Likewise, I have understood worldviews as (minimally) sets of propositions. Suppose that a worldview consists of asserting a truth claim about every possible proposition. For any propositions, then, a particular worldview will assert that the proposition is true or false. ${ }^{145}$ Two different worldviews will necessarily disagree on the truth value of certain propositions, otherwise they would be same the worldview. But since they disagree, the set of propositions they affirm as true (or false) is different from one another. Thus, overlap and agreement between two worldviews about a number of propositions does not imply that they are identical worldviews overall. Donaldson fails to appreciate this point.

\section{Worldviews Cannot be Evaluated from the Outside}

Nicholas Wolterstorff explains that worldviews serve to regulate beliefs in two ways:

(1) Because we hold them we are led to reject certain sorts of theories - some because they are inconsistent with those beliefs; others because, though consistent with those beliefs, they do not comport well with those beliefs.

(2) Control beliefs lead us to devise theories. We want theories that are consistent with our control beliefs. Or, to put it more stringently, we want theories that comport as well as possible with those beliefs (Wolterstorff quoted in Lovering 2001, 33).

According to Lovering:

Given the view, then, that worldviews function as regulative beliefs and, thus, that experience is theory-laden, one is faced with a potentially unsavory conclusion regarding philosophical investigations and, in particular, worldview debate: not only does one's worldview determine what one considers to be an acceptable fact, theory, method, goal, problem, and semantic, one's worldview also determines what one will

${ }^{145}$ Or perhaps also unsure, agnostic, or indifferent, etc. 
consider an acceptable argument and/or item of evidence for any given position (Lovering 2001, 38).

If this is correct, then the way I have been employing worldview could entail conceptual relativism. If conceptual relativism faces similar philosophical challenges to other varieties of relativism, then this is a serious objection to the Due Diligence Argument. ${ }^{146}$ In sum, Lovering suggests that:

[A]ccording to the conceptual relativist, since it is logically impossible for us to step outside of every conceptual scheme, we are unable to pass judgment on other conceptual schemes without using our own. We cannot say what the facts are, we cannot apprehend and describe reality, independent of all conceptual choices (Lovering 2001, 105).

Both Rudolf Carnap and Hilary Putnam argue that conceptual relativism entails ontological relativism (Lovering 2001, 108). They suggest that existence is not possible without a conceptual framework (i.e. a worldview). Conceptual relativism entails a vicious circularity when one attempts to evaluate or argue in favour of one's worldview. Thus, “when arguing for one's view of reality, one starts and finishes with one's conceptual scheme, hence the circular justification" (Lovering 2001, 116). If conceptual relativism is correct with respect to worldviews, then a worldview cannot be subject to objective defeaters. A worldview could never be considered objectively theoretically better or worse than any other worldview. Worldviews can only be evaluated from within (Lovering 2001, 122). Part of what motivates this objection is the idea that worldviews, as described in this chapter, are similar to Thomas Kuhn's notion of paradigm. Lovering explains that for Kuhn:

$[\mathrm{P}]$ aradigms consist of a set of concepts and hypotheses such that, once a scientist adopts a paradigm, she can only perceive and understand the world in terms of it; that is, paradigms serve as the backdrop against which scientists interpret and understand the world. While worldviews consist of patterns or arrangements of concepts that enable us to make sense of the world. [That is] without paradigms, it would not be

\footnotetext{
146 Paul Moser writes: Different people can, and sometimes do, adopt different specific notions of justification and use those different notions in explaining, evaluating, and arguing for claims. [Conceptual relativism] is about the adoption and the use of specific notions in explanatory, evaluative, argumentative contexts (Moser quoted in Lovering 2001, 104).
} 
possible to investigate the world for the sake of science, for such an investigation would be rendered unintelligible. Similarly, it is said that without worldviews one could not make sense of one's experience. That is, it is only against the background of a worldview that one's experience is rendered intelligible. Thus, like paradigms, worldviews are necessary for investigating the world (Lovering 2001, 72-73).

For Kuhn, paradigms are incommensurate and each contains its own set of empirical data. A paradigm determines what exists and hence each paradigm states what counts as a problem and adequate solution (Lovering 2001, 77). Therefore, "we can picture individuals of different worldviews living on different 'planets', solving different problems, providing solutions in their own distinctive terms, and describing and recording them in their own languages" (Lovering 2001, 79). ${ }^{147}$

Reply:

Experience can lead us to change or give up a worldview. It is, however, an open question how much experience factors into regulating one's worldview (Lovering 2001, 41-42). If what an agent sees as data, evidence, methods, goals, solutions, etc., is worldview dependent, then, provided that agent's worldview is internally consistent, it is reasonable to continue to hold that worldview, even in the face of peer disagreement. If independent criteria for worldview evaluation are impossible, then worldview disagreement cannot threaten the rationality of an agent's worldview. This solution is far from ideal, however, because of the many philosophical problems associated with conceptual relativism. For example, the fact that there is a strong intuitive pull to think that some worldviews are superior to others is reason in itself to be sceptical about the impossibility of objective or worldview-independent evaluative standards. ${ }^{148}$

${ }^{147}$ Lovering believes that while Kuhn seeks to avoid conceptual relativism, many think that his account cannot avoid it. Here I assume that at the least Kuhn's ideas can be used to support conceptual relativism with regards to worldviews.

${ }^{148}$ Or weaker still, a set of evaluative standards that many worldviews will agree upon. 
John Searle argues that if conceptual relativism is true then communication - let alone disagreement - is impossible (Lovering 2001, 127). Lovering explains that:

If disagreement is to be understood as a difference in view of 'the way things really are,' then conceptual relativism seems to preclude the possibility of interconceptual scheme disagreement and argumentation. Thus, if conceptual relativism is the 'correct' position, 'it is not only impossible in principle to resolve fundamental disagreement, it is impossible even to formulate it.' If there are no conceptual scheme-independent standards in terms of which we can judge between alternate conceptual schemes, i.e., if conceptual relativism is 'true', then public communication, disagreement, and argumentation between conceptual schemes is in principle impossible... Thus, if conceptual relativism is true, then the Christian theist and the Naturalist cannot communicate with each other, much less disagree and argue with each other (Lovering 2001, 127).

Thus, "if public communication, disagreement, and argumentation are to be possible, there must be conceptual scheme-independent standards in terms of which we can judge between alternative worldviews" (Lovering 2001, 128). And because such communication and argumentation is obviously possible, conceptual relativism cannot be true.

This response involves a modified version of conceptual relativism that is compatible with the existence of worldview independent standards. The benefit of this view is that the regulative element of a worldview can remain intact. This response draws a distinction between institutional facts and brute facts. Institutional facts are made by human agreement. Brute facts exist independently of human agreement (Lovering 2001, 132). ${ }^{149}$ Lovering says that:

According to Searle, true representations of the world correspond to facts. Some representations correspond to brute facts, some to institutional facts. Those that correspond to brute facts may be understood in terms of absolutism. Those that correspond to institutional facts may be understood in terms of conceptual relativism (Lovering 2001, 132-133).

${ }^{149}$ See also Searle 1995. 
Thus, for example, 'this piece of paper exists' is a brute fact, but 'this piece of paper is a five dollar bill' is an institutional fact (Lovering 2001, 133). A system of representation, or a worldview, is conventional in the sense that there are multiple ways to divide up the world. Searle says that:

Because any true description of the world will always be made within some vocabulary, some system of concepts, conceptual relativity has the consequence that any true description is always made relative to some system of concepts that we have more or less arbitrarily selected for describing the world. [This need not conflict with the claim that there are objective standards by which to assess worldviews because f]rom the fact that our knowledge/conception/picture of reality is constructed by human brains in human interactions, it does not follow that the reality of which we have the knowledge/conception/picture is constructed by human brains in human interactions (Searle quoted in Lovering 2001, 134).

What I take to be the most promising reply to this objection is that the charge of conceptual relativism appears to underappreciate the shared features across worldviews. This includes both institutional facts and brute facts. The conceptual relativist wrongly downplays the widespread agreement across worldviews. For example, the objection focuses on all of the differences between two parties and points out that there is no way for an agent to get beyond her own worldview to objective standards. What I am suggesting here is that even if everyone is conceptually bound by their worldview, there is actually widespread agreement on a great number of topics across worldviews. This agreement points to the fact that there are some objective standards by which to evaluate worldviews. Or, at the very least, there are standards that everyone can agree on, even if they are not 'objective' in the sense of being independent of any and all worldviews.

Consider a common case of worldview disagreement that occurs frequently among contemporary Western philosophers. This is the case of worldview disagreement between the naturalist and the theist. It turns out that the theist and naturalist actually agree on a whole host of facts. The theist and naturalist could agree on almost every current piece of scientific knowledge. Many theists and naturalists both agree on what counts as scientific data and what makes a good 
scientific theory, etc. They might offer different explanations as to why science can presuppose the universe is structured, or about the cause of the universe, but on almost everything else they agree. Of course, a topic like the cause of the universe is a point of contention between many naturalists and theists, and hence I suspect that it becomes a focal point, rather than the many facts over which they agree.

Consider also the realm of ethics. At first glance, one might wonder whether the theist and naturalist will agree on much of anything regarding ethics. But again, this line of reasoning only focuses on the disagreement, not on the agreement between the two worldviews. Consider the claim 'rape is morally wrong'. Theists and naturalists will agree that this is an ethical fact of some kind. They may have different ways of explaining what it is precisely that makes it an ethical fact, but nevertheless agree that rape is morally wrong. While this discussion is quite brief, the point is that the charge of conceptual relativism wrongly focuses on the disagreement across worldviews, without focusing on the widespread agreement that exists between most worldviews. The widespread agreement points to the fact that there are objective, worldview independent standards by which to objectively evaluate worldviews, or at least that there are standards of evaluation that all worldviews can agree upon.

\section{Worldview Disagreement and Deep Disagreement}

The epistemology of disagreement literature has mostly operated separately from work focusing on deep disagreement. ${ }^{150}$ The concept of deep disagreement arises in Wittgenstein's On Certainty where he argues that disagreements are deep when they are over hinge commitments and are not subject to rational resolution (or rational discourse, for that matter). Robert Fogelin's 1985 paper,

${ }^{150}$ Notable exceptions include a recent issue of Topoi focuses on bringing these two topics into discussion with one another. 
“The Logic of Deep Disagreements," is sympathetic to Wittgenstein's approach and generated much of the contemporary discussion on the nature of deep disagreements.

In this project I have stayed with contemporary orthodoxy in keeping my discussion about the epistemology of disagreement distinct from deep disagreements. However, this chapter clearly brings the two topics together. This is because at times my reference to worldview disagreement appears to be quite close to what many refer to as deep disagreements. So, it is a relevant question just how similar these two topics are to one another. The answer to this question will help show whether the Due Diligence Argument can be applied to deep disagreement.

Elsewhere, I apply the Benefits to Inquiry Argument to deep disagreement (Lougheed 2018). I argue that there are epistemic benefits to be gained from deep disagreement in much the same way that there are epistemic benefits to be gained from disagreement over particular propositions, at least within certain contexts. But I specifically avoid the question of whether deep disagreements are subject to rational resolution. There are, however, different understandings of deep disagreements. And the Due Diligence Argument's applicability to deep disagreements changes depending on how one understands the nature of deep disagreement. In this section I do not intend to fully settle the issue of how to understand deep disagreements and whether my arguments can be applied to them (as opposed to side-stepping the issue as I do in Lougheed 2018). Rather, I will explain two different conceptions of deep disagreement (Wittgensteinian theory and fundamental epistemic principle theory) and explore how they fare in application to my argument. This section is thus intended as exploratory. ${ }^{151}$

\section{Wittgensteinian theory}

${ }^{151}$ I gathered much of the information for this section from Ranalli (forthcoming). 
I do not claim that the following account captures Wittgenstein's own view about deep disagreements precisely. I do not wish to wade into interpretive issues regarding On Certainty in particular, and the later Wittgenstein more broadly. ${ }^{152}$ I take the Wittgensteinian theory of deep disagreement to represent a cluster of similar views (Fogelin 2005; Hazlett 2014; Godden and Brenner 2010). The Wittgensteinian theory of deep disagreements says that a disagreement is deep when it is over a hinge proposition. ${ }^{153}$ Chris Ranalli explains that "hinge commitments are the background presuppositions of our world views and general areas of inquiry, such as physics, history, or geology" (forthcoming). According to Crispin Wright they are:

'unearned certainties' or 'standing certainties' - certainties one brings to any normal context... It is the idea of a 'hinge' proposition as a kind of 'certainty of methodology', as it were-a proposition a doubt about which would somehow commit one to doubting not just particular beliefs which we already hold but aspects of the way we habitually praise beliefs. (Wright quoted in Ranalli forthcoming).

Duncan Pritchard explains that "the suggestion is that the very possibility that one belief can count as a reason for or against another belief presupposes that there are some beliefs which play the role of being exempt from needing epistemic support" (Pritchard quoted in Ranalli forthcoming). It is these exempt beliefs that are hinge propositions. A main worry for the Wittgensteinian theory of deep disagreement is to explain why disagreement about hinge commitments is not subject to rational resolution. Or, the theory needs at least to explain why rational evaluation is more difficult than assessing any ordinary 'whole system' of interconnected (non-hinge) propositions (Ranalli forthcoming).

There are two main theories of hinge commitments which dictate different answers to the question of whether deep disagreements are subject to rational resolution. ${ }^{154}$ The first is the non-

${ }^{152}$ For more on these interpretative issues see Pritchard 2011.

${ }^{153}$ See Prichard 2016a, b for more on hinge propositions.

${ }^{154}$ For my purposes I use 'hinge propositions' and 'hinge commitments' interchangeably. 
epistemic theory which says that "hinge commitments are outside the scope of rational evaluation, and as such are neither justified nor unjustified" (Ranalli forthcoming). ${ }^{155}$ If this view is correct then deep disagreements are not resolvable. The Wittgensteinian theory which embraces the nonepistemic theory of hinge commitments is clearly incompatible with the Due Diligence Argument that I have defended in this chapter. This is because my project is within the context of epistemic justification. Peer disagreement constitutes a possible epistemic defeater for belief. The arguments I have offered are intended to show how one could be epistemically justified in light of that defeater. Thus, any theory of worldview disagreement which says that such disagreements are really about non-epistemic hinge commitments is incompatible with my project. Again, I am not attempting to evaluate the non-epistemic theory. I am merely observing that it is incompatible with my project.

The second theory of hinge commitments is the epistemic theory which says that "hinge commitments are within the scope of rational evaluation, and are potentially justified or unjustified, but in a non-paradigmatic way. In particular, our justification for hinge commitments consists in having a default entitlement to trust or accept them, in the absence of evidence or anything which indicates that they're true" (Ranalli, forthcoming). ${ }^{156}$ Ranalli argues that on this view it is less clear whether deep disagreements can be subject to rational resolution. He explains that:

On the one hand, they won't be able to exchange reasons in the ordinary sense, since they will lack evidence - or in general, anything which favors the truth of their hinge commitment - which rationally ought to get them to retain or change their attitude. On the other hand, the theory permits that there is some degree of rational support for hinge commitments by way of a default non-evidential entitlement to trust them. Provided that one can exchange this non-evidential rational support then there will be a sense in which disputants can rationally resolve their deep disagreements, namely,

${ }^{155}$ For defenses of this view see Prichard 2016; Moyal-Sharrock 2016, 2004

${ }^{156}$ For defenses of this view see Wright 2004b, 2014; Hazlett 2014b; Williams 1991. 
by appealing to the hinge commitments that they are mutually entitled to trust (forthcoming).

While this position is interesting in explaining how deep disagreements might be subject to rational resolution, this conception also does not easily apply to my project. For consider that Ranalli explains that:

[W]hile hinge commitments are justifiable on this account - and thus inside the space of epistemic reasons - it is not by way of evidence or anything which indicates that the hinge commitments are true. But cases of deep disagreement seem to be ones in which the disputants present what strikes them as evidence for their beliefs and evidence against their opponent's beliefs (Ranalli, forthcoming).

My project falls squarely within evidentialism. The beliefs in question which are challenged by the existence of peer disagreement are assumed to be evidentially well-supported prior to the parties discovering their disagreement. The believers have evaluated first-order reasons and arrived at doxastic attitudes in light of those reasons. The discovery of disagreement is additional higher-order evidence. It is therefore difficult to see how any non-epistemic (i.e. non-evidential) theory of hinge commitments could be consistent with any of my arguments. Thus, the Wittgensteinian theory of deep disagreements is, when taken to be representative of worldview disagreements, entirely incompatible with my project.

\section{The Fundamental Epistemic Principle Theory}

The other main competing theory of deep disagreements is what Ranalli refers to as the Fundamental Epistemic Principle Theory. On this view, "deep disagreements are disagreements over fundamental epistemic principles" (forthcoming). Something counts as a fundamental epistemic principle if it "can't be shown to be true without employing the source that the relevant principle endorses is reliable. For this reason, explicit defenses of such principles will always be subject to a charge of circularity" (Lynch 2016, 250 quoted in Ranalli forthcoming). Ordinary 
beliefs based on sense perception are a standard example. For such beliefs cannot be justified without appeal to sense perception (Ranalli forthcoming). ${ }^{157}$

Ranalli observes a number of problems with the fundamental epistemic principle theory, including the main worry that the theory is too conservative. He writes that "it will only count disagreements over or grounded in fundamental epistemic principles as deep, but this seems to discount clear cases of deep moral and deep metaphysical disagreement, where fundamental epistemic principles aren't obviously involved" (Ranalli forthcoming). It seems as if there can be deep disagreements about moral matters, such as whether persons have moral status or murder is wrong. Yet if deep disagreement can only be about epistemic matters then such disagreements are not really deep. However, if such beliefs are held for epistemic reasons, then moral disagreement may reduce to epistemic disagreement. Ranalli observes that one way around these sorts of worries is to say that deep disagreements are disagreements over fundamental normative principles (forthcoming). There are two problems with this view. The first is that the criteria for what constitutes a fundamental normative principle probably cannot be circular, since some normative principles are merely taken as self-evident. The second is that this theory says little about nonnormative metaphysical disagreements (Ranalli forthcoming).

On the surface, the fundamental epistemic theory of deep disagreements appears to be more compatible with my Due Diligence Argument. Yet it is clear that many of the propositions I have in mind are not only justified via circular reasoning. Many beliefs which seem very important to one's worldview are not fundamental in this sense. Indeed, it is difficult to see how the Due Diligence Argument could be applied to beliefs only justified via circular reasoning. If what is

${ }^{157}$ Likewise, Kappel says that "the best epistemic reasons for it are epistemically circular" (Kappel quoted in Ranalli forthcoming) 
essential to one's worldview (i.e. required for deep disagreement) are beliefs justified via circular reasoning, then this view is incompatible with my arguments, and indeed with how I've described worldviews throughout this project. I need not deny that there are beliefs in one's worldview (partly) not believed for epistemic reasons. Indeed, to deny this seems to deny a truism. Yet my project is only concerned with those beliefs that are (or could be) believed for epistemic reasons. Anything outside of this is well beyond the scope of my project. It is thus not entirely clear that the fundamental epistemic principle theory is compatible with my thesis either.

\section{Conclusion}

In this chapter I offered the Due Diligence Argument. When it is discovered that a disagreement over one proposition amounts to a disagreement between worldviews, an agent should re-evaluate her own worldview. Doing so will help an agent to better understand and appreciate her worldview. This method yields the correct results in the different cases of disagreements, since the Due Diligence Argument will not be available in the simple cases. There is enough agreement between different worldviews to establish a set of criteria which can be used to evaluate them. This evaluation is certainly difficult, and much more complicated than evaluating isolated propositions in simple cases of disagreement, but it is the most promising way forward with respect to making progress regarding cases of real-world disagreements. 


\section{Chapter Nine: Disagreement and Change of View}

\section{Introduction}

In this final chapter I address a major concern for all of the arguments and themes I have presented throughout this project. The worry is that what I have said will, if true, license an irrational dogmatism by allowing an agent to remain steadfast in her beliefs by appealing to some vague notion of potential future epistemic benefits. I conclude the project by discussing this worry within the context of intellectual humility and competing epistemic values. My discussion will shed light on the appropriate conclusions to draw about the scope and strength of my arguments. I will also note some of the similarities between my view and two dynamic responses to disagreement, Thomas Kelly's 'Total Evidence View' and Jennifer Lackey's 'Justificationist View'. I then respond to one last objection, which is that even if the Due Diligence Argument is sound, its conclusion is trivial.

\section{Intellectual Humility as an Objection}

\section{The objection}

A significant worry for the Benefits to Inquiry Argument, the Benefits to Non-Inquiry Argument, and the Due Diligence Argument is that they might license an unthinking dogmatism which allows an agent to never adjust her beliefs in the face of disagreement. While I responded to this worry throughout the project in discussing GUP, in this section and the next I will make two final comments about this objection. The first is that it could be that my project runs contrary to intellectual humility. This is problematic inasmuch as intellectual humility turns out to be an important feature for any successful epistemic agent to possess. ${ }^{158}$ To discover whether this worry has any merit it is necessary to gain a more precise understanding of intellectual humility. Thus,

${ }^{158}$ By successful epistemic agent I mean one who achieves positive veritistic ends. 
in what follows I explore a canonical account of intellectual humility offered by Robert C. Roberts

and W. Jay Wood (2007). ${ }^{159}$ The second is that there are different competing epistemic values. The application of GUP will be effected by what set of epistemic values one happens to adopt.

\section{Ideal Epistemic Agents}

Robert C. Roberts and W. Jay Wood explain that an ideal epistemic agent will possess certain "dispositional properties that tend to the moral but make people better or worse epistemic agents" (Roberts and Wood 2007, 258). ${ }^{160}$ They suggest that one of the very important properties of an ideal epistemic agent is intellectual humility. Roberts and Wood claim that intellectual humility is closely related to moral humility. And moral humility is most easily described as the opposite of certain moral vices. Thus, intellectual humility is best understood in contrast to certain moral vices. Roberts and Wood explain that "[h]umility is [the] opposite [of] a number of vices, including arrogance, vanity, conceit, egotism, grandiosity, pretentiousness, snobbishness, impertinence (presumption), haughtiness, self-righteousness, domination, selfish ambition, and selfcomplacency" (Roberts and Wood 2007, 258). All of these amount to an improper pride. The more precise worry, then, is that the Due Diligence Argument runs contrary to intellectual humility, and hence justifies agents in exhibiting these vices. In the following section I explore Roberts and Wood's analysis of humility in more detail by examining their focus on the vices of vanity and arrogance. ${ }^{161}$

${ }^{159}$ It might appear too recent to refer to this account as canonical, but it seems to already have become a standard reference point for thinking about intellectual humility.

${ }^{160}$ By 'tend to the moral' I take them to mean tend to make one morally good.

${ }^{161}$ Of the other vices mentioned they say: Conceit is the dispositions of thought, action, and emotion that stem from an unwarrantedly high opinion of oneself. Egotism is a disposition to exaggerate the importance of, and focus attention on, oneself and one's own interests, to the neglect of others and their interests. Grandiosity is a disposition, in thought and self-presentation, to exaggerate one's greatness. Pretentiousness is a disposition to claim, in action and demeanour, higher dignity or merit than one possesses. Snobbishness is a disposition to associate oneself, in thought and practice, with persons of high social rank, intellect, or taste, and to shun... persons of lower rank. Impertinence or presumption is a disposition to act without proper respect for the limits of one's competence or social station. Haughtiness is a disposition to treat others as hardly worthy of one's attention or respect. Self-righteousness 


\section{Vanity}

According to Roberts and Wood:

Vanity is an excessive concern to be well regarded by other people, and thus a hypersensitivity to the view others take of oneself. Its emotional marks are anxiety about how one appears, joy at making a good appearance, embarrassment or shame at making a bad appearance, resentment of those who criticize or withhold the prescribed admiration, etc. (Roberts and Wood 2007, 259).

Vanity involves the desire to make a good appearance in order to gain positive social status. Gaining the approval of specific persons gives the agent in question value. The vain person obsesses over this approval. On the other hand, "[h]umility, as vanity's opposite, is a striking or unusual unconcern to be well regarded by others, and thus a kind of emotional insensitivity to the issues of status" (Roberts and Wood 2007, 261). This does not imply the humble person is selfeffacing, she simply lacks anxiety about how she appears to other people. Roberts and Wood believe that this obsession with status can have negative epistemic costs. The humble person, thus, will not experience interference from this obsession (Roberts and Wood 2007, 262-263).

\section{Arrogance}

According to Roberts and Wood '[a]rrogance is a disposition to 'infer' some illicit entitlement claim from a supposition of one's superiority, and to think, act, and feel on the basis of that claim" (Roberts and Wood 2007, 265). This amounts to an agent forming incorrect beliefs about being superior. A humble person could want the very same things as an arrogant person and yet not think that she is entitled to those things. The unarrogant person may be just as aware of her entitlements as any other person but is simply not focused on them. She will probably be more focused on some

is a disposition to ascribe to oneself a greater moral excellence than one possesses, especially in acts of comparing oneself with others. Domination is a disposition to excessive exertion and enjoyment of control over others. Selfish ambition is a disposition to advance one's own long-term interests to the exclusions or detriment of others' interests. Self-complacency is a disposition to approve uncritically of one's own abilities and accomplishments. Most of these vices have intellectual variants (Roberts and Wood 2007, 258-259). 
more "noble concern - typically for something outside himself like the health of the community, the excellence of the music, the truth of philosophical claims" (Roberts and Wood 2007, 267).

\section{Intellectual Humility}

After analyzing intellectual humility as the opposite of certain vices, Roberts and Wood conclude with a positive account of intellectual humility. They argue that there are certain epistemic goods that an agent is more likely to obtain if she is intellectually humble. ${ }^{162}$ While not necessarily true in every instance of humility, they claim that "over the long run, just about everybody will be epistemically better off for having, and having associates who have, epistemic humility" (Roberts and Wood 2007, 271-272). They propose that:

The humility that is the opposite of intellectual vanity and arrogance has the primarily negative role of preventing or circumventing certain obstacles to acquiring, refining, and transmitting knowledge. Vanity and arrogance are epistemic liabilities with which most people are somewhat beset, and the intellectually humble person stands out in his or her freedom from these impediments (Roberts and Wood 2007, 272).

Epistemic humility is ideal for pursuing epistemic goods especially in social settings. That is, "[e]pistemic humility seems to promote these processes in two dimensions: in the epistemic functioning of the individual who possesses the virtue, and in the functioning of the social context with which he or she is interacting - colleagues, teachers, and pupils" (Roberts and Wood 2007, 272). A vain person will be less willing to admit when someone has a good objection to her view. She is an intellectual liability because she is concerned with how she appears to others. Since the humble person does not care about this she has one less obstacle to overcome in her pursuit of knowledge (or other relevant epistemic good). Interestingly, Roberts and Wood note that the "humble person will be free to test his ideas against the strongest objections. His humility may

${ }^{162}$ I use epistemic humility and intellectual humility interchangeably. 
also make for intellectual adventure: he will not be afraid to try out ideas that others may ridicule (here, if one lacks humility, courage may be a substitute)" (Roberts and Wood 2007, 272).

A vain or arrogant person is likely to ignore or trivialize other ideas, arguments, or objections. Doing so risks losing out on acquiring true beliefs and other related epistemic goods (Roberts and Wood 2007, 273). Thus, intellectual humility helps to avoid undermining different justificatory processes that ideas need to be put through to get closer to the truth. Roberts and Wood conclude that:

People can be debilitated not only by intellectual vanity and arrogance, but also by timidity and diffidence. To be the most advancing of knowers, people need to be willing to think outside the presuppositions of their intellectual communities, to doubt authorities and imagine unheard of possibilities. And it seems intuitively clear that intellectual timidity and diffidence hinder such activities. We might worry that an inquirer who markedly lacks intellectual vanity, arrogance, domination, and grandiosity is very unlikely to be daring and self-confident... The humble intellectual - that is, the one who lacks to an unusual extent the impulses of vanity, arrogance, domination, self - complacency, and the like - will have a special freedom and suppleness of action and judgement that promote his or her epistemic ends (Roberts and Wood 2007, 278-279).

\section{Reply: Intellectual Humility and the Due Diligence Argument}

At this point it is difficult to understand exactly what role intellectual humility plays in the process of obtaining relevant epistemic goods such as true beliefs, justified beliefs, or knowledge. It appears as though Roberts and Wood are simply describing an ideal epistemic agent and using the term humility as a place holder for some of the attributes in question. Roberts and Wood describe the characteristics that an agent needs in order to be an effective epistemic agent. But this is exactly what I have been attempting to accomplish, in part, by describing how an agent ought to respond to the existence of peer disagreement. The Due Diligence Argument is, in part, simply providing a description of what an ideally rational agent ought to do when she encounters worldview disagreement. This description is hardly at odds with Roberts and Wood's account. Rather, it 
coincides with their description, particularly the ideas about being willing to pursue a line of reasoning regardless of what others may think, along with also being willing to seriously consider objections to one's view. Therefore, the idea that my project runs contrary to intellectual humility and promotes any epistemic vices is false. Indeed, it is hard to imagine a plausible account of intellectual humility that will conflict with the Benefits to Inquiry Argument, the Benefits to NonInquiry Argument, or the Due Diligence Argument.

\section{Competing Epistemic Values}

In this section I explore what sometimes goes unnoticed in contemporary epistemology in that there are two different, and sometimes competing epistemic values. The weight one gives to these competing values may affect the scope of the Benefits to Inquiry Argument. In particular, it will affect how one interprets and applies GUP. One value is the value of avoiding false beliefs. A lot of work in epistemology seems particularly concerned with this value. But there is also another value which is the value of holding true beliefs. I postulate that those who worry that my account is overly permissive are probably more concerned with avoiding false beliefs than with possessing true beliefs. What I say in this section is tentative and exploratory, but it is worth highlighting the implications of how an individual's epistemic values will directly impact how my arguments are likely to be evaluated.

Wayne D. Riggs argues that every theory of justification (or knowledge) implicitly involves a balancing act between the two different epistemic values. For example, "[an agent] want[s] to have beliefs that are true, and [she does] not want to have beliefs that are false. That is, [an agent] value[s] having true beliefs and... disvalue[s] having false ones" (Riggs 2008, 1). Thus, every time an agent believes something she is taking an epistemic risk in one way or another. Riggs explains that: 
Different people can assess differently the risks involved in believing or withholding, even if they have the same evidence, and hence make the same judgment regarding the likelihood of the truth of the proposition under consideration. For some, the risk of being wrong simply doesn't weigh as heavily on them as it does on others, and so they value the possibility of gaining a truth relatively high, and vice versa for others (Riggs 2008, 4).

It might be objected that what an agent values in this sense cannot be epistemic because such values are not objective. Riggs, however, responds that there is no obvious way of discovering an objective weighting between the two epistemic values. This appears to open up space for the two epistemic values to be relative to an individual's preference. An agent may simply value discovering a new truth more than she is concerned about her beliefs being proven wrong. According to Riggs, there is no principled way to argue that in such a case her values are any less rational than a peer who worries more about being wrong with respect to, say, her important worldview beliefs.

Still, it is not clear that Riggs's argument succeeds. There might be no obvious way to rank one epistemic value over another, but it does not follow that this means that the values of avoiding falsehoods and possessing true beliefs are therefore purely subjective. It could simply mean that both values ought to be treated as equally important. Consider the following five types of rationality that emphasise the two epistemic values to varying degrees:

\section{Cliffordian Rationality:}

I name this after W.K. Clifford's famous essay "The Ethics of Belief." Clifford's well known principle is that 'it is wrong always everywhere and for everyone to believe anything on insufficient evidence'. I believe that this principle lies at the heart of the very narrow accounts of rationality found in philosophers such as Christensen and Feldman that I discussed in Chapter Five. This type of rationality focuses solely on the epistemic value of avoiding false beliefs. No 
trade-offs are allowed in order to gain true beliefs at the cost of acquiring some false beliefs. Only current (or synchronic) evidence counts as justification for the belief in question.

\section{Synchronic Rationality:}

This includes the values of both avoiding false beliefs and gaining true beliefs. In Chapter Five I argued that the Semmelweis, Galileo, and Darwin cases are all paradigmatic examples of including in their reasons what I refer to as synchronic epistemic reasons, not practical reasons. The idea here is that potential future epistemic benefits of disputed beliefs can serve as the proximate epistemic justification for such beliefs.

\section{Modest Trade-Off Rationality:}

This type of rationality involves a willingness to take on trivial false beliefs in order to gain important true beliefs. Avoiding false beliefs and possessing true beliefs are equally important on this view. Trade-offs are only acceptable if the false beliefs an agent takes on are trivial and inconsequential. They are also only acceptable if the true beliefs gained are significant. This assumes some form of epistemic consequentialism.

\section{Licentious Trade-Off Rationality:}

This is a more extreme version of the above that permits the taking on of non-trivial false beliefs in order to gain valuable true beliefs. It does not, however, permit taking on non-trivial false beliefs in order to gain true beliefs that are trivial or inconsequential. Thus, this type of rationality favours the value of possessing true beliefs over avoiding false beliefs. But it does not completely disregard the importance of avoiding false beliefs.

\section{Extreme Jamesian Rationality:}

I name this version of rationality after William James's The Will to Believe. In this influential work, James highlights the importance of having true beliefs, despite needing to avoid false beliefs. 
Taken to its very extreme, this idea entails believing everything in order to gain as many true beliefs as possible. This type of rationality allows for any trade-offs, including taking on nontrivial false beliefs in order to gain trivial true beliefs. The only goal is to hold as many true beliefs as possible, while no attention is given to the consequence of avoiding false beliefs. ${ }^{163}$

I will not rehearse what I said in defense of synchronic epistemic rationality in Chapter Six. My motivation for discussing these different types of rationality here is this: Philosophers concerned only with Cliffordian Rationality are wrongly exclusively obsessed with the epistemic value of avoiding false beliefs. This is made clearer by considering the extreme opposite of this view in Extreme Jamesian Rationality. Anyone attracted to this view, on the other hand, falls victim to the mistake of thinking that the only significant epistemic value is having as many true beliefs as possible, regardless of how many false beliefs are acquired in the process. Therefore, both of these views equally fail to appreciate both the value of avoiding false beliefs and the value of holding true beliefs. The former view warrants believing almost nothing, and the latter warrants believing almost everything.

Additionally, it could be argued that while Licentious Trade-Off Rationality appropriately values avoiding false beliefs, it probably does not value their avoidance enough, and, if followed, would lead to epistemically troubling consequences. I have suggested that the arguments I have offered in this project are perfectly compatible with synchronic epistemic reasons (they just also take into account diachronic epistemic reasons). Finally, I think, too, that philosophers ought to focus more attention on Modest Trade-Off Rationality. But defending this claim any more than I have already done so in Chapter Six is beyond the scope of this project.

${ }^{163}$ Many of the ideas for these five types of rationality come from Lougheed and Simpson 2017. 
My examples of different conceptions of rationality also account for P.D. Magnus's interesting suggestion that:

Commitments do more than define a single threshold to balance the value one might gain by believing truth against the cost one might pay for believing in error. Rather, different possible truths may offer different value, and different possible falsities may impose different costs. This allows for some people to rationally believe $\mathrm{P}$ and others to rationally believe -P (P.D. Magnus 2014, 134).

Again, I doubt that the cost-benefit analysis suggested by Magnus is purely subjective. Still, the idea that philosophers have different commitments elucidates why some will find my account overly permissive. I hope that by now it is clear my project has been concerned with both epistemic values. The Benefits to Inquiry Argument, the Benefits to Non-Inquiry Argument, and the Due Diligence Argument all affirm a commitment to the epistemic value of possessing true beliefs. But the qualification provided by GUP and worldview evaluative criteria also demonstrate a commitment to the avoidance of false beliefs.

While what I have discussed in this section is meant to be exploratory, I have gestured toward reasons for thinking that: (i) the reason why certain philosophers will find my account overly permissive is that they are (wrongly) exclusively focused on the value of avoiding false beliefs, and (ii) the claim that because there is no obvious way to rank the two epistemic values, they therefore must be subjective and hence relative to an agent's preference is false; or, minimally, more work needs to be done to defend that idea.

\section{Two Dynamic Views on Disagreement}

Much of the epistemology of disagreement is construed as a debate between two opposing views, conciliationism and non-conciliationism. Throughout this project I have understood the debate in these terms too. There are, however, two dynamic or hybrid views which claim that sometimes peer disagreement requires belief revision, and sometimes it does not. In this section I outline 
Thomas Kelly's ‘Total Evidence View' and Jennifer Lackey's 'Justificationist View'. Since my view shares the spirit of these middling accounts in only sometimes recommending revision, it is important that I explore the similarities and dissimilarities between my account and these two nonstandard accounts.

\section{Kelly on First-Order Evidence and Psychological Evidence as Higher-Order Evidence}

Kelly finds conciliationism counterintuitive because, once two peers are aware that they disagree with each other, the only factor that seems to matter in assessing the rationality of the belief in question is the psychological states of the two peers. For the peers ought to adjust their beliefs on the basis of the existence of certain psychological states. The original first-order evidence in question no longer matters (Kelly 2010,124). Kelly is baffled by a view which entails that higherorder evidence about a peer's psychological state always swamps first-order reasons. He says that he "find $[\mathrm{s}]$ the suggestion that the original evidence makes no difference at all once we respond to it a strange one" (Kelly 2010, 124). But he does not endorse a strong non-conciliationist position, which claims that the existence of peer disagreement can never swamp first-order evidence. ${ }^{164}$ The challenge is locating a middle position that is able to accommodate first-order reasons and also the higher-order evidence from peer disagreement.

Kelly believes that the reason peer disagreement might constitute a defeater for an agent's belief, even if the peer in question responded inappropriately to the same evidence, is because it is often impossible to tell whether or not they have responded appropriately to the evidence. This is due to the fact that "one does not occupy the God's-eye point of view with respect to the question of who has evaluated the evidence correctly and who has not" (Kelly 2010,138). While in some

164 This is a distinct move away from Kelly 2005 where he does seem to think that the existence of disagreement can never swamp first-order reasons. 
cases an agent might be reasonably confident that she has responded appropriately to the evidence, an agent will often be uncertain of her response. According to Kelly, a reason for an agent to doubt she has responded appropriately to a certain body of evidence is the existence of peer disagreement about that body of evidence. Kelly says " $[\mathrm{t}] \mathrm{o}$ give no weight to the fact that a peer responds to the evidence differently is in effect to treat it as certain that one's peer is the one who has misjudged the evidence. But it would be unreasonable to be certain of this, even when it is true" (Kelly 2010, 138).

Kelly claims that conciliationism and non-conciliationism are both problematic because “they embody overly simple models of how one's first-order evidence and one's higher-order evidence interact in determining facts about what it is reasonable to believe all things considered" (Kelly 2010, 141). Conciliationism entails that the reasonable response to peer disagreement rests solely on the belief distribution of peers. Non-conciliationism entails that first-order reasons always supervene on facts about peer disagreement (Kelly 2010, 141). Kelly suggests that:

In some cases, the first-order evidence might be extremely substantial compared to the higher-order evidence; in such cases, the former tends to swamp the latter. In other cases, the first-order evidence might be quite insubstantial compared to the higherorder evidence; in such cases the latter tends to swamp the former... In still other cases, the two kinds of evidence might play a more or less equal role in fixing facts about what it is reasonable to believe. So the question of which counts for more - peer opinion, or the evidence on which the peers base their opinion? - is not, I think, a good question when it is posed at such a high level of abstraction (Kelly 2010, 142).

Thus, Kelly claims that where the higher-order evidence matters greatly are in those cases in which a large number of peers believe a proposition and only a small number disbelieve the same proposition. Kelly writes that "[a]t some point, when the number of peers grows large enough, the higher-order psychological evidence will swamp the first-order evidence into virtual insignificance" (Kelly 2010, 144). But cases where this happens are probably quite rare because, 
to count as additional disagreement, peers must form their judgments independently of one another (Kelly 2010, 147). ${ }^{165}$

\section{Assessing Kelly's 'Total Evidence View'}

Kelly's account uses the common starting point of shared evidence to discuss disagreement. In Chapter Four I argued that the epistemology of disagreement literature should stop employing the assumption of shared evidence, particularly with respect to complex cases of disagreements. Despite this, Kelly's account remains plausible because, as I mentioned in Chapter Four, it is still possible for an agent to wonder whether her opponent has better evidence and/or has responded to that evidence more appropriately than she has herself. Unless the agent has a reason for thinking her evidence or assessment of the evidence is superior, the spirit of Kelly's account remains consistent with what I have argued throughout this project.

Also note that, in particular, Kelly's account is not in conflict with the Due Diligence Argument. In theory, if one person held a unique worldview and millions of peers disagreed with her, the Due Diligence Argument could justify her remaining steadfast. If, however, the millions of peers formed independent judgments based on first-order reasons against the minority worldview in question, then this immense amount of independent disagreement becomes very epistemically significant. ${ }^{166}$ Given the Due Diligence Argument, the agent who holds the minority view ought to re-evaluate the first-order reasons for her worldview. Given the large independent disagreement, it is unlikely that the minority worldview would stand up to the type of evaluation describe in Chapter Seven. Likewise, given so much independent disagreement, it is probable that some of her opponents possess better evidence and/or have evaluated that evidence more

165 This assumes that independence is a requirement of rationality.

${ }^{166}$ Again, this assumes the independence principle. While it is widely accepted, it is not without controversy. For the sake of discussion I will assume that the independence principle is true. 
accurately than she has assessed it. True, the Due Diligence Argument makes it in principle possible for a worldview in such circumstances to be epistemically rational. But it is a very small possibility, and so, again, my arguments are consistent with the spirit of Kelly's account.

The Due Diligence Argument requires most people to pause when they encounter worldview disagreement. The frequency of worldview disagreement should generate many pressing questions. Does the Christian theist have reason to think she is better positioned to gain religious truths than the millions who disagree with her? Does the secular humanist or Muslim also think they are better positioned to access the truth than the millions who also disagree with them? I could continue to list many worldviews and related questions. While the Due Diligence Argument in principle justifies remaining steadfast in the face of vast disagreement by appealing to future epistemic benefits, doing so is only rational if the Due Diligence Argument is not violated. And it turns out that the more independent disagreement that exists, the more likely it is that one will have to adjust her worldview in the face of such widespread disagreement.

What distinguishes my view from Kelly's 'Total Evidence View', however, is that there is a sense in which my position entails that the psychological evidence about a belief never swamps the first-order reasons for that belief. I argue that disagreement should trigger an evaluation of the first-order reasons for the agent's worldview in question (inasmuch as the specific disagreement is connected to the agent's overall worldview). Any adjustment or change in worldview only occurs after an agent has re-evaluated those first-order reasons, and never solely on the basis of disagreement alone. It is ultimately a reflection on the first-order reasons that causes belief revision. But the reflection is triggered by the existence of disagreement. Oppy notes that:

[I]t is just a mistake to think that, because there is a doxastic symmetry in our position that arises from our being doxastic peers, I cannot simply rest on my first order reasons for believing as I do in order to explain why it is that I am right and you are wrong. 
My grounds for believing that I am right and you - my doxastic peer - are wrong are just my grounds for believing as I do (Oppy 2010, 198).

Presumably, what would be inconsistent with Oppy's claim is a scenario where an agent failed to possess appropriate first-order reasons for a belief, and then refused to take seriously the existence of peer disagreement. On my account, an agent can rest on the first-order reasons for maintaining a worldview, provided that there has been due diligence in evaluating those first-order reasons. Once the evaluation is complete and it has been established that one's worldview is superior to the other(s) in question, the potential epistemic benefits of remaining steadfast can serve as the epistemic justification for remaining steadfast in the face of disagreement.

To discover whether an agent is called to revise her worldview ultimately requires evaluating the first-order reasons for her worldview. Not only that, it involves comparing those first-order reasons to those on offer for the worldview of the opponent in question. It demands the enormous and complicated task of worldview evaluation. Conciliationists might worry that this is a trivial conclusion which downplays the epistemic significance of peer disagreement. That is, they might suggest that my account never allows peer disagreement to count as evidence against a belief. But on my account the existence of peer disagreement ought to very often trigger worldview evaluation. This conclusion is far from trivial. Re-evaluating first-order reasons for a worldview is an incredibly demanding epistemic project. Likewise, the fact that such evaluation can cause an agent to adjust her current worldview or altogether change worldviews is far from a trivial conclusion.

\section{Worldview Evaluation and Partial Defeat}

Michael Thune argues that the epistemic significance of disagreement is generally understood in terms of full defeat or no defeat (Thune 2010). Thune suggests that Kelly's dynamic account is generally correct, but ought to be reformulated to include the idea that disagreement can sometimes 
constitute partial defeat. According to Thune, this is reasonable on the assumption that a belief can be held in varying degrees. He suggests that the degree of confidence an agent has in the truth of a belief should correspond closely to the degree of justification that is enjoyed by that particular belief. Justification for a belief can be gained or lost as the result of additional evidence (Thune 2010, 358). Thune says that "what is missing from [Kelly's] discussion is an account of when disagreement yields a partial defeater for one's belief... I think this happens when one's first-order evidence outweighs one's higher-order evidence, though not significantly" (Thune 2010, 360). Thune therefore defends the following principle:

\section{Principle of partial defeat:}

[I] $\mathrm{f}$ in a disagreement $\mathrm{S}$ believes or epistemically should believe that a conversational partner is as reliable as $\mathbf{S}$ (with respect to some topic) and that it is not obvious which party (if either) is in a more privileged epistemic position (concerning the particular disputed proposition), even if these beliefs are not fully justified or strongly held, then S's belief (about the proposition which is the subject of that disagreement) is at least partially defeated (Thune 2010, 364).

Thune claims that this principle is compatible with many different (internalist or externalist) accounts of epistemic justification.

I have not explicitly discussed the idea of partial defeaters in this project. It is unclear whether the Due Diligence Argument is compatible with the claim that disagreement can sometimes constitute partial defeat. Suppose an agent is a theist of a particularly conservative stripe. When assessing her worldview against others she may discover it does not fare very (epistemically) well. While the agent would have to change many of her beliefs about particular religious doctrines, perhaps she need not give up her more general belief in theism. So only part of her worldview is defeated by disagreement. Still, Thune's discussion is about defeat for individual beliefs. And in the case of the conservative Christian theist, some of her individual beliefs (which are part of her worldview) might be completely defeated after worldview evaluation. 
Likewise, if her belief that theism is true remains intact, then on my account her belief in theism is not partially defeated if it survives the scrutiny triggered by disagreement. She has still changed worldviews in such a case; for she is no longer a conservative theist. But there is significant overlap between her old worldview and new one (e.g. she still believes that God exists).

It should, however, be acknowledged that the notion of partial defeat might be consistent with the Benefits to Inquiry Argument, since that argument is about individual propositions. But contested beliefs are supposed to enjoy protection on that argument based on potential future epistemic benefits. In Chapter Five I argued that those benefits may not be (fully) obtainable without the strong doxastic stance of belief (rather than merely accepting or entertaining). Likewise, it could be that without a relatively high credence in the belief, a researcher would be less likely to maintain an inquiry belief in the face of disagreement. Hence, she and the community would be less likely to gain the epistemic benefits from remaining steadfast. As it stands, then, neither the Benefits to Inquiry Argument nor the Due Diligence Argument appear to be obviously consistent with the concept of partial defeat, at least in the way Thune's account refers to partial defeat for particular propositions. However, my account is indeed consistent with an agent modifying parts of her worldview (by adding or subtracting different propositions).

\section{Lackey's 'Justificationist View'}

Lackey's 'Justificationist View' of disagreement requires conciliation based on the degree to which the belief in question is confidently held, and such confidence is highly justified (Lackey 2010a, 277). Lackey's initial formulation of her view relies on the following two principles:

No Doxastic Revision Required (NDRR). In a case of ordinary disagreement between $\mathrm{A}$ and $\mathrm{B}$, if A's belief that $p$ enjoys a very high degree of justified confidence, then A is rationally permitted to retain her same degree of belief that $p$ if and only if $\mathrm{A}$ has personal information that provides a relevant symmetry breaker. 
Substantial Doxastic Revision Required (SDRR). In a case of ordinary disagreement between $\mathrm{A}$ and $\mathrm{B}$, if $\mathrm{A}$ 's belief that $p$ enjoys a relatively low degree of justified confidence, then $\mathrm{A}$ is rationally required to substantially revise the degree to which she holds her belief that $p$ (Lackey 2010a, 277). ${ }^{167}$

Lackey claims that her view is superior to standard non-conciliationist and conciliationist views for at least two reasons. First, her view is not threatened by the one against many problem, which is a serious challenge to non-conciliationism. The one against many problem is that on nonconciliationism the number of peers in question does not seem to matter. But if multiple peers form independent judgments that horse A won the race, then surely that counts significantly more than if just one peer judges that horse A won the race (Lackey 2010a, 278-279).

Second, Lackey's account is not susceptible to the many against one problem that threatens the rationality of conciliationism. According to most forms of conciliationism, the existence of just one peer who disagrees with an agent should require that agent to make major doxastic revisions. But if many peers agree on the total of the restaurant bill, then the one agent who disagrees with them should surely conform her belief about the bill to the group's belief. Thus, Lackey explains that on her view "the amount of doxastic revision required is determined by the level of justified confidence possessed by the target belief in conjunction with whether the presence of personal information is sufficient to serve as a symmetry breaker" (Lackey 2010a, 281).

One objection to Lackey's account is that it is really a conciliationist view posing as a dynamic view because it will always require doxastic revision in the face of peer disagreement, even if the required revision is only slight. Consider the following case of disagreement:

Elementary Math:

Harry and I, who have been colleagues for the past six years, were drinking coffee at Starbucks and trying to determine how many people from our department will be attending the upcoming APA. I, reasoning aloud, say: "Well, Mark and Mary are going on Wednesday, and Sam and Stacey are going on Thursday, and since $2+2=4$, there will be four other members of our department at that conference." In response, Harry

${ }^{167}$ Lackey's original defense of this view can be found in Lackey $2010 \mathrm{~b}$. 
asserts: "But $2+2$ does not equal 4." Prior to this disagreement, neither Harry nor I had any reason to think that the other is evidentially or cognitively deficient in any way, and we both sincerely avowed our respective conflicting beliefs (Lackey 2010a, 283).

Lackey explains that while on her account the disagreement with Harry is still a piece of evidence, it does not necessarily require any doxastic revision. She states that this is due to the fact that "the extraordinary evidence that I have for believing that $2+2=4$, along with the personal information I possess about myself and my recognition of the fact that Harry and I are in disagreement, serve as good evidence that Harry is not my epistemic peer on this matter after all” (Lackey 2010a, 283). Thus, Lackey's account sometimes requires doxastic revision, but also sometimes requires revising the belief that the opponent in question is an epistemic peer. Lackey explains that:

At the heart of my justificationist view is the thesis that the amount of doxastic revision required in the face of peer disagreement tracks the amount of justified confidence present: the more justified and confident a belief is, the less doxastic revision is required, and the less justified and confident a belief is, the more doxastic revision is required (Lackey 2010a 287).

Lackey acknowledges a more promising objection to her Justificationist account as currently formulated with NDRR and SDRR. Consider the following example of disagreement:

Bird:

While reading in the library with my friend Eva, I glance out the window, catch a glimpse of a bird flying by, and on this basis hastily form the belief that a magpie just flew by. After saying to Eva, who was looking out the window at the same time, that I enjoyed the magpie that just flew by, she responded, "Nothing flew by the window." Prior to this disagreement, neither Eva nor I had any reason to think that the other is evidentially or cognitively deficient in any way, and we both sincerely avowed our respective conflicting beliefs (Lackey 2010a, 287).

The belief that a magpie flew past the window enjoys a relatively low degree of justification, but on Lackey's view it is rational to maintain the belief in the face of disagreement. She has personal information that her contact lenses are in, she has not been drinking or taking drugs, and thus she can downgrade Eva as a peer (presumably because she doesn't have this same information about Eva) (Lackey 2010a, 287-288). Lackey concedes that "it now looks as though the amount of 
doxastic revision needed does not track the level of justification possessed - which is the denial of a thesis that lies at the heart of my justificationist view" (Lackey 2010a, 288).

While this counterexample undermines her view as currently formulated, Lackey believes it actually supports a slightly modified version of her view. Lackey explains that while it could be contested that it was a magpie that flew by the window, her belief that something flew by the window is both confidently held and enjoys a high degree of justification. This fact can serve to protect the belief that it was a magpie that flew by the window (Lackey 2010a, 288). Consider the following modified principles:

No Doxastic Revision Required* (NDRR*). In a case of ordinary disagreement between $\mathrm{A}$ and $\mathrm{B}$, if (N1) A's belief that $\mathrm{p}$ enjoys a very high degree of justified confidence, or (N2) A's belief that $p$ is 'protected' by a belief that enjoys a very high degree of justified confidence, then $A$ is permitted to rationally retain her same degree of belief that $\mathrm{p}$ if and only if $\mathrm{A}$ has personal information that provides a relevant symmetry breaker.

Protected: A's belief that $p$ is protected by A's belief that $q$ if and only if both A's belief that $p$ and A's belief that $q$ are members of a subset of A's beliefs, each member of which is challenged by the same instance of ordinary disagreement with $\mathrm{B}$, and where A's belief that q meets condition (N1) above (which thereby justifies A in downgrading the epistemic status of B).

Substantial Doxastic Revision Required* (SDRR*). In a case of ordinary disagreement between A and B, if (S1) A's belief that $p$ enjoys a relatively low degree of justified confidence, and (S2) A's belief that $p$ is not 'protected' by a belief that enjoys a very high degree of justified confidence, then $\mathrm{A}$ is rationally required to substantially revise the degree to which she holds her belief that p (Lackey 2010a, 288-289).

In Bird it is an entire subset of beliefs that are challenged. The subset includes the beliefs that Lackey saw a magpie, a bird, a small bird, a small object, and merely something. At minimum the belief that she saw something fly by the window is protected by N1 because it enjoys a high degree of justified confidence. Based on this high degree of justification, Lackey is able to downgrade her opponent. It also protects her belief that a magpie flew past the window (Lackey 2010a, 289). But if the disagreement was only about which type of bird flew past the window, then 
at least some doxastic revision is required because N1 would not be satisfied. In such a case even if Lackey were to know she is not suffering from something making her perception unreliable, such personal information could not count as a relevant asymmetry. This is because the belief that a specific kind of bird flew past the window does not enjoy a high degree of justification. Thus, this modified version of Lackey's justificationist view provides the intuitively correct answers to Bird (Lackey 2010a, 289). She writes that:

The upshot of these considerations is that the relationship between beliefs - both in terms of their being supported and challenged - is complex. One instance of disagreement can challenge multiple beliefs, and a challenge can be answered for multiple beliefs by the high level of justification for one of them. This should come as no surprise, as the factors contributing to the justification of a given belief can be complex and varied. Given the justificationist nature of my view, then, one should likewise expect the same when it comes to the epistemic significance of disagreement (Lackey 2010a, 290).

Recall the medical diagnosis case from Chapter Three. On the assumption that the symptoms are equally compatible with both diagnoses, it is unlikely that Lackey's account will require no belief revision. This is because neither diagnosis can be both highly justified and held confidently. How much revision is required will depend on the specific features of the case in question. For example, if Dr. Haggard has treated more patients with chronic fatigue syndrome, then he may be more likely to 'see' it when diagnosing. Similarly, if Dr. Wolf has treated more patients with lupus he may be more likely to 'see' it when diagnosing. If this is the scenario then significant doxastic revision is required because their diagnoses risk being coloured by their past experience. But perhaps they only disagree because they place different weight on how likely it is that a patient suffering from lupus will have a rash. If this is the case, then only minimal revision is required (Lackey 2010a, 291). Lackey concludes that:

Whether epistemic peers are debating abortion, God's existence, or art, the degree of doxastic revision required will be determined by the level of justified confidence with which the beliefs in question are held. And both the degrees of justification and 
confidence enjoyed by a given belief can be influenced by countless factors (Lackey 2010a, 292).

\section{Assessing Lackey's 'Justificationist View'}

Given what I discussed in Chapter Two about the nature of introspection, it is not clear that Lackey can appeal to personal considerations to downgrade her opponent. I will not rehearse the details here, but an agent may not be well equipped to assess whether or not her own cognitive faculties are functioning properly. If this is right, then personal reasons cannot generate a relevant asymmetry between two opponents in a disagreement. While this might push Lackey's view toward a position that always requires doxastic revision, I set this concern aside for the remainder of my discussion of her view.

Lackey's 'Justificationist View' may deal with fundamental worldview disagreement in a way that is compatible with the Due Diligence Argument. A worldview is not a specific belief, and so is not one that could satisfy N1. But a worldview is a set of beliefs that could possibly satisfy N1, assuming that each belief in the set (i.e. in the worldview) enjoys a high degree of justified confidence. Thus, Lackey's account does seem to provide a way for there to be reasonable worldview disagreement. Of course, an objector might wonder how each belief in a set could possibly enjoy a high degree of justified confidence. But Lackey concluded her account by suggesting that if a religious believer had a religious experience that made it obvious to her that God existed, then such a belief would enjoy a high degree of justified confidence (Lackey 2010a, 292). If this is right, then there's a way for many important beliefs in a worldview to enjoy a high degree of justified confidence.

Note too that my account can help Lackey's view in explaining how beliefs about controversial subjects such as abortion, God, or art - beliefs that are deeply connected to an agent's worldview - can enjoy a high degree of justified confidence. Inasmuch as those beliefs are closely 
connected to an agent's worldview, they will enjoy a high degree of justified confidence based on how the worldview in question scores on the evaluative criteria I mentioned in Chapter Eight. A worldview is superior to its competitors based on explanatory scope, fit with current data, simplicity, internal consistency, predictive power, etc. If a worldview scores worse than its opponents on these criteria, then any beliefs closely connected to that worldview cannot have a high degree of justified confidence. Thus, there is a distinct sense in which Lackey's account is compatible with the Due Diligence Argument.

A significant difference between my account and Lackey's is that her view does not rely on epistemic benefits to preserve the rationality of a belief, or set of beliefs (i.e. a worldview) in the face of disagreement. Her view is not conciliatory in this way. While my view could be construed as dynamic, since I argue that revision is not always required in the face of disagreement, my view is perhaps better understood as a limited form of conciliationism. Given my account of Sceptical Epistemic Peerhood, genuine epistemic peer disagreement is going to obtain in many real-world life cases. Lackey's account begins right away by asking whether N1 obtains when such a disagreement occurs. My account asks whether there are any potential epistemic benefits to be gained from the disagreement. Having said that, the recommendation that Lackey's view and my view make in the face of disagreement (i.e. when an agent should revise or remain steadfast) may turn out to be very similar in a number of cases.

\section{The Difficulty of Changing Worldviews}

I conclude this project by emphasising the fact that my arguments are not trivial, especially since they could ultimately recommend worldview revision. Consider the familiar story, at least within the Western academy, of religious believers who begin to question their religious convictions for the first time while studying at university. In the West, many of these students come from 
conservative Christian backgrounds. University may be the first time where their religious convictions are openly challenged. Many of these students will have never thought about the firstorder reasons for their religious beliefs in very much detail before studying while at university. Taking university classes often stimulates the following response: 'There are many very intelligent people who disagree with my religious convictions. I wonder whether there are any good reasons for thinking my religious beliefs are true.' I believe that in these cases it very often is the existence of disagreement with professors, classmates, and canonical authors which causes students in these circumstances to critically reflect on and engage with the first-order reasons for their religious beliefs for the very first time. The story need not always end with the religious student abandoning her religious convictions. Nevertheless, sometimes such critical evaluation of first-order reasons results in major adjustments to the student's worldview, and sometimes even a complete change in worldview. While the evaluation itself is no easy epistemic task, changing worldviews can be a psychologically painful and time consuming experience. On the other hand, it can also be an experience filled with wonder and freedom.

If the results of worldview evaluation as described in Chapter Eight clearly favour a worldview different from the agent's, she may experience an existential crisis. It is an incredibly psychologically demanding task to change worldviews. It requires that an agent completely reorient her life purposes and values. Religious believers who abandon their religious faith typically describe it as incredibly painful experience. They risk being ostracized by friends and family. They may struggle to find meaning and value in life. Likewise, someone who converts to a religion finds their entire life reoriented. Their life purposes and values will be realigned with their newfound beliefs. They may also encounter the same sort of social challenges that face a believer who gives up a religious worldview. But again, this could also turn out to be a very 
fulfilling process. Perhaps one experiences a new found freedom and openness in their new worldview.

Given the extremely difficult and complex nature of worldview evaluation, after reexamining the first-order reasons for a worldview, it might be unclear whether an agent's worldview does better or worse than its competitors. In this case an agent ought not to suspend judgment. If the agent is uncertain or perceives a tie between worldviews, she should maintain her current worldview. This is because, in such a case, changing worldviews will not make it more likely that she will arrive at the truth (or related epistemic end). Oppy states that:

I have reasons for holding the view that I do... I have reasons for supposing that my views are true (and that competing views are false). When I allow that you have reasons for holding the views that you do, I allow that you reasonably take yourself to have reasons for believing what you do. However, by my lights, while you reasonably take yourself to have reasons for believing what you do, your beliefs - insofar as they disagree with mine, and insofar as you are unable to furnish me with a reason to change my mind and agree with you - are false (Oppy 2010, 197).

Given the extremely complex nature of worldview evaluation, it is not implausible to think that different people will assess worldviews differently. The fact that every agent will be assessing worldviews using different bodies of evidence also opens up space for reasonable worldview disagreement. Suspending judgment about a worldview is not a possible option. At least, as I have described them here, necessarily every person has a worldview. Of course, some will be more fractured and less coherent than others, but they are worldviews nonetheless. Being unsure about how to answer the worldview questions I ask in Chapter Eight does not preclude one from having a worldview. That is, having no specific answers to such questions still constitutes a kind of answer. The lesson here is that if the agent's evaluation of her worldview is inconclusive she should remain steadfast.

\section{Conclusion}


This project was intended as a response to strong forms of conciliationism found in philosophers such as Feldman and Christensen. Sadly, I am aware that my conclusions risk satisfying neither conciliationists nor non-conciliationists about peer disagreement. Conciliationists are likely to object that my account is too permissive. Such conciliationists may be unwilling to give ground to an account that relies on diachronic epistemic reasons. While I admit that GUP is vague, perhaps the conciliationist will also challenge the Due Diligence Argument. I have answered all that I can regarding these concerns. On the other hand, non-conciliationists may complain that my arguments are not permissive enough, especially with respect to worldview disagreement. In other words, the need for an agent to re-evaluate her worldview in the face of disagreement might be viewed as an unnecessary and overly burdensome response to disagreement.

A more charitable interpretation of my project, though, is that it occupies a middle position between strong forms of conciliationism and non-conciliationism. Many disagreements over isolated propositions amount to worldview disagreements. An agent is required to revise her worldview when, after evaluation, it turns out to be inferior to other worldviews. An agent is not required to revise her worldview when, after evaluation, her worldview is superior to others, or it is unclear how it compares. This is far from a trivial conclusion, as evaluating, let alone changing, worldviews is a challenging and complicated task. I realize, though, that there will be those who disagree. 


\section{Bibliography}

Alston, William. (1991). Perceiving God. Ithaca: Cornell University Press.

Anantharaman, Muralidharan. (2015). "Defending the Uniqueness Thesis - A Reply to Luis Rosa." Logos and Episteme 6 (1):129-139.

Ballantyne, Nathan. (2016). "Verbal Disagreements and Philosophical Scepticism." Australasian Journal of Philosophy 94 (4): 752-765.

. (2015a). "Debunking Biased Thinkers (Including Ourselves)." Journal of the American Philosophical Association 1 (1): 141-162.

. (2015b). "The Significance of Unpossessed Evidence." The Philosophical Quarterly 65 (260): 315-335.

. (2014). "Counterfactual Philosophers." Philosophy and Phenomenological Research 88 (2): 368-387.

. (2013). "The Problem of Historical Variability." In Disagreement and Skepticism, Diego E. Machua (eds). Routledge, 239-259.

Ballantyne, Nathan and E.J. Coffman. (2011). "Uniqueness, Evidence and Rationality." Philosophers' Imprint 11 (18): 1-13.

Barnett, Zach. (2019a). “Philosophy Without Belief.” Mind 128 (509): 109-138.

. (2019b). "Belief dependence: How do the numbers count?" Philosophical Studies 176 (2): 297-319.

Barnett, Zach and Han Li. (2016). "Conciliationism and Merely Possible Disagreement." Synthese 193 (9): 1-13.

Benjamin, Sherman. (2014). "Moral Disagreement and Epistemic Advantages: A Challenge to McGrath. Journal of Ethics and Social Philosophy 8 (3): 1-18.

Bergmann, Michael. (2017). "Religious Disagreement and Epistemic Intuitions.” Royal Institute of Philosophy Supplement 81: 19-43. . (2009). "Rational Disagreement after Full Disclosure.” Episteme 6 (3): 336-353.

Berker, Selim. (2013). "Epistemic Teleology and Separateness of Propositions." Philosophical Review 122 (3): 337-393.

Besong, Brian. (2017). “Disagreeing with Confidence.” Theoria 83 (4): 419-439. 
Billig, M. (1996). Arguing and thinking: A rhetorical approach to social psychology. Cambridge: Cambridge University Press.

Blinder, A.S. and J. Morgan. (2000). "Are two heads better than one? An experimental analysis of group vs. Individual decision making." Working Paper 2909, National Bureau of Economic Research, Princeton, N.J.

Bogardus, Thomas. (2009). “A Vindication of the Equal Weight View.” Episteme 6 (3): 324-335.

Bogner, Frieder, Markus Seidel, Konstantin Schnieder and Thomas Meyer. (2018). "Rational Peer Disagreement Upon Sufficient Evidence: Leaving the Track to Truth? In Peter van Inwagen, Materialism, Free Will and God Ludger Jansen and Paul Nager (eds). Dordrecht: Springer, 17-39.

Boyce, Kenneth and Allan Hazlett. (2016). "Multi-Peer Disagreement and the Preface Paradox." Ratio 29 (1): 29-41.

Broome, John. (2013). Rationality through Reasoning. Oxford: Oxford University Press. . (2008). “Is Rationality Normative?” Disputatio 11, 153-71. 37. . (2005). “Does Rationality Give Us Reasons?” Philosophical Issues 15 (1): 321. (2001). "Normative Practical Reasoning." Proceedings of the Aristotelian Society Supplementary Volume 75, 175-93. . (1999). "Normative Requirements.” Ratio 12 (4): 398-419.

Brossel, Peter and Anna-Maria A. Eder. (2014). "How to resolve doxastic disagreement." Synthese 191 (1): 2359-2381.

Bundy, Alex. (2011). "In Defense of Epistemic Abstemiousness.” Logos \& Episteme 2 (2): 287292.

Cannella, A.A., Park, J.H., and H.U. Lee. (2008). "Top management team functional background diversity and firm performance: examining the roles of team member collocation and environmental uncertainty." Academy of Management Journal 51 (4): 142-148.

Carnap, Rudolph. (1956). "Empiricism, Semantics, and Ontology." In Meaning and Necessity, Rudolph Carnap. Illinois: University of Chicago Press, 205-221.

Carter, Adam J. (2016). “Group Peer Disagreement.” Ratio 29 (1): 11-28. 
Chalmers, David J. (2015). “Why Isn't There More Progress in Philosophy?” Philosophy 90 (1): 3-31. . (2011). "Verbal Disputes." The Philosophical Review 120 (4): 515-566.

Chalmers, David J., David Manley and Ryan Wasserman (eds). (2009). Metametaphysics: New Essays on the Foundations of Ontology. Oxford: Clarendon Press.

Christensen, David. (2016b). "Disagreement, Drugs, Etc.: From Accuracy to Akrasia." Episteme 13 (4): 397-422.

. (2016a). "Conciliation, Uniqueness and Rational Toxicity." Nous 50 (3): 584-693.

- (2014). "Disagreement and Public Controversy." In Essays in Collective Epistemology, Jennifer Lackey (eds). Oxford University Press, 142-162.

. (2013). "Epistemic Modesty Defended." In The Epistemology of Disagreement: New Essays, David Christensen and Jennifer Lackey (eds). Oxford: Oxford University Press, 77-97.

(2011). "Disagreement, Question-Begging and Epistemic Self-Criticism." Philosopher's Imprint 11: 1-21.

. (2009). "Disagreement as Evidence: The Epistemology of Controversy." Philosophy Compass 4 (5): 756-767.

. (2007). "Epistemology of Disagreement: The Good News." Philosophical Review 116 (2): 187-217.

Clouser, Roy A. (1991). The Myth of Religious Neutrality: An Essay on the Hidden Role of Religious Belief in Theories. Notre Dame: University of Notre Dame Press.

Cohen L. Jonathan. (1992). An Essay on Belief and Acceptance. New York: Oxford University Press.

Conee, Earl. (2010). "Rational Disagreement Defended." In Disagreement, Richard Feldman and Ted A. Warfield (eds). Oxford University Press, 69-90.

Copp, D. (2007). Morality in a Natural World: Selected Essays in Metaethics. New York: Cambridge University Press.

Crano, W.D. (2012). The rules of influence: Winning when you are in the minority. New York: St. Martin's Press.

Crisp, R.J. and R.N. Turner. (2011). "Cognitive adaptation to the experience of social and cultural diversity.” Psychological bulletin 137 (2): 242-266. 
Darwin, Charles. (2011). The Various Contrivances by which British and Foreign Orchids are Fertilised by Insects. New York: Cambridge University Press.

. (2009). The Descent of Man, and the Selection in Relation to Sex. New York: Cambridge University Press.

. (2006). The Origin of the Species by Means of Natural Selection, New York: Dover Publications.

David, Marian. (2001). "Truth as the epistemic goal.” In Knowledge, truth, and duty. M. Steup (ed.), New York: Oxford University Press, 151-169.

Davidson, Donald. (1973). "On the Very Idea of a Conceptual Scheme." Proceedings and Addresses of the American Philosophical Association 47: 5-20.

Dawson, Erica, Thomas Gilovich, and Dennis T. Regan. (2002). "Motivated Reasoning and Performance on the Wason Selection Task." Personality and Social Psychology Bulletin 28 (10): 1379-87.

Decker, Jason. (2014). “Conciliation and Self-incrimination.” Erkenntnis 79 (5): 1099-1134.

De Cruz, Helen and Johan De Smedt. (2013). "The Value of epistemic disagreement in scientific practice: The case of Homo floresiensis." Studies in History and Philosophy of Science 44 (2): 169-177.

de Riddler, Jeroen. (2014). "Why Only Externalists Can Be Steadfast.” Erkenntnis 79 (1): 185199.

Desmond, Adrian J. (2019). "Charles Darwin," Encyclopaedia Britannica Online Academic Edition.

Dessalles, J.L. (2007). Why we talk: The evolutionary origins of language. Oxford: Oxford University Press.

Douven, I. (2009). “Uniqueness Revisited.” American Philosophical Quarterly 46 (4): 347-361.

Downs, Robert B. (1982). Landmarks in Science: Hippocrates to Carson. Littleton, Colo.

Duarte, L. Jose. Jarret T. Crawford, Charlotta Stern, Jonathan Haidt, Lee Jussim, Philip E. Tetlock. (2015) "Political Diversity Will Improve Social Psychological Science." Behavioral and Brain Sciences e130: 1-58.

Ehrlinger, Joyce, Thomas Gilovich, and Lee Ross. (2005). "Peering Into the Bias Blind Spot: People's Assessments of Bias in Themselves and Others." Personality and Social Psychology Bulletin 31 (5): 680-692. 
Elga, Adam. (2010). "How to Disagree About How to Disagree." In Disagreement, Richard Feldman and Ted A. Warfield (eds). Oxford University Press, 175-186. . (2007). "Reflection and Disagreement." Nô̂s 41 (3): 478-502.

Elgin, Catherine. (2018). "Reasonable Disagreement." In Voicing Dissent: The Ethics and Epistemology of Making Disagreement Public, Casey Rebecca Johnson (eds). New York: Routledge, 10-21. (2017). True Enough. Cambridge MA: The MIT Press. . (2010). "Persistent Disagreement." In Disagreement, Richard Feldman and Ted A. Warfield (eds). Oxford University Press, 53-68.

Elkin, Lee and Gregory Wheeler. (2018). "Resolving Peer Disagreements Through Imprecise Probabilities.” Noûs 52 (2): 260-278.

Engel (2000). Believing and Accepting. USA: Kluwer Academic.

Enoch, David. (2007). "Not Just a Truthometer: Taking Oneself Seriously (but not Too Seriously) in Cases of Peer Disagreement.” Mind 119 (476): 953-997.

Everett, Theodore J. (2015). "Peer Disagreement and Two Principles of Rational Belief." Australasian Journal of Philosophy 93 (2): 273-286.

Feldman, Richard. (2011). "Reasonable Religious Disagreements." In Social Epistemology: Essential Readings, Alvin Goldman and Dennis Whitcomb (eds). Oxford University Press, 137-157.

. (2007). "Reasonable Religious Disagreements." In Philosophers Without Gods, Louise Antony (eds). Oxford University Press, 194-214.

(2006)."Epistemological Puzzles about Disagreement" In Epistemology Futures, Stephen Hetherington (eds). Oxford: Oxford University Press, 216-236.

Feyerabend, Paul. (1988). Against Method. New York: Verso Publishing.

Firth, Roderick. (1998a) [1978]. "The Schneck Lectures, Lecture 1: Epistemic Utility." First delivered as a lecture at the University of Arizona, 1978.

. (1998b) [1981]. "Epistemic Merit, Intrinsic and Instrumental." Proceedings and Addresses of the American Philosophical Association 55, 5-23. Reprinted in Firth 1998, 259-71. 
Fiske, S.T., Harris, L.T., and A.J.C. Cuddy. (2004). "Why ordinary people torture enemy prisoners." Science 306 (5701): 1482-1483.

Fogelin, Robert, J. (1985) [2005]. “The Logic of Deep Disagreements” Informal Logic 7 (1): 1-8.

Foley, Richard. (2001). Intellectual Trust in Oneself and Others. Cambridge: Cambridge University Press.

Frances, Bryan. (2014). Disagreement. Cambridge: Polity Press.

(2010). "The Reflective Epistemic Renegade," Philosophy and Phenomenological Research LXXXI (2): 419-463.

Fritz, James. (2018). “Conciliationism and Moral Spinelessness.” Episteme 15 (1): 101-118.

Fumerton, Richard. (2010). "You Can't Trust a Philosopher" In Disagreement, Richard Feldman and Ted A. Warfield (eds) Oxford: Oxford University Press, 69-90.

. (2001). "Epistemic Justification and Normativity." In Knowledge, truth, and duty, M. Steup (ed.). New York: Oxford University Press, 49-60.

Gelfert, Axel. (2011). “Who is an Epistemic Peer?” Logos \& Episteme II (4): 507-514.

Gertler, Brie. (Winter 2014 Edition). "Self-Knowledge.” The Stanford Encyclopedia of Philosophy Edward N. Zalta (ed.), URL = <http://plato.stanford.edu/archives/win2014/entries/selfknowledge/>.

Gierlinksi Gerard D., Grzegorz Niedzwiedzki, Martin G. Lockley, Athanassios Athanassiou, Charalampos Fassoulas, Zofia Dubicka, Andrzej Boczarowski, Matthew R. Bennett, and Per Erik Ahlberg. (2017). "Possible hominin footprints from the late Miocene (c. $5.7 \mathrm{Ma}$ ) of Crete?" Proceedings of the Geologists' Association 128 (5-6): 697-710.

Godden, David and Brenner William H. (2010). "Wittgenstein and the logic of deep disagreement." Cogency 2: 41-80

Goldberg, Sanford. (2013). "Disagreement, Defeat, and Assertion." In The Epistemology of Disagreement: New Essays, David Christensen and Jennifer Lackey (eds). Oxford University Press, 167-189.

. (2016). "On the Epistemic Significance of Evidence you Should have Had." Episteme 13 (4): 449-470.

Goodman, Nelson. (1978). Ways of Worldmaking. Indiana: Hackett Publishing Company.

Graham, Andrew. (2014). "On the Very Idea of a Verbal Dispute." Dialogue: Canadian Philosophy Review 53 (2): 299-314. 
Graves, Shawn. (2013). "The Self-Undermining Objection in the Epistemology of Disagreement." Faith and Philosophy 30 (1): 93-106.

Greaves, Hilary. (2013). "Epistemic decision theory.” Mind 122 (448): 915-952.

Harman, Gilbert. (1986). Change in View: Principles of Reasoning. USA: MIT Press.

Hazlett, Allan. (2014a). "Entitlement and Mutually Recognized Reasonable Disagreement." Episteme 11 (1): 1-25.

. (2014b). "How to defeat belief in the external world. Pacific Philosophical Quarterly 87(2): 198-212.

Heesen, Remco and Pieter van der Kolk. (2016). "A Game-Theoretic Approach to Peer Disagreement.” Erkenntnis 81 (6): 1345-1368.

Hirvela, Jaakko. (2017). “Is It Safe to Disagree?” Ratio 30 (3): 305-321.

Holley, David M. (2013). "Religious Disagreements and Epistemic Rationality." International Journal for Philosophy of Religion 74 (1): 33-48.

Jackson, Brendan Balcerak. (2014). "Verbal Disputes and Substantiveness.” Erkenntnis 79 (1): 31-54.

Jehle, David and Branden Fitelson. (2009). "What is the 'Equal Weight View'?" Episteme 6 (3): 280-293.

Jenkins, Carrie. (2007). “Entitlement and Rationality.” Synthese 157 (1): 25-45.

. (2014). "Merely Verbal Disputes.” Erkenntnis 49 (1): 11-30.

Kahneman, Daniel. (2011). Thinking, Fast and Slow. New York: Farrar, Straus \& Giroux.

Kappel, Klemens. (2012). “The Problem of Disagreement.” Discipline Filosofiche 22 (2): 7-25.

Kelly, Thomas. (2013). "Disagreement and the Burdens of Judgment." In The Epistemology of Disagreement: New Essays, D. Christensen and J. Lackey (eds). Oxford University Press.

. (2010). "Disagreement and Higher Order Evidence." In Disagreement, Richard Feldman and Ted A. Warfield (eds). Oxford University Press, 111-174.

. (2005). "The Epistemic Significance of Disagreement." In Oxford Studies in Epistemology, John Hawthorne and Tamar Szabó Gendler (eds). Oxford University Press 1:167-196. 
. (2003). "Epistemic Rational as Instrumental Rationality: A Critique." Philosophy and Phenomenological Research LXVI (3): 612-640.

King, Nathan L. (2012). "Disagreement: What's the Problem? or A Good Peer is Hard to Find." Philosophy and Phenomenological Research LXXXV (2), 249-272.

Konigsberg, Amir. (2013). "The Problem with Uniform Solutions to Peer Disagreement.” Theoria 79 (1): 96-126.

Kornblith, Hilary. (2010). "Belief in the Face of Controversy." In Disagreement, Richard Feldman and Ted A. Warfield. Oxford University Press, 29-52.

Kraft, James. (2007). "Religious disagreement, externalism, and the epistemology of disagreement: listening to our grandmothers." Religious Studies 43 (4): 417-432.

Kripke, Saul. (2011). “On two paradoxes of knowledge.” In Philosophical troubles, Saul Kripke. Oxford: Oxford University Press, 27-49.

Kruger, Justin and Tomas Gilovich. (1999). "Naïve Cynicism in Everyday Theories of Responsibility Assessment: On Biased Assessments of Bias." Journal of Personality and Social Psychology 76 (5): 743-753.

Kuhn, D. (1992). “Thinking as argument.” Harvard Educational Review 62 (2): 155-78.

Lackey, Jennifer. (2014). "Taking Religious Disagreement Seriously." In Religious Faith and Intellectual Virtue, L.F. Callahan and T. O'Connor (eds). Oxford University Press.

. (2013). "Disagreement and Belief Dependence: Why Numbers Matter." In The Epistemology of Disagreement: New Essays. David Christensen and Jennifer Lackey (eds). Oxford University Press, 243-268.

. (2010a). "What Should We Do When We Disagree?" In Oxford Studies in Epistemology. Tamar Szabo Gendler and John Hawthorne (eds). Oxford University Press 3: 274-293.

. (2010b). “A Justificationist View of Disagreement's Epistemic Significance." In Social Epistemology, Adrian Haddock, Alan Millar, and Duncan Pritchard (eds). Oxford University Press.

Lam, Barry. (2013). "Calibrated Probabilities and the Epistemology of Disagreement." Synthese 190 (6): 1079-1098.

Laughlin, P.R., Bonner, B.L. and Minder, A.G. (2002). "Groups perform better than the best individuals on letters-to-numbers problems." Organizational Behavior and Human Decision Processes 88(2), 605-20. 
Laughlin, P.R., Hatch, E.C., Silver, J.S. and Boh, L. (2006). "Groups perform better than the best individuals on letter-to-numbers problems: Effects of group size." Journal of Personality and Social Psychology 90(4), 644-51.

Laughlin, P.R., Zander, M.L., Knievel, E.M. and Tan, T.S. (2003). "Groups perform better than the best individuals on letter-to-numbers problems: Informative equations and effective reasoning." Journal of Personality and Social Psychology 85(4), 684-94.

Lee, Matthew. (2012a). "The role of the Uniqueness Thesis in the Epistemology of Disagreement." In Proceedings of the $34^{\text {th }}$ International Wittgenstein Symposium: Epistemology: Contexts, Values, Disagreement, C. Jager and W. Loffler (eds). Ontos Verlag.

. (2012b). "Conciliationism without Uniqueness." Grazer Philosophische Studien, 88(1): 161-188.

Licon, Jimmy Alfonso. (2013). "On Merely Modal Epistemic Peers: Challenging the Equal Weight View." Philosophia 41 (3): 809-823.

Lo Guercio, Nicolas. (2013). “Reply to Palmira.” Logos \& Episteme IV (3): 361-365. . (2012). "Philosophical Peer Disagreement.” Logos \& Episteme III (3): 459- 467.

Lombardelli, C., Proudman, J. and Talbot, J. (2005). "Committees versus individuals: An experimental analysis of monetary policy decision-making." International Journal of Central Banking 1 (1): 181-205.

Lord, Errol. (2014). "From Independence to Conciliationism: An Obituary." Australasian Journal of Philosophy 92 (2): 365-377.

Lougheed, Kirk. (2018). “The Epistemic Value of Deep Disagreements.” Informal Logic 38 (2): 263-292.

Lougheed, Kirk and Robert Mark Simpson. (2017). "Indirect Epistemic Reasons and Religious Belief.” Religious Studies 53 (2): 151-169.

Lovering, Rob. (2001). The concept of worldview in contemporary philosophy of religion. Dissertation at the University of Colorado, Boulder.

Lynch, M.P. (2016). "After the spade turns: disagreement, first principles and epistemic contractarianism." International Journal for the Study of Skepticism 6 (2-3): 248-259. . (2012). In Praise of Reason. Cambridge, Mass: MIT Press. 
.(2010). "Epistemic Circularity and Epistemic Incommensurability." In Social Epistemology A. Haddock, A Millar and D. Pritchard (eds). Oxford University Press, 262-277.

Machuca, Diego E. (2017). "A neo-Pyrrhonian response to the disagreeing about disagreement argument." Synthese 194 (5): 1663-1680.

. (2015). "Conciliationism and the Menace of Scepticism." Dialogue: Canadian Philosophical Review 54 (3): 469-488. . (eds). (2013). Disagreement and Skepticism. Routledge.

Magnus, P.D. (2014). “Science and rationality for one and all.” Ergo 1 (5): 129-138.

Martini, Carlo. (2013). “A Puzzle About Belief Updating. Synthese 190 (15): 3149-3160.

Matheson, Jonathan. (2015a). The Epistemic Significance of Disagreement. New York: Palgrave Macmillan.

. (2015b). "Disagreement and Epistemic Peers." Oxford Handbooks Online.

. (2015c). "Disagreement and the Ethics of Belief." In The future of social epistemology: a collective vision, James H Collier (eds). USA: Rowman and Littlefield, 139-148.

. (2014). "Disagreement: Idealized and Everyday." In The Ethics of Belief: Individual and Social, Jonathan Matheson and Rico Vitz (eds). Oxford University, 315-330.

. (2011). "The Case for Rational Uniqueness." Logos and Episteme: An International Journal of Social Philosophy 6 (3): 269-279.

. (2009). "Conciliatory Views of Disagreement and Higher-Order Evidence." Episteme 6 (3): 269-279

McGinn, Colin. (1993). Problems in Philosophy: The Limits of Inquiry. Wiley-Blackwell.

McGrath, Sarah. (2011). "Reply to King." Journal of Philosophical Research 36: 235-241. . (2008). "Moral Disagreement and Moral Expertise." In Oxford Studies in Metaethics, Russ Shafer-Landau (eds). Oxford University Press 4: 87-108.

Menz, M. (2012). "Functional top management team members: A review, synthesis, and research agenda." Journal of Management 38 (1): 45-80. 
Mercier, H. (2011) "Reasoning Serves Argumentation in Children." Cognitive Development 26 (3): 177-191.

Mercier, Hugo and Dan Sperber. (2017). The Enigma of Reason. Massachusetts: Harvard University Press.

. (2011). "Why do humans reason? Arguments for an argumentative theory." Behavioral and Brain Sciences 34 (2): 57-74.

Michaelsen, L.K., Watson, W.E. and Black, R.H. (1989). "A realistic test of individual versus group consensus decision making." Journal of Applied Psychology 74 (5): 834-39.

Mill, John Stuart. (1959) [2003]. On Liberty. New Haven: Yale University Press.

Moffett, M. (2007). "Reasonable Disagreement and Rational Group Inquiry.” Episteme 4 (3): 352367.

Molden, D.C. and Higgins, E.T. (2005). "Motivated thinking." In The Cambridge handbook of thinking and reasoning, K. Holyoak and R. Morrison (eds). Cambridge University Press.

Moon, Andrew. (2018). "Independence and New Ways to Remain Steadfast in the Face of Disagreement." Episteme 15 (1): 65-79.

Moore, G.E. (2004). "Proof of an External World." In Philosophical Papers. USA: Routledge.

Moscovici, C and Personnaz, B. (1980). "Studies in social influence: V. Minority influence and conversion behavior in a perceptual task." Journal of Experimental Social Psychology 16 (3): 270-282.

Moshman, David and Molly Geil. (1998). "Collaborative reasoning: Evidence for collective rationality." Educational Psychology Papers and Publications 4 (3): 231-248.

Moyal-Sharrock, D. (2016). "The animal in epistemology." International Journal for the Study of Skepticism 6 (2-3):97-119.

Mulligan, Thomas. (2015). "Disagreement, peerhood, and three paradoxes of Conciliationism." Synthese 192 (1): 67-78.

Nemeth, C.M. (1995). "Dissent as driving cognition, attitudes, and judgments." Social Cognition 13 (3): 273-291.

Nemeth, C., Brown, K. and Rogers, J. (2001). "Devil's advocate versus authentic dissent: Stimulating quantity and quality." European Journal of Social Psychology 31 (6): 707720. 
Nisbett, Richard and Timothy Wilson. (1977). "Telling More than We can Know: Verbal Reports on Mental Processes.” Psychological Review 84 (3): 193-210.

Nolan, Daniel. (1997). "Quantitative Parsimony." The British Journal for the Philosophy of Science 48 (3): 329-343.

Olsson, Erik, "Coherentist Theories of Epistemic Justification", The Stanford Encyclopedia of Philosophy (Spring 2014 Edition), Edward N. Zalta (ed.), URL = <http://plato.stanford.edu/archives/spr2014/entries/justep-coherence/>.

Oppy, Graham. (2010). “Disagreement.” International Journal for Philosophy of Religion 68 (13): 183-199.

Page, Scott. (2007). The Difference: How the Power of Diversity Creates Better Groups, Firms, and Societies. USA: Princeton University Press.

Palmira, Michele. (2013a). "On the Necessity of the Evidential Equality Condition for Epistemic Peerage." Logos \& Episteme IV (1): 113-123.

(2013b). "A Puzzle About the Agnostic Response to Peer Disagreement." Philosophia 41: 1253-1261.

Pasnau, Robert. (2015). "Disagreement the value of self-trust." Philosophical Studies 172 (9): 2315-2339.

Perelman, C. and Olbrechts-Tyteca, L. (1969). The new rhetoric: A treatise on argumentation. University of Notre Dame Press.

Pettit, Philip. (2006a). "No Testimonial Route to Consensus.” Episteme 3 (3): 156-165.

. (2006b). "When to defer to majority testimony - and when not." Analysis 66 (3): $179-187$.

Pittard, John. (2017). “Disagreement, reliability, and resilience.” Synthese 194 (11): 4389-4409.

. (2015). “Resolute Conciliationism.” The Philosophical Quarterly 65 (260): 442-463.

. (2014). "Conciliationism and Religious Disagreement." In Challenges and Moral and Religious Belief: Disagreement and Evolution. Michael Bergmann and Patrick Kain (eds), 80-99.

Plantinga, Alvin. (2000). Warranted Christian Belief. New York: Oxford University Press. . (1981). “Is Belief in God Properly Basic?” Nous 15 (1): 41-51. 
Popkin, Richard. (1967). "Skepticism." In The Encyclopedia of Philosophy, Paul Edwards (eds). New York: Macmillan 7: 449-461.

Priest, Maura. (2016). “Inferior Disagreement.” Acta Analytica 31 (3): 263-283.

Pritchard, Duncan. (2016). Epistemic angst: radical skepticism and the groundlessness of our believing. Oxford Univeristy Press.

. (2011). "Wittgenstein on scepticism. In Oxford Handbook of Wittgenstein, Oskari Kuusela and Marie McGinn (eds). Oxford University Press.

Pronin, Emily, Daniel Y Lin, Lee Ross. (2002). "The bias blind spot: perceptions of bias in self versus others." Personality and Social Psychology Bulletin 28 (3): 369-381.

Pronin, Emily. (2007). "Perception and misperception of bias in human judgment." Trends in Cognitive Sciences 11 (1): 37-43.

Psaroudaki, Katerina. (2016). "Defending Conciliationism From Self-Defeat." Southwest Philosophy Review 32 (1): 69-76.

Putnam, Hilary. (1985). “The Many Faces of Realism.” Indiana: The Open Court Press.

Quine, W. V. and Ullian, J.S. (1970). The Web of Belief. New York: Random House.

Ranalli, Chris. (forthcoming). "What is Deep Disagreement?" Topoi.

Rattan, Gurpreet. (2014). "Disagreement and the First-Person Perspective." Analytic Philosophy, 55 (1): $31-53$.

Reining, Stefan. (2016a). “On The Supposed Dilemma of Conciliationism.” Episteme 13 (3): 305328. 419.

. (2016b). "Peerhood in deep religious disagreements," Religious Studies 52 (3): 403-

Rescher, Nicholas. (1985). The Strife of Systems: An Essay on the Grounds and Implications of Philosophical Diversity. Pittsburgh: University of Pittsburgh Press. . (1973). The Coherence Theory of Truth. Oxford: Oxford University Press.

Ribeiro, Brian. (2011). "Philosophy and Disagreement." Critica 43 (12):127, 3-25.

Riggs, Wayne. (2008). “Epistemic Risk and Relativism.” Actica Analytica 23 (1): 1-8. 
Roberts, Robert C and Jay Wood. (2007). "Humility and Epistemic Goods" In Intellectual Virtue: Perspectives from Ethics and Epistemology, Micahel DePaul and Linda Zagzebski (eds). Oxford University Press.

Roche, William. (2018). "Is Evidence of Evidence Evidence? Screening-Off Vs. NoDefeaters." Episteme 15 (4): 451-462.

. (2014). "Evidence of Evidence is Evidence Under Screening-Off." Episteme 11

(1): 119-124.

Rosenberg, Jay F. (1984). The Practice of Philosophy. New Jersey: Prentice-Hall, Inc.

Rotondo, Andrew. (2015). "Disagreement and Intellectual Scepticism." Australasian Journal of Philosophy 93 (2): 251-271.

Rott, Hans. “A Puzzle About Disputes and Disagreements.” Erkenntnis 80 (1):167-189.

Rowbottom, Darrell Patrick. (2016). "What is Agreement?" Philosophy and Phenomenological Research 97 (1): 223-226.

Sampson, Eric. (forthcoming). "The Self-Undermining Argument From Disagreement." Oxford Studies in Metaethics 14.

Schafer, Karl. (2015). "How Common is Peer Disagreement? On Self-Trust and Rational Symmetry." Philosophy and Phenomenological Research XCI (1): 25-46.

Schellenberg, John L. (2015). Evolutionary Religion. Oxford University Press.

Schoenfield, Miriam. (2015). “A Dilemma for Calibrationism." Philosophy and Phenomenological Research XCI (2): 425-455.

. (2014). "Permission to Believe: Why Permissivism is True and What it Tells us about Irrelevant Influences on Belief." Nous 48 (2): 193-218.

Schulz-Hardt, S., M. Jochims and D. Frey. (2002). "Productive Conflict in Group Decision Making: Genuine and Contrived Dissent as Strategies to Counteract Biased Information Seeking." Organizational Behavior and Human Decision Processes 88 (2): 563-586.

Schwitzgebal, Eric. (2008). “The Unreliability of Naive Introspection.” The Philosophical Review, 117 (2): 245-273.

Searle, John. R. (1995). The Social Construction of Reality. New York: Free Press.

Semmelwis, I. (1861). The Etiology, Concept, and Prophylaxis of Childbed Fever K., $\quad$ Codell Carter (trans). USA: University of Wisconsin Press. 
Sherman, Ben. (2015). "Questionable Peers and Spinelessness." Canadian Journal of Philosophy 45 (4): $425-444$.

Silwa, Paulina and Sophie Horowitz. (2015). "Respecting all the evidence." Philosophical Studies 172 (1): 2835-2858.

Simpson, Robert Mark. (2013). "Epistemic peerhood and the epistemology of disagreement." Philosophical Studies 164 (2): 561-77.

Skipper Rasmussen, Mattias, Asbjørn Steglich-Petersen and Jens Christian Bjerring. (2018). "A Higher-Order Approach to Disagreement." Episteme 15 (1): 80-100.

Skipper, Mattias and Asbjorn Steglich-Petersen. (forthcoming). "Group Disagreement: A Belief Aggregation Perspective." Synthese.

Sniezek, J.A. and Henry, R.A. (1989). "Accuracy and confidence in group judgment." Organizational Behavior and Human Decision Processes 43 (1): 1-28.

Sosa, E. (2010). "The Epistemology of Disagreement." In Social Epistemology, Alan Haddock, Adrian Millar, and Duncan Pritchard (eds). Oxford University Press, 278-297. [First published in (2009). Episteme 6 (3): 269-279.]

Sperber, C., Clement, F., Heintz, C., Mascaro, O., Mercier, H., Origgi, G., and Wilson, D. (2010). Epistemic vigilance. Mind \& Language 25 (4): 359-393.

Sperber, Dan. (2000). "Metarepresentations in an evolutionary perspective." In Metarepresentations: A multidisciplinary perspective D. Sperber (eds) Oxford University Press, 117-137.

Sperber, Dan. (2001). "An evolutionary perspective on testimony and argumentation." Philosophical Topics 29 (1-2): 401-13.

Stasson, M.F., Kameda, T., Parks, C.D., Zimmerman, S.K. and Davis, J.H. (1991). "Effects of assigned group consensus requirement on group problem solving and group members' learning." Social Psychology Quarterly 54 (1): 25-35.

Stewart, Todd M. (2016). “Comments on Katerina Psaroudaki's 'Defending Conciliationism From Self-Defeat.” Southwest Philosophy Review 32 (2): 11-14.

Street, S. (2011). "Mind-Independence Without the Mystery: Why Quasi-Realists Can't Have it Both Ways." In Oxford Studies in Metaethics. Edited by Russ Shafer-Landau. New York: Oxford University Press 6: 190-204.

Surowiecki, James. (2004). The Wisdom of Crowds: Why the many are smarter than the few and how collective wisdom shapes business, economies, societies, and nations. USA: Random House, Inc. 
Tal, Eyal and Juan Comesana. (2017). "Is Evidence of Evidence Evidence?” Nous 51 (1): 95-12

Talbot, Brian. (2014). "Truth promoting non-evidential reasons for belief." Philosophical Studies 168 (3): 599-618.

Taylor, Shelley and Jonathan Brown. (1988). "Illusion and Well-Being: A Social Psychological Perspective on Mental Health.” Psychological Bulletin 103 (2): 193-210.

Tebben, Nicholas. (2013). "Peer Disagreement and the Limits of Coherent Error Attribution." Logos \& Episteme IV (2): 179-197.

Tindale, R.S. and Sheffey, S. (2002). "Shared information, cognitive load, and group memory." Group Processes \& Intergroup Relations 5 (1): 5-18.

Titelbaum, Michael. (2015). "Rationality's Fixed Point (Or: In Defense of Right Reason)." In Oxford Studies in Epistemology, Tamar Szabo Gendler and John Hawthorne (eds). Oxford University Press 5: 253-294.

Thune, Michael. (2010). "Religious Belief and Epistemology of Disagreement." Philosophy Compass 5 (8): 712-724.

Vahid, Hamid. (2014). "Some Problems With Steadfast Strategies for Rational Disagreement." Symposion: Theoretical and Applied Inquiries in Philosophy and Social Sciences 1(1): 89107.

Van Helden, Albert. (Accessed August 21, 2014). “Galileo.” Encyclopaedia Britannica Online Academic Edition.

van Inwagen, Peter. (1996) "It is wrong, everywhere, always, and for anyone, to believe anything upon insufficient evidence." In Faith, Freedom, and Rationality: Philosophy of Religion Today, J. Jordan and D. Howard-Snyder (eds). London: Rowman \& Littlefield.

Vavova, Katia. (2014a). "Debunking Evolutionary Debunking." In Oxford Studies in Metaethics, Russ Shafer-Landau (eds) New York: Oxford University Press 9:76-101.

. (2014b). "Moral Disagreement and Moral Skepticism." Philosophical Perspectives 28 (1): 302-333.

Vidal, Clement. (2012). "Metaphilosophical Criteria for Worldview Comparison." Metaphilosophy 43 (3): 306-347.

Vorobej, Mark. (2011). “Distant Peers.” Metaphilosophy 42 (5): 708-722.

Wald, Benjamin. (2009). "Dealing With Disagreement: Distinguishing Two Types of Epistemic Peers." Spontaneous Generations 3 (1): 113-122. 
Weatherson, Brian. (2013). "Disagreements, Philosophical and Otherwise." In The Epistemology of Disagreement: New Essays, David Christensen and Jennifer Lackey (eds). Oxford University Press, 54-75.

Wedgewood, Ralph. (2010). "The Moral Evil Demons." In Disagreement, Richard Feldman and Ted A. Warfield (eds). Oxford University Press, 216-246.

Weintraub, Ruth. (2013). “Can Steadfast Peer Disagreement Be Rational?” The Philosophical Quarterly 63 (253): 740-759.

White, Roger. (2005). “Epistemic Permissiveness.” Philosophical Perspectives 19 (1): 445-459.

Wiland, Eric. (2016). "Peer Disagreement and the Dunning-Kruger Effect." Episteme 14 (4): 481 498.

Williams, K.Y. and O'Reilly, C.A. (1998). "Demography and diversity in organizations: A review of 40 years of research.” Research in Organizational Behavior 20, 77-140.

Williams, Michael. (1991). Unnatural doubts: epistemological realism and the basis of scepticism. Oxford University Press.

Wilson, Timothy and Nancy Brekke. (1994). "Mental Contamination and Mental Correction: Unwanted Influences on Judgments and Evaluations." Psychological Bulletin 116 (1): 117142.

Wittgenstein, Ludwig. (1969). On Certainty. USA: Blackwell Publishing Ltd.

Wolterstorf, Nicholas. (2014). “The Significance of Inexplicable Disagreement." In Religious Faith and Intellectual Virtue, L.F. Callahan and T. O'Connor (eds). Oxford: Oxford University Press, 317-30.

Worsnip, Alex. (2014). "Disagreement about Disagreement? What Disagreement about Disagreement?” Philosopher's Imprint 14 (18): 1-20.

Wright, Crispin. (2014). "Welfare State Epistemology (Entitlement II)." In Contemporary Perspectives on Scepticism and Perceptual Justification. Dylan Dodd and Elia Zardini (eds). Oxford University Press, 213-247.

(2004a). "On Epistemic Entitlement: Warrant For Nothing (And Foundations For Free?).” In Aristotelian Society Supplementary Volume 71 (8): 167-212.

. (2004b). "Wittgensteinian certainties." In Wittgenstein and scepticism. Edited by McManus D. Routledge. 
Young, James O. (2015). "The Coherence Theory of Truth." The Stanford Encyclopedia of Philosophy (Fall 2015 Edition), Edward N. Zalta (ed.), URL = <http://plato.stanford.edu/archives/fall2015/entries/truth-coherence/>.

Zoltán, Imre. (2019). "Ignaz Philipp Semmelweis.” In Encyclopaedia Britannica Online Academic Edition. 